\title{
Preparing Chinese Students for the New Zealand Academic Environment: The Foundation Studies Programme
}

\author{
By \\ Melinda Hall \\ A Thesis \\ Submitted to Victoria University of Wellington \\ In fulfillment of the requirements for the degree of \\ Master of Arts \\ In Chinese
}

School of Asian and European Languages and Cultures

Victoria University of Wellington

2009 


\section{Abstract}

This research project examines the Foundation Studies Programme at Victoria University of Wellington to see if it succeeds in its aim to prepare students for undergraduate study in New Zealand, and to identify what factors contribute to a Chinese international student's success. The research is conducted in two phases - the first phase considers the achievement of 40 Chinese international students - half of whom have been through the Foundation Studies programme and half of whom have not - and finds that there is a significant correlation between completing the Foundation Studies programme and academic achievement in undergraduate courses. Reasons for this are explored in the second phase of study through interviews with twenty Chinese international students, ten who have taken the Foundation Studies programme and ten who have not. Some of the explanations found for the difference in achievement are that the Foundation Studies graduates are more confident in using English, are more adjusted to life in New Zealand, and are more prepared for the New Zealand academic environment, having gained essential essay-writing and study skills during the Foundation Studies programme. The main issue raised is the need for institutions to better prepare Chinese international students who gain admission directly into undergraduate programmes before they commence their studies, so that they are more able to succeed in the New Zealand academic environment.

\section{Acknowledgements}

First, and most importantly, I would like to thank my supervisor Limin Bai for all her advice and encouragement in this project. Also my thanks to Trevor for helping me to understand more about statistics. To my colleagues who listened every time I found something new and interesting, which I just had to share thank you for being a sounding board and also for giving helpful feedback. Finally, to my friends who I have neglected while locking myself away to write this thesis - I hope you will take me back! 


\section{Contents}

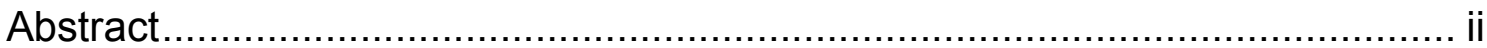

Acknowledgements ..................................................................... ii

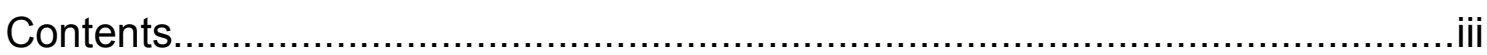

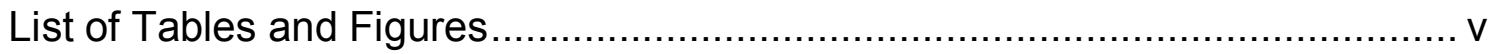

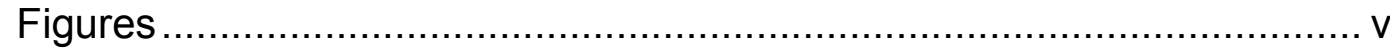

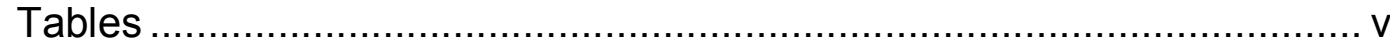

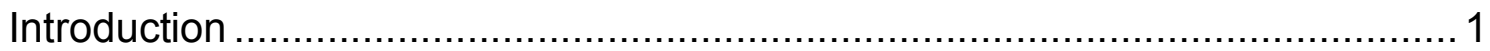

Chapter One: Background .................................................................... 3

The Foundation Studies Programme ........................................... 3

Otago University Foundation Year Study ........................................ 6

Why Chinese Students? ................................................................. 7

Studies on Chinese Students in New Zealand ................................... 8

Factors Affecting International Students ........................................... 14

Language ............................................................................. 16

Adjusting to the New Culture ................................................. 18

Differing Academic Systems and Conventions ............................ 19

Chapter Two: Research Aim, Methodology and Design............................. 23

Research Questions and Aim ..................................................... 23

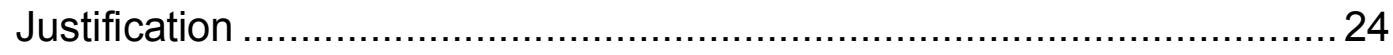

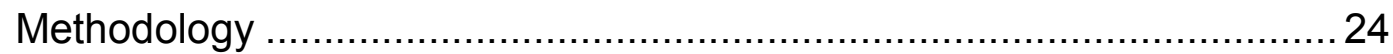

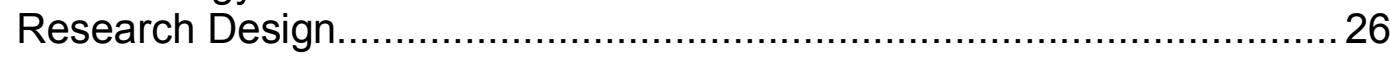

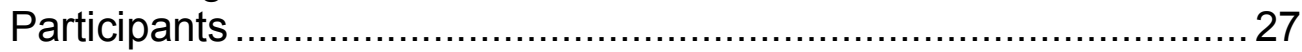

Method of Recruitment........................................................... 28

Data Collection Methods ........................................................... 29

Data Analysis .......................................................................... 33

Research Trustworthiness ................................................... 35

Definitions and Limitations ...................................................... 37

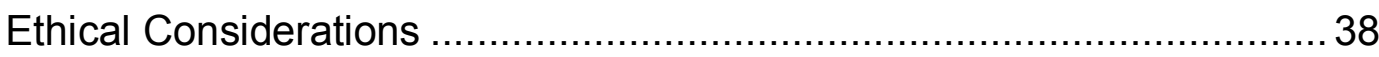

Chapter Three: Academic Achievement (Quantitative Study) .......................40 40

Findings ...................................................................................... 40

Achievement of FS and DE Students Over All Courses................. 40

Withdrawal Rate.................................................................... 42

Achievement of FS and DE Students Year By Year .....................43

Achievement of FS and DE Students By Specific Subjects ............ 45

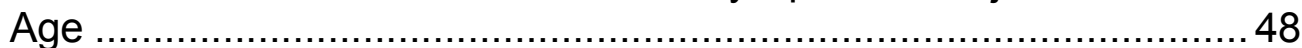

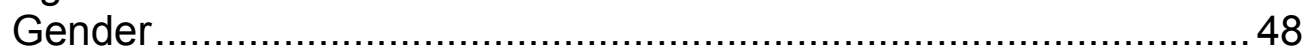

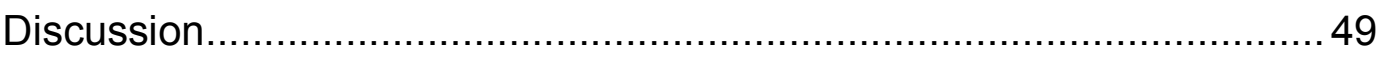

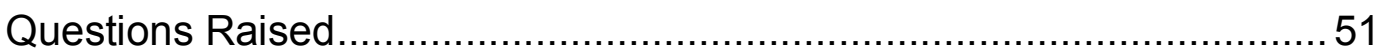


Chapter Four: The Students' Perspective (Qualitative Study) ........................52

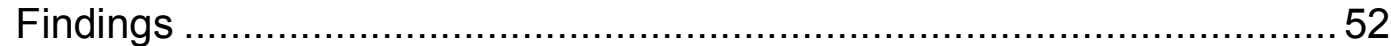

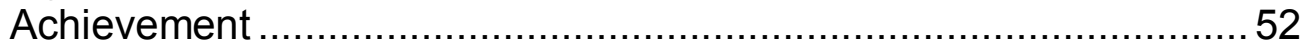

Self-rating: "How Good a Student" ............................................ 53

English Language ................................................................ 55

Life in New Zealand ............................................................. 61

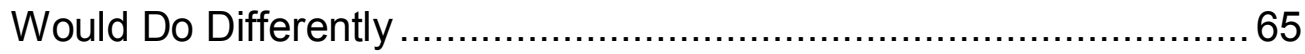

Reasons for Coming to New Zealand to Study ...........................66

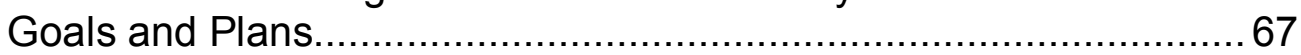

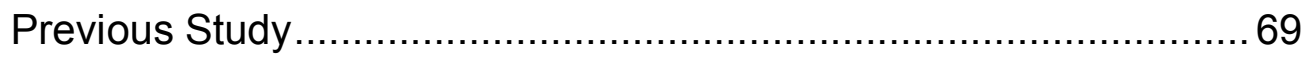

Study Techniques and Help Wanted...................................... 70

Differences in Education Systems ......................................... 72

First Trimester Experience ....................................................... 75

What FS Students Say About the Foundation Studies Programme.. 75

Summary of Results...................................................................... 77

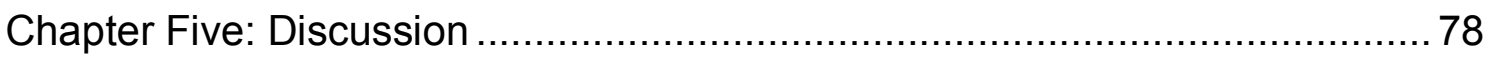

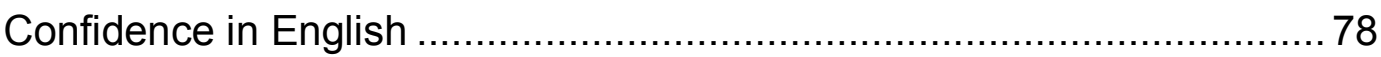

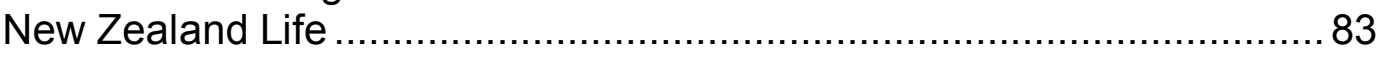

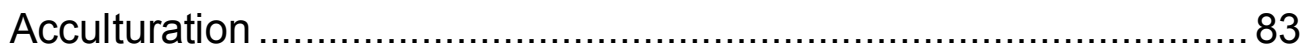

Contact with New Zealanders ............................................... 84

Feelings about Life in New Zealand ............................................ 85

Help and Support .................................................................... 86

Would Do Differently ............................................................ 87

Reasons for Choosing New Zealand .......................................... 88

Future Goals ..................................................................... 88

Academic Adjustment and Preparedness ........................................ 89

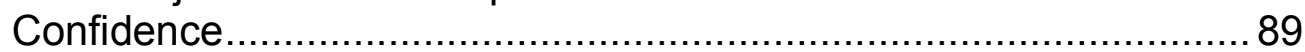

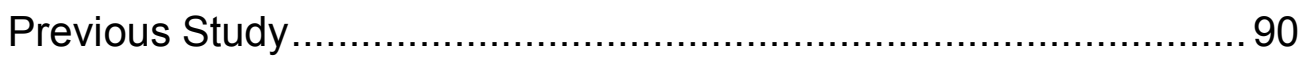

Differences in Education Systems ......................................... 91

Adjusting to New Zealand Academic Conventions......................... 94

Issues Raised ........................................................................ 97

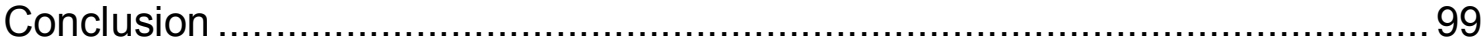

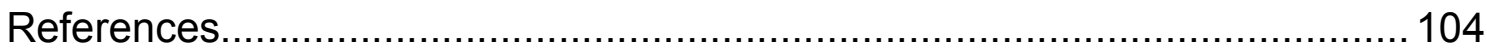

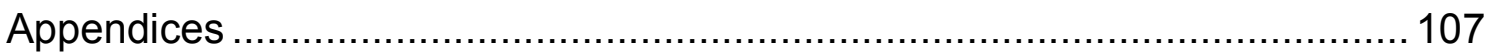

Appendix One: Student Achievement Data ................................... 107

Appendix Two: Interview Questions ............................................ 123

Appendix Three: Ethical Approval .................................................. 125

Appendix Four: Information Sheet for Participants.......................... 126

Appendix Five: Interview Consent Form ........................................ 128

Appendix Six: t-Tests Conducted for Quantitative Study.....................129

t-Tests Comparing FS and DE Students .................................. 129

t-Tests Comparing Male and Female ....................................... 130 


\section{List of Tables and Figures}

Figures

Figure $1 \quad$ Grade point average for DE students ................................ 41

Figure $2 \quad$ Grade point average for FS students................................... 41

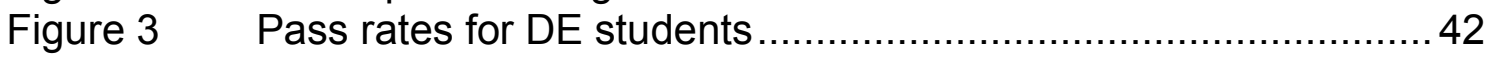

Figure $4 \quad$ Pass rates for FS students ............................................. 42

Figure $5 \quad$ Mean grade point averages per year for FS and DE students.... 44

Figure $6 \quad$ Mean pass rates per year for FS and DE students ...................44 44

Figure $7 \quad$ Grades gained by DE students in ECON130 ..........................46

Figure $8 \quad$ Grades gained by FS students in ECON130 ..........................46

Figure $9 \quad$ Grades gained by DE students in INFO101 ............................47

Figure 10 Grades gained by FS students in INFO101 ........................ 47

Figure 11 Achievement of DE students ............................................. 53

Figure 12 Achievement of FS students ......................................... 53

Figure 13 DE students self-rating for English language .........................56

Figure $14 \quad$ FS students self-rating for English language ..........................56

Figure 15 Plans after completing undergraduate studies.........................69

\section{Tables}

Table $1 \quad$ Interview participants ........................................................ 28

Table 2 Grade point averages and pass rates for FS and DE students....40

Table $3 \quad$ GPAs and pass rates by year ....................................... 43

Table $4 \quad$ Grades gained by FS and DE students in two courses ...............45

Table $5 \quad$ GPAs and gender .......................................................... 48

Table $6 \quad$ Pass rate and gender ....................................................... 49

Table $7 \quad$ Achievement in undergraduate courses ............................... 52

Table $8 \quad$ Self-rating: "how good a student" ........................................... 54

Table $9 \quad$ Explanations for the rating given ......................................... 54

Table $10 \quad$ English language ability - self-rating ..................................56

Table 11 Achievement and self-rating of English language level ..............57

Table 12 Achievement and language adequacy.................................59

Table 13 Areas of English language identified as adequate or weak .........59

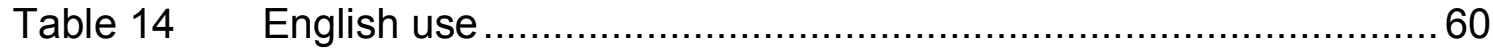

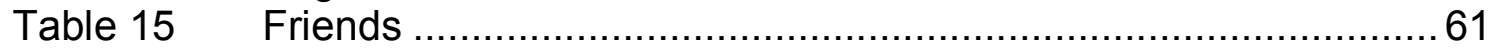

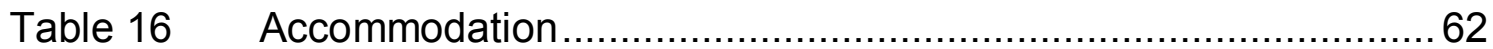

Table 17 What participants would do differently if they could start again ...66

Table 18 Reasons for choosing New Zealand as the study destination .....67

Table 19 Plans after completing undergraduate studies - by group...........69 69

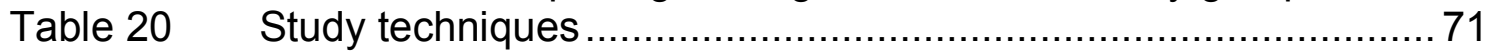

Table $21 \quad$ Help wanted in university studies ....................................... 72

Table 22 Achievement and adjustment to academic conventions .............74 


\section{Introduction}

International students face a variety of challenges in their pursuit of education. Not only are they away from home - many for the first time in their life - but they are also thrust into a different culture, a different educational system and often a different language. They must learn to adapt to these differences in order to be successful in their studies and their personal lives. For Chinese international students studying in New Zealand, the challenges they face - in learning to understand and adapt to the educational system and the general way of life - are vast. Education providers should, therefore, help these students to recognize, accept and adjust to the differences, so that they can successfully complete their education and gain a positive experience of life in New Zealand.

One example of an educational institute endeavouring to help students in this way is the Foundation Studies Programme at Victoria University of Wellington. This programme aims to prepare international students for undergraduate study in New Zealand universities by helping them improve their English, become familiar with the education system and learn the needed academic skills, and gain knowledge of the New Zealand culture. The research project reported on in this thesis examines the Foundation Studies Programme to see if it succeeds in its aim to prepare students for undergraduate study in New Zealand, and also investigates what factors contribute to an international student's success.

This thesis consists of five chapters and the conclusion. Chapter one covers the background to the study, first introducing what the Foundation Studies Programme is and does, then considering a study done at Otago University about their Foundation Year programme. The reason for focusing on Chinese students is explained, and previous studies about Chinese international students in New Zealand are discussed. Finally other relevant literature is reviewed. 
The second chapter outlines the research questions and aims of the project. Justification is given and the methodologies used and research design are explained. Ethical considerations are also discussed.

Chapter three presents the first study conducted for this research - a quantitative study examining the achievement of Chinese international students in their undergraduate courses at Victoria University and comparing students who have been through the Foundation Studies Programme with students who have not. The findings are expounded and discussed, and the questions raised by this study are noted.

The fourth chapter gives the findings of the second stage of research - a qualitative study involving interviews with Chinese students, seeking their perspective on life and education in New Zealand.

Chapter five focuses on a detailed discussion of the findings in chapter four and then highlights the issues raised by this study.

This research project finds that there is a significant correlation between completing the Foundation Studies programme and academic achievement in undergraduate courses, with students who have been through the Foundation Studies programme outperforming students who have not. Some of the explanations found for this difference are that the Foundation Studies graduates are more confident in using English, are more acculturated to New Zealand, and are more prepared for the New Zealand academic environment, having gained essential essay-writing and study skills during the Foundation Studies programme. 


\section{Chapter One: Background}

\section{The Foundation Studies Programme}

As the aim of this research project is to investigate the Foundation Studies Programme, to discover if it is producing successful students, and to identify the factors that are keys to success, it is important to understand what the Programme is.

The Foundation Studies Programme is run by Victoria University of Wellington. It is a non-matriculating programme at pre-degree level specifically set up for international students or those with New Zealand residency who do not have English as their first language. Successful completion of this programme gives students a university entrance qualification, allowing them to enrol in most undergraduate programmes in any New Zealand university. ${ }^{1}$ Students take the Foundation Studies Programme when they do not have entrance into undergraduate courses by either not meeting the English language criteria (an International English Language Testing System [IELTS] score of 6.0 or higher, or equivalent, is needed for undergraduate study in New Zealand) or by not having the required academic background. Students who have only finished high school in China do not meet this second requirement. Most students who enrol in Foundation Studies are lacking both of these degree-entrance criteria.

The basic programme is two trimesters long (8 months) but some students may take three, or sometimes four, trimesters to complete. Students take a maximum of three courses per trimester and must pass a total of six courses. There is one compulsory course that every student must take: Academic Writing and Research. This course focuses on English language improvement as well as academic writing skills - such as how to structure essays and avoid plagiarism. Students must also take at least one of the "New Zealand" papers, which are Politics and Government, Modern New Zealand Literature, and Modern New Zealand History. These courses have a strong language focus, with a lot of reading and writing, as well as a New Zealand focus - teaching

\footnotetext{
${ }^{1}$ Some specific courses at some universities may have additional entry requirements.
} 
students some useful and important aspects of New Zealand society and culture. The four electives are chosen from the remaining two New Zealand papers, Information Management, Commerce and Economics, Computing Technologies, Mathematics, Accounting, Design, Biological Sciences, and Physical Sciences. Students are encouraged to choose courses in a related field to their intended degree - so students wanting to do a Commerce degree are encouraged to take Commerce and Economics as well as Accounting.

Students must meet the requirements to gain entry to the programme. The minimum language level needed is an IELTS score of 5.5 or equivalent (for students who have taken the Victoria University English Preparation Programme, a score of two $3 \mathrm{~s}$ and two $4 \mathrm{~s}$ is considered equivalent). There is also an academic requirement, which is country specific. For Chinese students this is completion of Senior High School with a minimum average of $70 \%$. Students who do not meet these requirements must take further English language courses or continue at high school until they meet the entry level.

The current form of the Foundation Studies Programme began in 2004, although the programme has been running since 2001. For the first three years it consisted of two consecutive certificates, each taking one trimester: the first was the Certificate of Proficiency in English; the second the Certificate of University Proficiency. The Certificate of Proficiency in English was an English language course designed for students for whom English is a second language. The Certificate of University Proficiency was for students who did not have a university entrance qualification and it aimed to prepare these students academically for university study. Successful completion of both certificates gave international students both the English language and the academic requirements for entry into undergraduate courses in New Zealand universities.

With the increasing numbers of international, and in particular Chinese, students in 2003, it became obvious that the Foundation Studies Programme was not adequately serving the needs of the international students, and at the same time a need for a university preparation course for domestic students was identified. The Foundation Studies Programme was restructured and became a separate qualification of its own - the Certificate in Foundation Studies. This 
new programme began in 2004 in its current form. Since 2004, there have been approximately 430 students through the Foundation Studies Programme. Almost half $(48 \%)$ of these are Chinese. The Certificate of University Proficiency remained and was restructured to cater for New Zealand domestic students, and in 2005 was renamed the Certificate of University Preparation.

The Certificate of Proficiency in English is also still running. It places students in classes according to their language level and attracts students for various reasons: some only need to meet the English language requirement for undergraduate entry - these students will take the language course rather than Foundation Studies; some need to improve their English to the level of entry into Foundation Studies; some want to study English for various other reasons.

The Foundation Studies Programme has produced a number of internal reports. These have included the number of students beginning and successfully completing the programme, the percentage of students who continue on in undergraduate study at Victoria University, a study on some specific 100-level courses comparing the achievement of Foundation Studies graduates with other international students and New Zealand domestic students, and the tracking of some Foundation Studies graduates during their degree study, to gain an overall picture of the success of Foundation Studies. The data for these reports was collected at various times throughout 2006 to 2009 from the university database.

The findings paint a very positive picture of Foundation Studies - showing that over $80 \%$ of students who began the programme successfully completed it and $90 \%$ of those went on to undergraduate study at Victoria University. In 8 of the 13 undergraduate courses considered, Foundation Studies graduates achieved an average pass rate higher than international students who did not take Foundation Studies, and when the pass rate for all students was compared, Foundation Studies graduates again had a higher average in 8 courses. Overall the average pass rate in all courses was $79.0 \%$ for Foundation Studies graduates, $78.1 \%$ for other international students, and $77.8 \%$ for all students (domestic and international). 
These results raise the questions of how Chinese students in particular compare, and what specific features of the Foundation Studies Programme may account for its success. The research project conducted for this thesis considers these issues.

\section{Otago University Foundation Year Study}

Most of the universities in New Zealand (Waikato, Massey, Canterbury, Lincoln and Otago) offer a foundation course for international students similar to the Victoria University Foundation Studies Programme. However, it seems that very little research has been done on any of these programmes except at Otago University where one study has been carried out on the academic progress of former Foundation Year students during their undergraduate studies (Stroven 2003).

The study took 230 Foundation Year (FY) graduates who were enrolled in degree programmes at Otago University between 1998 and 2002, to see what degree courses they were choosing, what grades they gained, and what courses they were passing or failing. Results showed the top five subject choices to be COMP, ECON, FINC, BIOL and MATH. The paper with the highest pass rate among former FY students was BIOL111 with an $88 \%$ success rate. The most failed course was MANT112, with only a $60 \%$ pass rate. The most common grades gained were Cs, with Bs coming in second.

The question of how the performance of these FY students compares to other international students is raised. As the data in this study was insufficient to answer this question, the report recommends further study in which a comparison be made between the achievement of former FY students with other university students from the same country of origin who did not do the Foundation Year. It is also recommended to explore a correlation between the country students are from and what courses they are passing or failing in order to investigate the specific needs of different groups of students. A third recommendation from this report is to undertake qualitative research to seek "student feedback on how factors such as accommodation, cultural norms, 
social life, etc may play a role in their academic performance" (Stroven 2003:910).

The research project undertaken for this thesis will cover two of these recommendations by comparing Chinese students who have completed Victoria University's Foundation Studies Programme with Chinese students who have not, and also by asking students to talk about their life and study in New Zealand, thereby gathering qualitative data with which to consider what contributes towards a student's success.

\section{Why Chinese Students?}

Although the number of international students in New Zealand has dropped since the peak of $2002 / 3$, they still form a significant group of university students, with over 31,000 international students being enrolled in tertiary institutions in 2007. Of these, 43\% (13,262) were from the Peoples' Republic of China, making China the largest source country, providing six times more students than the second largest source country, South Korea, from which came $7 \%$ of the international students in tertiary institutions in 2007 (Ministry of Education, International Division 2008). As already noted, almost $50 \%$ of all students in the Foundation Studies Programme are from China, making them the most significant group of students.

It is essential that more understanding of Chinese students in New Zealand is gained. Ho et al. (2007:53) recognise:

\footnotetext{
"As the PRC is a leading source country of international students in New Zealand, it is important to continue research with this group to understand and address their concerns, and to enhance New Zealand's competitive edge to attract and retain these students."
}

For New Zealand to remain competitive in the global market of international education, customer satisfaction is vital. Learning about Chinese students' feelings towards the education they receive here is of great importance. Identifying the factors that contribute towards success, and implementing those 
factors will benefit not only the students themselves, but also the education providers.

\section{Studies on Chinese Students in New Zealand}

In recent years, some significant studies on Chinese international students in New Zealand have been done. The first of these studies to be considered here was commissioned by Education New Zealand in 2005 and the research was undertaken by $\mathrm{Ho}, \mathrm{Li}$, Cooper and Holmes. The resulting report, entitled "The experiences of Chinese international students in New Zealand" was published in 2007. The aim of the project was to explore reasons for Chinese students' apparent dissatisfaction with New Zealand yet conflicting desire to gain residency - as highlighted by the Ministry of Education's 2004 national survey of international students (Ward \& Masgoret 2004), as well as to gain understanding of the Chinese students' perspective on life and study in this country.

The research was conducted through 80 interviews and 4 focus group discussions with a total of 83 Chinese students, who were studying at various language schools, private training establishments, secondary schools and tertiary institutions in Auckland, Hamilton, Rotorua and Christchurch. The participants were aged between 16 and 33 years, and 46 were male and 37 female. The interviews and discussions were conducted in Mandarin or Cantonese. The study investigated many aspects of the students' experiences in New Zealand: reasons for choosing New Zealand; education experience, including pathways, challenges and problems; feelings about life in New Zealand; accommodation; social networks; and future plans.

Regarding reasons for choosing New Zealand, the study found that only 28 out of the 80 students interviewed chose New Zealand as their first choice. Many came here when they were not able to get their first choice. The main reasons for choosing New Zealand - among the group that arrived before 2003 included cheap fees, a low exchange rate, ease of getting a visa, and no English language requirement. For those coming after 2003, the reasons given 
for choosing New Zealand included a good environment, quality of education, immigration policies and the opportunity to gain residency, and having friends and family already in New Zealand. More than half of the students interviewed said that it was their parents, not themselves, who initially wanted them to study abroad. They thought their overseas education would give them better work and life opportunities. Students also anticipated greater freedom in New Zealand, and looked forward to being independent and having opportunity to do things they can not do in China, such as learn to drive, work part-time, and live away from home. Some students unfortunately included gambling, truancy and cohabitation on this list. $80 \%$ of the participants came to New Zealand with the goal of gaining a bachelor degree or higher. $56.2 \%$ also intended to stay and work in New Zealand and $42.5 \%$ wanted to apply for residency. (Ho et al. 2007:13-16).

Another area the study investigated was the education experiences of the students. Although the goal of most students was university study, only four of the 80 students interviewed entered directly into university. Most students began in a language school, and a few in high school. Although at the time of the interviews over half of the students were studying what they had planned to do - at degree or diploma level - many students took longer to reach this point than anticipated. The biggest barrier for most was English language. Students typically expected to study in a language school for 3 months and then begin at university; however, the average length of time spent at language schools was 14-15 months. Likewise, students who begin in New Zealand high schools underestimated how long it would take them to gain university entrance through the NCEA system. Despite the desired results taking longer to achieve than expected, students were happy with the teachers, the teaching styles, and the education they received. (Ho et al. 2007:16-20).

Some of the ways students mentioned in which New Zealand education differed from China included learning about the internet and library for research, developing one's own way of thinking, and systematic learning. The difficulties faced were understanding lectures, note-taking, classroom interaction, asking questions in class, oral presentations, and group work (especially with domestic students). The difficulty in doing group work with domestic students was due to 
a lack of common interests, having different ideas and different ways of thinking, not understanding each other due to cultural differences and language barriers. (Ho et al. 2007:21).

Participants were asked to rate their life in New Zealand on a scale of one to ten. Although the lowest rating given was 2 and the mean was 5.88, almost $45 \%$ had some dissatisfaction with New Zealand life. Some of the reasons given for this dissatisfaction were the cost of living and rising tuition costs, unmet expectations of what life would be like, and feelings of loneliness and isolation. (Ho et al. 2007:30).

Another aspect considered was accommodation. The study found that most students began in a homestay but at the time of the interviews only $21 \%$ were still living in a homestay. Students in tertiary institutions were most likely to be flatting. Generally students were positive about their homestay experience; however, there were a few horror stories. Most students felt it was good for new students to begin in a homestay as it provided opportunity to learn about New Zealand, improve English, and feel at home. The main reasons given for students moving into flatting situations were more freedom and it is cheaper. Food was also an issue in many homestay situations. (Ho et al. 2007:31-33).

When considering friendships and support, it was found that most students went to their Chinese friends in New Zealand for help. About a quarter of students still looked to their parents in China, and a few had family in New Zealand they could go to. Very few had New Zealand friends. Chinese students reported difficulty in making New Zealand friends. They suggested reasons for this included the Chinese students' perceived communication problems and lack of confidence in their language ability, a lack of common interests between the two groups, and the impression that New Zealanders did not want international friends. When it came to formal support, there was very little knowledge among the students about the services and facilities institutions provided for emotional and health problems, accommodation, language and learning support, and questions about everyday living issues. Many students had not heard of the 
term "Pastoral care" ${ }^{2}$, and very few used the services that were provided. (Ho et al. 2007:35-39).

Participants in this study were asked about their future plans in regards to working and living in New Zealand. Prior to coming to New Zealand, 56.2\% planned to work in New Zealand after completing their studies and $42.5 \%$ intended to apply for residency. At the time of the interviews, $71.3 \%$ wanted to work in New Zealand and $67.5 \%$ hoped to gain residency. The researchers argue that this change in plans was influenced by the changes taking place both in China and New Zealand over the time students were studying here. The value of an overseas qualification has dropped in China, and unemployment has increased, so returning students have less chances of securing a good job in China than originally expected. In New Zealand, changes to immigration policies have made it easier for students to look for work after graduating and then apply for residency. (Ho et al. 2007:48-50).

Among the recommendations made in this report was the encouragement to give more information and help to students in planning their study, especially in terms of getting from language school into university. It was further suggested that universities should provide ongoing English language teaching (possibly credit gaining) alongside regular courses. (Ho et al. 2007:54).

The next study on Chinese students in New Zealand to be considered is Limin Bai's (2008a) research into the value Chinese students place on their New Zealand education. This study also resulted from Ward and Masgoret's 2004 report and sought to discover reasons for the low levels of satisfaction among Chinese students in New Zealand, and their contradictory desire to stay on in New Zealand for work and to gain residency. The research was conducted between late 2004 and early 2005. Data was collected through a survey carried out in Auckland, Hamilton, Wellington, Christchurch and Dunedin amongst Chinese students, from which 432 valid questionnaires were obtained. Subsequent interviews with 100 of those students were conducted.

\footnotetext{
${ }^{2}$ All education providers in New Zealand who enrol International students must be signatories to the Ministry of Education's Code of Practise for the Pastoral Care of International Students 2003. Details of the Code can be found at http://www.minedu.govt.nz/goto/international
} 
The findings show that one third of students considered New Zealand to be an ideal place for study, while less than one quarter $(22 \%)$ thought it was not. When asked about their plans after completing their studies, almost half of the students $(43 \%)$ wanted to stay in New Zealand. Just under a third $(32 \%)$ planned to go to other countries and one quarter intended to return to China. Further findings revealed that the main reason students chose New Zealand for their overseas education was cost (being the cheapest), and the biggest difficulty faced by students was financial - followed by English language issues. Regarding the value of the qualification they would gain in the Chinese job market, $34 \%$ of students rated a New Zealand degree valuable or very valuable, whereas $18 \%$ considered it not valuable or worthless. The majority of students were happy with their teachers and their learning in New Zealand, and most also preferred the New Zealand education system to the Chinese system. (Bai 2008a:214-219).

Bai (2008a:220-230) goes on to discuss the value of a New Zealand degree for Chinese students. She claims that many Chinese international students are dissatisfied with their New Zealand education because it is not considered good value for money, and is not enough to secure a good future. The everincreasing tuition fees and the relatively strong New Zealand dollar means most students ended up paying more than they anticipated it would cost, and almost as much as they would pay to study in Australia. However, a New Zealand degree is considered to be worth much less than an Australian (or other western country's) qualification, predominately due to New Zealand being a small and seemingly undeveloped country. ${ }^{3}$ As graduate unemployment continues to grow in China, a New Zealand degree can not compete against a degree from one of the bigger countries (such as the United States or Australia), or the top Chinese universities in the job market. Therefore students studying in New Zealand feel they do not get a good return for their expenditure, and are concerned about their future job prospects. Bai (2008a:236) argues that this is the reason why students are more inclined to stay in New Zealand to work or gain residency - the degree itself it not enough, but work experience and/or

\footnotetext{
${ }^{3}$ Generally speaking, the Chinese concept of a developed country is big cities with tall buildings, large shopping malls, lights and glamour, and shops being open very late. New Zealand, with its small towns, green image, and emphasis on the outdoors is considered to be the "countryside" and therefore not very developed.
} 
residency in a western country can add value to their investment here, perhaps making it more worthwhile.

One further aspect this report examined was the comparison between the education systems in New Zealand and China. Most students felt the quality of education in New Zealand was higher than in China - due to the way of teaching and learning. The focus in China is on examinations and learning the "right" answers, often through memorization, whereas the New Zealand way encourages more independent learning, research and problem solving. Students also felt the New Zealand education was more "international" than the Chinese, because of the background of academics in New Zealand universities (with staff coming from and having been educated in many different countries), and the early availability of new materials. Another advantage of the education system in New Zealand is the ability to choose electives and study a broad range of subjects. (Bai 2008a:232-235).

A third study to be considered here is one undertaken by Prue Holmes (2004) examining Chinese students in a New Zealand university business school and how they communicate and approach their learning. This was an ethnographic study conducted over 18 months in which 13 students participated. All students were in their first year of study in the university, and all were ethnic Chinese but coming from different places: China (7), Malaysia (3), Taiwan (2) and Hong Kong (1). Data was collected from the three interviews held with each participant over the course of the study.

Findings showed that these students knew very little about New Zealand before they arrived, which caused some initial adjustment difficulties and culture shock. They were not familiar with the concept of discussion in tutorials and found it difficult to communicate in this way. They also struggled with lectures as their listening skills were not adequate for listening to the New Zealand accent and idiosyncrasies for long periods of time. All participants commented on how much reading was required, and had not expected this. Writing proved one of the biggest challenges for these students as the conventions for writing in English (the western system) are quite different from the Chinese conventions. The new rules had to be learned by the students - often the hard way, as they 
were not explicitly taught. They also had to learn critical thinking and analytical skills, which were often counter-cultural - in Chinese society you do not criticize or disagree with an authority. (Holmes 2004:295-303).

Holmes claims that Chinese students are ill-equipped for the learning environment in New Zealand, and they are left to themselves to negotiate the different conventions they are faced with, learn and master the new rules, and so become successful students. She suggests that these students need better preparation, including foundation programmes and intercultural communication courses which will teach them about the different education system, and how to adapt to the way of learning in New Zealand. (Holmes 2004:303-304).

These three studies give much insight into Chinese students' feelings about life and education in New Zealand, as well as the challenges they face. Many of the same themes emerge in the research carried out for this thesis, giving a consistent picture of Chinese international students in New Zealand.

\section{Factors Affecting International Students}

Besides considering these studies on Chinese students in New Zealand, it is also necessary to deliberate what factors influence a student's success in university, and in particular the areas that affect international students, and the challenges and difficulties they face when studying abroad.

A study by McKenzie and Schweitzer (2001) on first-year Australian university students revealed some factors that have an impact on their achievement. Contrary to expectations, they found that integration into university culture had a negative effect on academic performance - the more integrated students had lower achievement than those who were not socially involved in university life. They explain this by suggesting that with modern technology to help, a "subgroup" of higher achievers who prefer to study alone can access information and utilize facilities without needing to spend a lot of time on campus, whereas the more socially integrated students may spend too much time on the social aspects of university life. They also found that self-worth had a positive effect 
on achievement, but students who gave themselves less credit did better than those who were more optimistic of their ability. Finally, results showed that fulltime students with no job outperformed students who worked part-time while studying full-time. This research was on Australian students, not international students, and raises the question of whether or not the same factors influence international students' achievement.

Morrison et al. (2005) undertook a research project to find out how international students in UK universities were performing and what factors affected their achievement. They found that international students from the EU, Asia, Africa and the Middle East in general did not perform as well academically as the UK students, but students from other countries did just as well as the domestic students. They also found that females did better than males and the mature students outperformed the young students. Other influencing factors were which discipline a student was studying in and their previous qualifications (Morrison et al. 2005:333-335). The biggest question raised by this study - in regard to the current research project - is why the academic achievement of the Asian students was lower than that of the domestic students.

International students, and in particular Chinese international students in New Zealand universities, are faced with many challenges that local students do not have to deal with. Although Borland and Pearce (2002:122) propose that many domestic students also struggle with language and academic skills, these are areas that are especially problematic for international students. They say "there is a complex interaction of linguistic and cultural experiences that underpin student preparedness and capacity to cope with the demands of university study". Students who are inadequately prepared in the areas of language and culture face obstacles in their academic pursuit. Some of the difficulties faced by Chinese students in New Zealand, as identified by Zhang (2004), are culture shock, language difficulties, loneliness and a loss of social support networks, and pressure to succeed academically within a different education system and different social norms. Three of the biggest issues - as described below in more detail - are language, adjusting to the new country and culture, and adapting to different academic systems and conventions 


\section{Language}

It seems that one of the biggest challenges faced by international students from a non-English speaking background studying in an English speaking country is the English language. Light et al. (1987) undertook a study of international graduate students at State University of New York, and found that being proficient in English is essential for successful university study. In Zhang's (2004:25) investigation of Chinese students in New Zealand, 56\% of those surveyed claimed they did not achieve their desired academic goals because of language problems or limitations. Choi (1997:269-270) found that international students had problems correctly using formal and informal language and were unsure of how to address teachers and peers, which lead to feelings of unease and shyness in speaking English. International students would therefore be less likely to approach teachers or classmates for help.

Zhang (2004:48-49) examined a sample of Chinese students in a New Zealand university. The findings showed correlations between language ability, achievement of academic goals, interaction with New Zealanders, and satisfaction with the education system. Students with language difficulties found it harder to achieve their academic goals, and therefore felt less satisfied with the education they were receiving. Students with weak English also generally had less interaction with New Zealanders and were less likely to take part in leisure activities. Whether it is their shyness in using English that prevents their participation or their not being accepted into certain social circles because of communication problems is unknown. But these students who did not interact socially were less satisfied with the education system, whereas those students who interacted more with New Zealanders (class mates, homestay families, etc) were more satisfied with their education in New Zealand. Therefore language ability is a major issue influencing academic achievement, social interaction, and overall satisfaction.

English as a Second Language (ESL) students often score lower in assignments because of language errors, lack of vocabulary, and essays not being as cohesive or as well written as expected at the university level (McKay 2000). It is often not so much to do with the student's understanding of the 
subject as their expression of the knowledge. However, it is not only language inadequacies that lead to international students scoring lower than domestic students, but both a lack of cultural understanding and not knowing how to reference correctly also play a role. These issues are addressed further in the following sections. Zamel and Spack (2006:129) noted that multilingual students in the US claimed to have some difficulty in expressing themselves fully in English. They were worried that their poor language might cause them to seem less knowledgeable in discussions. They were also concerned with their writing, and generally spent a lot of time trying to get it all grammatically correct. They had to put a lot more time and effort than native speakers, but even then there would be errors which made them look less intelligent, limited in their knowledge, or sloppy.

A study done by James (2006) suggests that teaching a particular subject within an English language course (known as "content-based English" courses) can be beneficial in helping students develop their language and academic skills simultaneously. James examined a content-based English for Academic Purposes (EAP) course involving first-year undergraduate students at a Canadian university in an engineering faculty. They were required to take the EAP course because of their low English proficiency. They also took first year engineering courses. In the EAP class they were assessed in both content knowledge and language skills. Findings showed that most of the students recognized that the reading and writing skills learned in the EAP course were useful for their other courses. Some also saw the listening and studying skills as transferable. The similar content and common vocabulary also helped students learn and transfer skills across courses. This study shows that ongoing English language courses - especially when integrated with the specific subjects students are studying - are useful for ESL students at university level.

Obviously, a student with poor English will struggle to succeed academically in an English-speaking environment, by not being able to understand what is being taught or have the ability to express what they have learned. However, a student with good English may also struggle in their studies. Fox (2004:438) claims "If English alone were sufficient for academic success, all first language 
speakers of English would succeed academically, and this is clearly not the case." So, although proficiency in English does play a major role in the international student's success, there are other factors that play equally important roles.

\section{Adjusting to the New Culture}

Another area in which international students face difficulty is in adjusting to the culture of the country they go to, which is often completely different from their own culture. Fox (2004:461) claims that successfully adjusting to the host culture is one of the factors contributing to academic achievement. Volet (1999) also suggests that acculturation plays an important role in successful learning. Students need to learn to transfer their knowledge and skills from one cultural and educational environment to another, and social interaction and adjusting to the new environment play a role in this transfer.

One of the main factors influencing international students' adjustment in a new country is cultural knowledge (Andrade 2006:131). Students need to learn about the culture they are living in, so as to respond appropriately to situations, to know what is required of them, and to live comfortably and happily. Gu and Schweisfurth (2006:82-85) found that the biggest challenge Chinese students faced in the UK was the emotional and physical difficulty of learning to live a completely different lifestyle. Students commented that life was boring and lonely, they lacked the friendships and social networks they had back home and they felt like an outsider because of communication issues and discrimination (perceived or real). However, these students were also more proud of their learned independence (such as looking after themselves and cooking for themselves) and with improved communication than with their adjusting to the academic conventions and succeeding at study.

According to a study undertaken by Choi (1997) on Korean students at university in Australia, most were not satisfied with the relationships they had, they felt they were not understood by Australians, and they found it difficult to make and keep Australian friends. Furthermore, they felt that most 
relationships with nationals seemed superficial, there was only a surface friendliness with their Australian peers, and their teachers appeared too busy and somewhat unapproachable. These beliefs can cause a feeling of isolation socially, and hinder adjustment to the host culture.

Gu and Schweisfurth (2006:88) recommend that institutions develop a support system for international students to help them with culture shock and adjusting to their new environment, so that they are able to benefit from the experience of studying abroad personally as well as academically.

\section{Differing Academic Systems and Conventions}

The third issue to be considered is the differences in education systems that students are faced with. In particular, the "western" education system used in New Zealand and the Asian system familiar to many of our international students are widely divergent. "A teaching or learning approach that is taken for granted and regarded as universal and common sense by people from one culture may be seen as idiosyncratic and ineffective in the eyes of people from a different culture" (Gu and Schweisfurth 2006:75). Until students recognize the differences and learn to operate by the new conventions, they will struggle to succeed in their studies. Gu and Schweisfurth (2006:82) talk of the "learning shock" faced by international students. This is a bit like culture shock but concerned with the differences in teaching and learning styles and difficulty with language that the students face.

Borland and Pearce (2002:110) claim that language proficiency is not enough for success at university for ethnic minority students because cultural differences can cause problems with communication and understanding, in both the academic and the social arenas. According to Holmes (2004), Chinese students generally associate success with hard work - they believe that simply working harder will produce better results. However, for many Chinese students in New Zealand, this does not always prove to be true: if they continue to work hard but follow the Chinese academic conventions, they will still not achieve the desired results. Only by recognizing the differences between the 
educational systems of China and New Zealand, and consequently changing the way they approach a task, can students improve their performance.

There are cultural differences in the way students from different countries learn and interact in class, and even in how they define what knowledge is (Borland and Pearce 2002:111-112). Essay writing techniques and how to form arguments differ between cultures as do methods of teaching. Borland and Pearce (2002:111-112) give an example of how in Australia it is common to use irony, humour, and provocative statements during lectures, but this is initially considered inappropriate and unprofessional by Asian students.

Some of the differences between the Chinese and New Zealand systems were discussed by Bai (2008a) and mentioned in the previous section. Holmes (2004) also notes, similarly, that the main differences between the two educational styles are the Chinese system requires more memorization, rote learning and repetition, while the New Zealand system emphasizes questioning, problem solving and critical thinking. However, she cautions against the claim that Asian students tend to use surface thinking while western students use deep thinking techniques, asserting that most students from any culture use both techniques, depending on which is more suitable for the situation. Holmes also details some of the adjustments Chinese students must make in going from a system where the teacher does all of the talking in Chinese classrooms, to the discussion-orientated tutorials found in New Zealand; from the teacher giving students everything they need to know in China, to the student needing to read widely and pull information together themselves in New Zealand; from the indirect writing style of referring to traditions and making inferences in China, to the direct, explanatory, critical style of writing in New Zealand. Often the conventions, especially relating to plagiarism, were not clearly expressed so Chinese students were easily caught out through ignorance. Choi (1997:271) also agrees that two of the problems faced by international students are different teaching styles than they are accustomed to, and the need to think critically and participate in class discussion - activities that are often new to international students. 
Despite differences between the educational systems in China and western countries, Doherty and Singh (2005) discovered that Asian students at an Australian university tended to view the Australian system as better and they adapted to the new conventions. Andrade (2006:137-138) also found that many students in her study reported a preference for the "western" style of education. Likewise Bai (2008a:230-235) asked Chinese students in New Zealand to compare the education systems of New Zealand and China and found that the majority of students rated New Zealand as "better" or "much better" than China. However, students also admitted initial difficulties with learning and adjusting to the new systems. Gu and Schweisfurth $(2006: 81,87)$ found that Chinese students in the UK made a conscious effort to adjust to the new conventions: they were determined "to survive and develop themselves". They were motivated to adapt simply because they had to - if they wanted to pass and gain the sought-after qualification, and better their future, they had to adjust. And they did.

From these studies it appears that although international students initially have difficulty with different academic systems and teaching styles, they are generally adaptable and are able to learn and conform to the required conventions, often preferring them over the academic systems in their home country. Although students are able to adapt, there should be more initiative from the education institutions to teach students about the new rules and help them get off to a good start, rather than leave them to fend for themselves and learn the hard way. Zamel and Spack (2006:130) lament that students are all too often left to learn what is expected on their own. Hofstede (1986:316) argues that when it comes to cross-cultural education, you must either "teach the teacher how to teach" or "teach the learner how to learn". Although he argues in favour of the former approach, when international students are the minority the latter is more feasible. Chinese international students need to be taught how to learn within the New Zealand university system.

These three factors - language, adjusting to the new culture, and adapting to the different academic conventions - play an important role in the international student's experience and success. The research carried out for this thesis investigates these areas to see if participants are struggling with the same 
issues, if they are getting help in these matters, and if there is any associated effect on their achievement. 


\section{Chapter Two: Research Aim, Methodology and Design}

\section{Research Questions and Aim}

This research project investigates the academic achievement and the experiences of Chinese international students who have been through the Foundation Studies Programme at Victoria University of Wellington, and those who have not, to explore the effectiveness of the programme in preparing students for degree study in New Zealand. The initial questions being considered are:

1. Does the Foundation Studies Programme help students to succeed in their subsequent undergraduate studies?

2. If so, in what ways does the programme help?

The aim is to identify and discuss factors that contribute toward successful undergraduate study for Chinese students in New Zealand, in order to raise the question of how universities in New Zealand can implement appropriate techniques to help their international students succeed. This will be achieved by:

- Examining the academic records of some Chinese international students at Victoria University of Wellington and comparing the achievement of students who have been through the Foundation Studies Programme with those who have not;

- Asking students about their experiences and feelings about studying and living in New Zealand;

- Exploring the issues raised in the interviews and identifying what factors positively influence a student's academic success;

- Evaluating the performance of the Foundation Studies Programme in preparing students for undergraduate study; 
Justification

Andrade (2006:133) says, "Institutions cannot simply admit foreign students and expect them to adjust to life in a new country and educational system without appropriate support and programming". But rather, they need to offer support so that international students achieve their goals, are satisfied with the education they receive (which they pay a lot of money for), and have a good experience in New Zealand. Ho et al. (2007:54) echo this view by recommending that students are given more help in their educational journey, specifically with moving from language schools or high schools into universities. They also suggest that universities provide ongoing English language teaching alongside regular courses to continue to help international students develop the skills they need to succeed. Holmes (2004) similarly suggests that institutions can give more help to international students by preparing them through foundation or bridging programmes, and Skyrme (2007) also asks universities to give international students more direct guidance in their first year, specifically through teachers giving more explicit instructions.

The Foundation Studies Programme at Victoria University of Wellington is designed to meet the needs of international students in this way, giving them help and support, and bridging the gap between high school or language school and university. For many students it becomes a necessary step on the pathway towards their final goal. Therefore it is essential to investigate whether or not the programme is actually succeeding in supporting international students and helping them reach their goals. Furthermore, in evaluating this programme, and in identifying what helps students succeed in their studies, the question of how institutions can better prepare Chinese students for the New Zealand academic environment is raised.

\section{Methodology}

A mixed methods approach was taken for this project. Mixed methods research is using both quantitative and qualitative methods within the course of study, in order to gain more understanding of the issues. According to Creswell and 
Plano Clark (2007:33), "the combination of qualitative and quantitative data provides a more complete picture by noting trends and generalisations as well as in-depth knowledge of participants' perspectives". As both quantitative and qualitative approaches have bias and limitations, mixing the methods can reduce the negative effects and offer researchers the best of both worlds (Creswell 2003:15). The view that both methods can be combined to form a single approach to research has arisen from a pragmatic perspective, which claims there are many ways to collect and analyze data, and researchers are able to choose the techniques that work best according to their needs and focus of study (Creswell 2003:12).

The type of mixed methods research used in this study is an explanatory sequential approach. This is a two-stage process in which a quantitative study identifies areas that need further explanation or elaboration and so a qualitative study is then undertaken with participants who are most able to shed light on the situation (Creswell \& Plano Clark 2007:71-72; Creswell 2003:16,215). The major advantage of this approach, according to Creswell and Plano Clark (2007:74), is that it is a straight forward, two-stage study with one part building upon the other. However, they also note the main challenge with this model is in deciding whether or not to use the same participants for each phase. This issue will be discussed in the Research Design section to follow.

This method was chosen as the initial information - the reports produced by the Foundation Studies Programme - showed that one group of students performed better than another group. The current research project developed in response to these findings, seeking to discover if the same results would occur when considering only Chinese students, and if so, how the results might be explained. These questions led to the obvious need for a quantitative study to compare the achievement of the two groups, and then a qualitative study to explore the factors contributing to this achievement. 


\section{Research Design}

As an explanatory sequential approach was taken, research was conducted in two separate studies, one after the other, using different methods. The quantitative study was conducted first, considering the question of whether or not doing the Foundation Studies programme prepares Chinese students for successful undergraduate study. This was done by considering the grades gained by undergraduate students and comparing a group of Chinese international students who went through the Foundation Studies programme with a group who did not. This study was carried out in July 2007, and the data was analysed and the results found over the following months. The results showed that Foundation Studies graduates outperformed students who did not do the Foundation programme, which raised the questions of why the Foundation Studies students did better and what aspects of the programme could account for this effect. In order to answer these questions, a second, qualitative, study was designed.

The qualitative study involved interviewing students and seeking to find factors that contributed to their success. Two groups of students were interviewed: all were Chinese international students who were working towards, or had recently completed, an undergraduate degree at Victoria University, but one group had been through the Foundation Studies programme before beginning their degree courses and the other group had not. The interviews were conducted throughout 2008. They were recorded and transcribed as soon after the interview took place as was practically possible. Coding of the transcripts also began straight away, so that analysing was taking place and themes were beginning to emerge while data collection was still continuing. The second study identified aspects of the Foundation Studies Programme that appeared to have a positive influence on the students who took it, and which may account for their higher achievement.

Each of the two studies were analysed and the results considered separately, at the time the study took place. When the second study was complete, and initial results had emerged, the two studies were considered together, to seek a more holistic understanding of the situation. In particular, the qualitative data was 
used to expand upon and explain the findings of the quantitative study, in agreement with the explanatory sequential model of research.

\section{Participants}

All participants in these studies are Chinese students from the People's Republic of China, excluding Hong Kong and Taiwan. The decision was made to exclude Hong Kong and Taiwan in order to reduce any possible variables that may arise from the different education systems, social policies, cultural and historical events between these two areas and mainland China. All were full fee paying international students.

The quantitative study consisted of 40 participants. All were enrolled in their third or subsequent year of undergraduate study (in any discipline) at Victoria University of Wellington at the time of data collection. 20 students had been through the Victoria University Foundation Studies Programme before commencing their undergraduate study (FS), and 20 had not taken this programme as they had degree entry (DE). Of the $20 \mathrm{FS}$ students, 13 were female and 7 male; of the 20 DE students, there was an even split of 10 males and 10 females. Ages of FS students ranged from 21 to 27 years, and DE students a similar 21 to 26 years.

The participants in the qualitative study were either enrolled in undergraduate programmes or had recently completed their undergraduate degree at Victoria University of Wellington. In order to ensure participants have been in the university environment long enough to be able to meaningfully answer the questions and talk about their experience, only students who had completed at least three trimesters of undergraduate courses were eligible. Participants came from a variety of disciplines. In total 21 students were interviewed. One interview was discarded as during the course of the interview it became clear that the student did not actually meet the criteria, despite having claimed to. Of the 20 interviews that were used, ten were with students who had completed the Foundation Studies Programme and ten were with students who had not. The age, gender, hometown in China and time spent in New Zealand of the 
participants are shown in Table 1. Although participants had spent varying amounts of time in New Zealand before commencing their undergraduate studies, they have all made the transition from the Chinese education system to the New Zealand one.

Table 1: Interview participants

\begin{tabular}{|l|l|l|l|}
\hline \multicolumn{2}{|c|}{} & DE Students & FS Students \\
\hline \multirow{3}{*}{ Gender } & Male & 5 & 4 \\
\cline { 2 - 4 } & Female & 5 & 6 \\
\hline Age & Beijing & $21-29$ years & $19-28$ years \\
\hline From & 3 & 2 \\
\cline { 2 - 4 } & Shanghai & 2 & 1 \\
\cline { 2 - 4 } & Nanjing & 1 & 1 \\
\cline { 2 - 4 } & Guangzhou & 1 & 1 \\
\cline { 2 - 4 } & Lanzhou & & 2 \\
\cline { 2 - 4 } & Dongying & & 3 \\
\cline { 2 - 4 } & Other minor cities & 3 & $2-6$ years \\
\hline \multicolumn{2}{|l|}{ Time in New Zealand } & $2-7$ years & \\
\hline
\end{tabular}

Consideration was given to the issue of whether or not to use the same participants in both studies. It was decided that there was no real advantage to using the same participants if the general trend of FS students outperforming DE students was consistent among all students. The advantages to not confining the first study to students who agreed to be interviewed for the second phase included being able to conduct the first study first, to see if any patterns emerged and questions were raised for the second study to build upon - in line with the explanatory sequential method of research; to not need to know the identity of the participants in the first study, thereby ensuring their privacy; and to not be faced with the issue of students completing their degree and returning to China in between the two studies, as the second study was started six months after the first.

\section{Method of Recruitment}

For the first phase, no participants were sought - data was provided from the university database as described in the next section. Participants were sought for the second phase of research, the interviews. 
Advertisements in both English and Chinese were placed around the university asking for Chinese international students to participate in a study. The advertisements briefly described the purpose of the study, what the participants would be required to do, approximately how much time it would take, and that participants' identity would not be disclosed. Interested parties were invited to contact me by phone, email or in person. Students who responded were given information about the purpose of the study and how the interview would be conducted. They were asked a few questions to make sure they met the required criteria. Those who qualified were asked to participate in an interview, at a time and place suitable for the participant. All interviews took place in public areas on the university campuses, except for one interview which was conducted in the public library. Those who did not qualify were informed and thanked for their time and interest. Advertising continued until the predetermined number of interviews (20) was obtained.

Participants were also sought through referral. At the end of each interview, participants were asked to recommend a friend for the study. Several students passed my contact details on to their friends. On two occasions, the respondents even brought friends who were interested in participating also along to the interviews with them.

\section{Data Collection Methods}

The data for the first phase was supplied by the Victoria University Central Services team for the purpose of this study only. The Central Services team was asked to provide, from the university database, a random selection of 40 international (full-fee paying) students from mainland China who were enrolled in their third or subsequent year of undergraduate study at Victoria University of Wellington, 20 of whom had completed the Foundation Studies Programme before commencing their undergraduate study and 20 who had not. The information requested included gender, age, all courses studied in Victoria University, and the grades gained in each course. The year and trimester each course was taken was also supplied. See Appendix One for the full list of data. 
The interviews were conducted one-on-one between the participant and myself. Before the interview commenced, participants were given an information sheet outlining the purpose of the study, describing how their anonymity will be assured, and asking if they would like to receive a summary of findings. They were then asked if they were happy for the interview to be audio taped, and they signed a consent form. All participants were willing to have their interview recorded, and all but one wanted to receive the summary of findings. The interviews were conducted in an informal manner and were semi-structured, following the question schedule but allowing the student to talk about whatever they wanted to say, and allowing me to follow any threads that seemed important or interesting. This approach ensured consistency over all the interviews while also allowing flexibility and the opportunity for new information to emerge (Ho et al. 2007:10). The participant had the right to not answer any question, ask for a question to be repeated or rephrased, or ask for clarification or an example when the question was not understood.

The questions covered many areas such as: how the participants feel their study is going, if they consider themselves a good student or not, what their expectations were before beginning their degree study and what they are now, future plans and motivation for study; their perception of their English language ability; their comfort in using English academically and socially; what they believe has helped or hindered language development; the academic background of the students and comparisons between teaching and learning styles in New Zealand and China; adjusting to New Zealand culture and university culture; relationships with New Zealanders, friends and teachers; and also their age and where they are from. The full list of interview questions is given in Appendix Two.

Much consideration was given as to which language to conduct the interviews in. Some researchers argue that interviews should be conducted in the participant's first language (Mangen 2007:21-23). As English is not the students' native language, by using it as the language for the interviews there is potential for misunderstanding and participants may have difficulty in expressing their true thoughts and meanings. However, there is also evidence that the appropriate language is the one that is contextually relevant (Holmes 1992:21- 
54). As the students are living and studying in an English environment, discussing their studies and life in New Zealand in English is appropriate. As I am not ethnically Chinese, there was also a risk that conducting the interviews in Chinese may have given the impression that I did not believe the participant's English was adequate, which could create an unwanted atmosphere of the participant feeling inferior. All participants had been studying in a New Zealand university a minimum of one year at the time of interviewing, and all had an IELTS score of 6.0 or higher - the entry requirement for undergraduate study therefore their English language was sufficient for the questions asked. The decision was made to conduct the interviews primarily in English, but participants were told of my background of having studied Chinese language for 6 years, two of which were in a university in China, and they were encouraged to use Chinese during the interview if they wanted to. Several participants used some Chinese but the majority was in English.

Another issue considered was the appropriateness of a New Zealander researching Chinese students as an outsider, and therefore being likely to bring New Zealand cultural biases and assumptions into the interpretation, according to Holmes (2004). She also points out, however, that outsiders can often see issues more clearly than those for whom it is considered the norm. As this study seeks to investigate how Chinese students perform within a New Zealand academic environment, which includes factors such as how they adjust to the New Zealand culture and education systems and relate to New Zealanders, as well as seeking to discover how New Zealand institutions can better help and equip Chinese students, cross-cultural communication and understanding are essential, therefore a cross-cultural method should be appropriate. I did all of the interviewing myself, in order to gain a fuller understanding of the participants and their experiences, which would not be obtained if the only data was the transcribed interviews. My own experience as an international student in China created an affinity with the participant, as well as minimizing some of the possible cross-cultural misunderstandings. Understanding the culture and language of the participants, being aware of the common language errors or misunderstandings, and being used to speaking English in a manner that is easily understood by international students are all areas of strength I brought to the interviews. 
While considering the issues involved in using interviews as a method of data collection, some of the shortfalls need to be discussed. One problem with seeking opinions and feelings about a past event is that people may not accurately remember details, or their recollection is coloured by their feelings and current state of mind. James (2006:788) points out that "interviews, similar to other forms of self-report data, raise concerns with regard to inaccurate memory and the provision of answers to meet an interviewer's expectations." Regarding the "interviewer's expectations", Holmes (2004) also comments on how the position of authority of the interviewer may affect the way a participant answers the questions - they may give what they think is the correct or soughtafter answer rather than a truthful answer, or they may be cautious in their response and less willing to give unsolicited information. Aware of this, I attempted to make the students feel at ease, first by laying out the common ground of having been an international student in China, and secondly encouraging them to answer honestly by reminding the participant throughout the interview that it was ok to be honest, to say what they thought, and that there is no right or wrong answer. Many participants prefaced their answer with "to be honest" or a similar phrase, indicating that they were aware that what they were about to say may not be favourable, but was truthful.

After the interview was conducted, I transcribed it myself. Paralinguistic features, pauses, stammering and grammar-related questions such as "is that the right word?" were not included unless they added important context or meaning to the conversation. I also added notes in parenthesis where it was thought explanation or clarification was needed for future reference - these included things such as the participant's non-verbal communication, alternative words where I was aware (from context, body language, and experience in communicating with Chinese students) that a word was used incorrectly or inappropriately, and translation of Chinese words and phrases. 


\section{Data Analysis}

\section{Quantitative study}

Accomplishment was primarily examined on a student by student basis, throughout their whole degree, rather than by comparing two groups of students within a few chosen courses. This approach is in line with a study conducted by Rosalie Robinson (2004), in which she did a longitudinal study of students over 7 years for a five-year degree programme. She claims there is an advantage in tracking individual students' achievement throughout their degree process rather than considering specific course enrolments and results for a period. One of the advantages of this approach is gaining insight into individual students' progress throughout their studies, and seeing if time spent in the university environment plays a role in their achievement. Another advantage is that this approach covers a wide range of courses, and patterns relating to students across a broad range of degrees and subjects can emerge. As this current research seeks to compare academic success, regardless of discipline, it is more appropriate to examine individual students' overall progress rather than focus on specific courses, although some specific courses have also been considered.

For each student, a grade point average (GPA) and pass rate were calculated. The GPA was calculated by allocating a number to each grade according to the following scale:

\begin{tabular}{|l|l|l|l|l|l|l|l|l|l|l|}
\hline $\mathrm{A}+$ & $\mathrm{A}$ & $\mathrm{A}-$ & $\mathrm{B}+$ & $\mathrm{B}$ & $\mathrm{B}-$ & $\mathrm{C}+$ & $\mathrm{C}$ & $\mathrm{D}$ & $\mathrm{E}$ & $\mathrm{K} / \mathrm{Q}^{4}$ \\
\hline 9 & 8 & 7 & 6 & 5 & 4 & 3 & 2 & 1 & 0 & 0 \\
\hline
\end{tabular}

An average for all of the grades gained by each student was then calculated numerically and rounded to one decimal place. The pass rate was calculated as the percentage of courses passed out of all courses completed - if a student withdrew from a course it was not included. GPAs and pass rates were calculated for a student's entire course of study, as well as examining each year

\footnotetext{
${ }^{4} \mathrm{~K}$ or $\mathrm{Q}$ grades are fail grades, given when the student has not met mandatory course requirements
} 
of study separately. Only undergraduate courses were included - the Foundation Studies and English language courses were excluded.

Comparisons between the GPAs and pass rates of FS and DE students were made over their entire course of study as well as year by year. Grades and pass rates of the two groups of students within specific courses were also examined. To see if other factors may influence success, age, gender and where a student is from were also considered.

\section{Qualitative study (Interviews)}

Information was taken from the transcribed interviews and placed in a chart under the appropriate categories, so that the data about and comments from each student could be compared against the other students for each theme or category identified. In total, 37 categories emerged, covering demographical information such as age, gender, and how long the student has been in New Zealand; as well as educational background, study techniques, achievement, language skills; and more personal information such as goals, motivations, and feelings about life and study in New Zealand. Often a comment by a student was placed in more than one category, as it covered several themes. Common words or sentiments were sought within categories and compared with opposing opinions. Answers were also placed on a scale where appropriate.

As there were only 20 participants in this study, the comparisons were made manually rather than using a computerised analysis programme (Creswell 2007:165). Creswell (2007:164) affirms that the same process is used, whether it is done manually or by a computer programme - that is something in the text is identified and coded, and then all examples within the same code are compared. 


\section{Research Trustworthiness}

In evaluating the trustworthiness of this research, consideration is given to both the quantitative and qualitative aspects of data collection and analysis. Quantitative methods consider the reliability and validity of data, while qualitative methods are concerned with credibility (Mertens 2005:349-358).

First, the issues associated with quantitative data collection are examined, beginning with reliability. Reliability describes the accuracy of the measurements, considering how much error is likely to occur in the measuring process. In this study, the descriptive statistics of mean and standard deviation have been calculated for each item. Although Cronbach's coefficient alpha, or a similar statistic, is often used to calculate reliability (Mertens 2005:349-350), in this case it is not relevant because only a single source of data taken at one point in time was used. However, because the data was collected from a single source at one time, external inconsistencies and variables are minimized. Reliability also comes from the data in this study giving similar results to previous studies.

Another issue associated with quantitative research is validity. Validity is concerned with the instrument actually measuring what it is meant to be measuring (Katzer et al. 1998:101). Mertens (2005:352-358) suggests five ways in which tests can be validated, encouraging as many ways as possible to be combined. These are:

- Construct validity: Different groups with different expected outcomes are constructed. Correlation with other tests that have been validated is sought.

- Content validity: Use the right content for the test.

- Predictive validity: A test is done, then when the predicted event happens, the test is evaluated to see how accurate it was.

- Concurrent validity: The test is done and can be checked for accuracy immediately.

- Consequential validity: The negative, positive, intended and unintended outcomes are all identified.

This study uses construct and content methods of validity. The different groups showed different outcomes which were consistent with results of previous 
studies. In addition the content is appropriate - looking at the grades gained by students to evaluate their academic achievement.

The second area to consider is in regard to qualitative methods, and concerns the credibility of the data. Both Creswell (2003:196-197) and Mertens (2005:358) list similar ways to ensure credibility of qualitative data, and recommend implementing several of these measures together. In the qualitative phase of this research, consideration was given to the following areas:

- Prolonged engagement - the interviews were conducted over 10 months and coding and analysis were on going throughout this time also, allowing for themes to emerge while data was still being collected. Furthermore, my own experience in studying in China for two years and working with international students in New Zealand for over four years adds to the length of engagement in this field of research.

- Peer debriefing - As themes began to emerge from the analysis of interviews, they were discussed with colleagues. A seminar was also presented on the results of the interviews, emerging themes and initial conclusions, from which useful feedback was received.

- External auditor - several of the typed transcripts were checked against the original recordings for accuracy and consistency.

- Rich description - data is presented with as much detail as possible, and often exact quotes are given, in order to present a full picture and allow the reader to draw their own conclusions.

- Present negative information - rather than only presenting the positive aspects, or where the data confirms the conclusions, the conflicting and irregular results are also shown and considered.

In addition to these measures taken to ensure credibility, a reflexive approach was taken in the collection and analysis of interview data. Gu and Schweisfurth (2006:78-79) describe this approach as the researcher looking at their own views, beliefs and ways of doing things, in order to be more sensitive to the often different views and beliefs of the participants, and to see other's views without one's own getting in the way. 


\section{Definitions and Limitations}

This research is primarily concerned with the academic achievement of students in their undergraduate studies. Although success in a broader sense can include such things as cultural adaptation, social integration, satisfaction with life in New Zealand, and optimism about future prospects, for the purpose of this study the narrow definition of successful study - passing courses and gaining a degree - is used. A successful student is one who is passing all or most of their courses, thereby being on track to achieve their goal of gaining a degree without spending too much additional time and money on repeating courses.

Morrison et al. (2005:327) say "Given that the primary goal of most international students in studying abroad is to gain a qualification, there is remarkably little published research on academic outcomes". They elaborate on this by explaining that the experiences of international students has been well covered in research, but the outcomes of these students' study less so, and that the outcomes should not be neglected. Although this research project investigates the experiences of Chinese students in New Zealand, these experiences are explored for the purpose of identifying the factors that contribute to successful study, therefore the aim is not the experiences themselves but the outcome of the international study experience.

Although success is considered in the narrow sense of academic achievement, the findings of this research shows that the broader definition of success adjusting academically, socially and culturally to New Zealand, feeling comfortable and happy with life and being confident in English language ability - plays an important role in academic success: successfully adjusting to New Zealand life helps in successful study within New Zealand.

The limitations of this study are to do with size and scope of the research conducted. The results are indicative of a small group of students within one university in New Zealand, and therefore may not necessarily be generalized for all Chinese international students in New Zealand, or other western countries. However, similar results were often found with other studies that have been 
conducted, suggesting that these factors may apply more broadly. These similarities are discussed in Chapter Five.

A second limitation is in regard to what information is presented in this thesis. Not everything that emerged from the interviews and analysis could be included as they were not relevant to the research question and focus of this project. Some of the interesting themes that came up, but are outside the scope of this thesis include the students' perspective of the value of their New Zealand university degree and the tendency to not recommend New Zealand as a good study destination to other potential students.

\section{Ethical Considerations}

Ethical considerations were identified and addressed before the commencement of this research project. Advice was sought from the director of the university's Central Student Administration regarding the collection and use of students' academic results for the purpose of this study, and assurance was given that the administration team was able to produce ethical and credible reports for this purpose. A request for data was made and a report was generated from the university database in which student identities were in no way revealed.

Ethical approval from Victoria University's Human Ethics Committee was obtained before interviews were conducted (see Appendix Three). Information sheets, outlining the background and purpose of the study, the rights of the participants and how their anonymity would be maintained were given to potential participants. A copy of the information sheet is given in Appendix Four. Interview times were then arranged. Before the interview commenced, participants were again reminded of the purpose of the study and their rights, and were assured that their names or any other identifying information would not be revealed. Permission was sought from participants to audio record the interview, and they were also reminded that they had the right to terminate the interview at any time or to not answer any questions they were not comfortable with. Participants were then asked to sign the consent form (see appendix 
Five). All recordings and transcripts of interviews are kept in a locked cupboard, and soft copies are kept in a password-protected and fully secure computer file, and will be destroyed five years after the completion of the study. 


\section{Chapter Three: Academic Achievement (Quantitative Study)}

This chapter presents the results of the first phase of research - the quantitative study. This study focuses on the achievement of Chinese international students in their undergraduate courses at Victoria University and compares students who have been through the Foundation Studies Programme with students who have not. The findings are presented and discussed, and questions are raised by this study, to be considered further in the second stage of research.

\section{Findings}

\section{Achievement of FS and DE Students Over All Courses}

Table 2 Grade point averages and pass rates for Foundation Studies and Degree Entry students

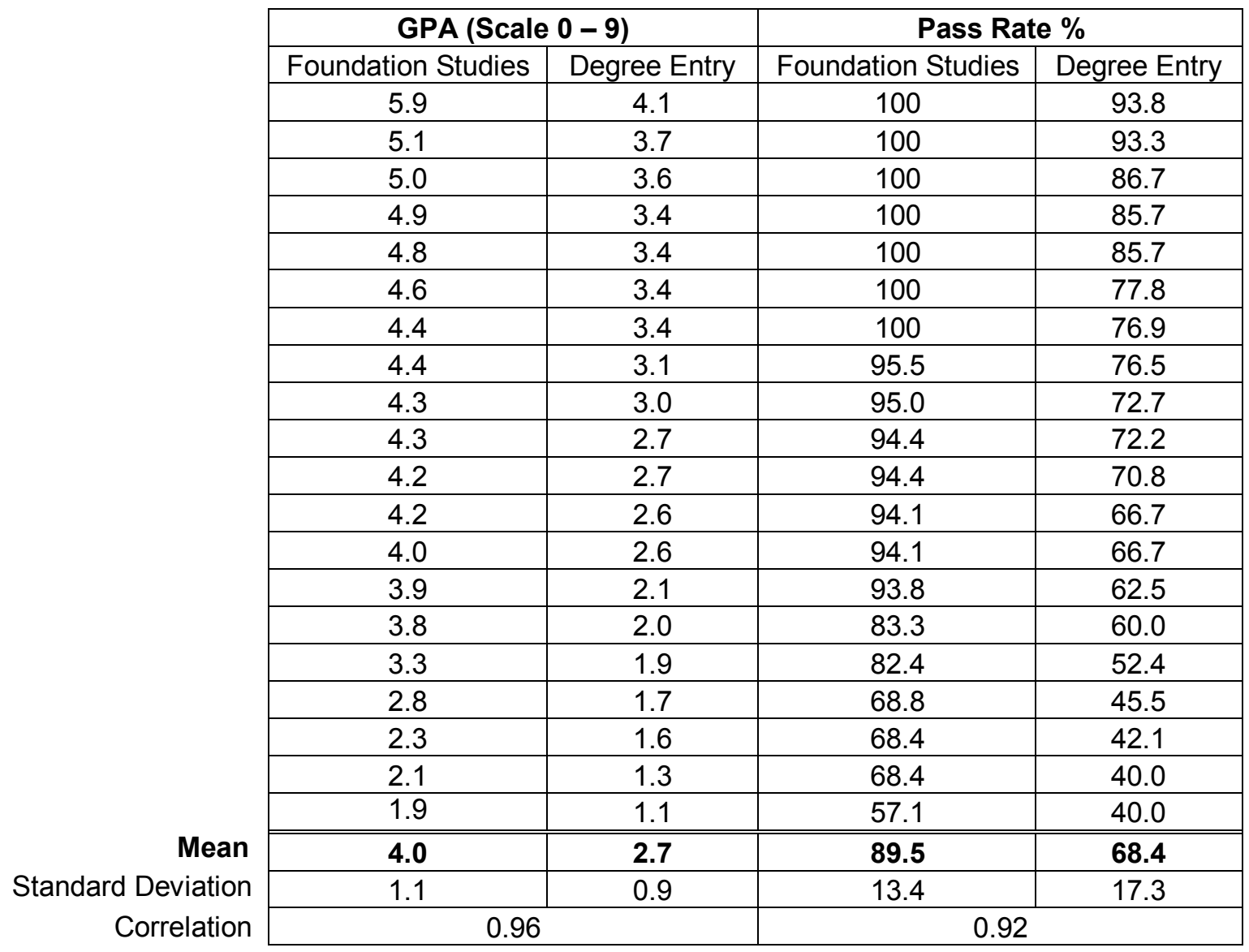


Table 2 shows the grade point averages and pass rates of each of the 40 students in this study. The results are ranked from highest to lowest in each group. As this table shows, FS students have a higher mean GPA and pass rate than DE students. There is a close correlation between the GPA scores of FS and DE student groups, as well as a close correlation between the pass rates of these two groups. The difference between the group means, for both GPA scores and pass rates, is significant at a $1 \%$ level. ${ }^{5}$ This data is further illustrated in Figures 1 to 4.

Figure 1 Grade point average for DE students

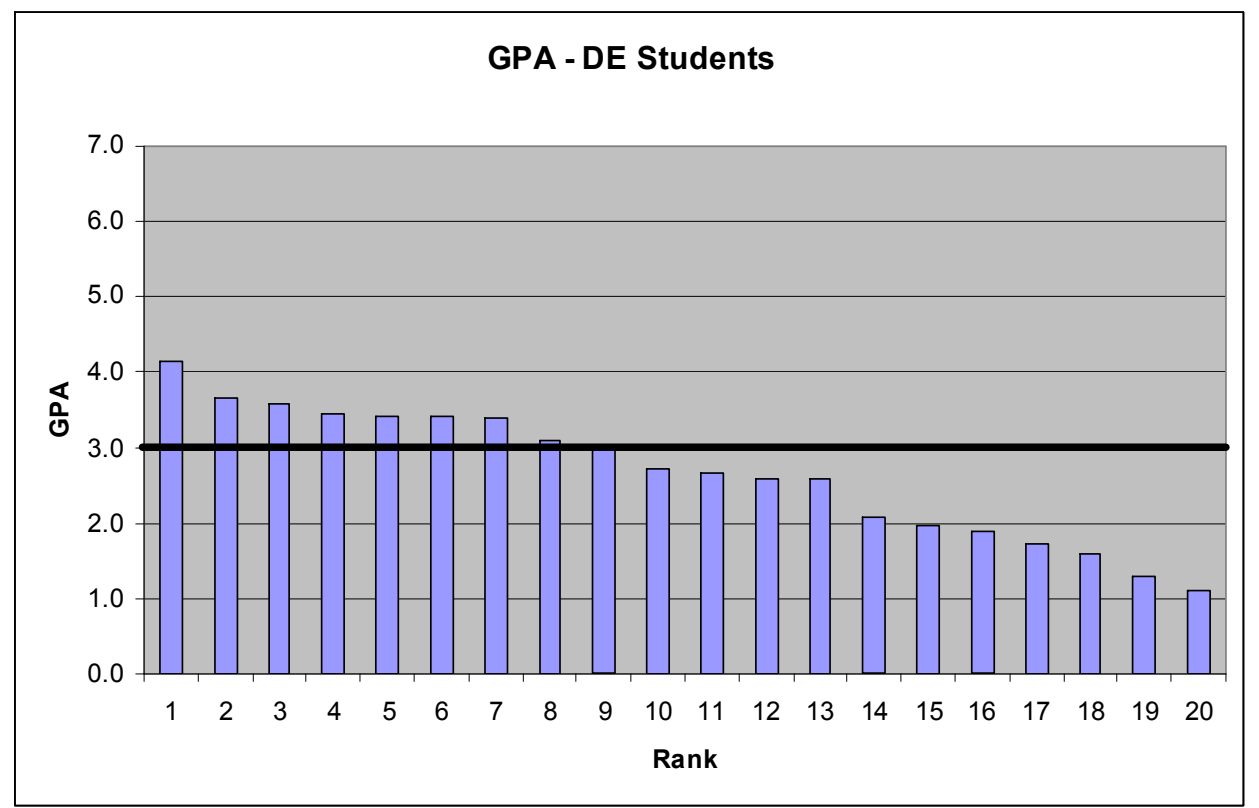

Figure 2 Grade point average for FS students

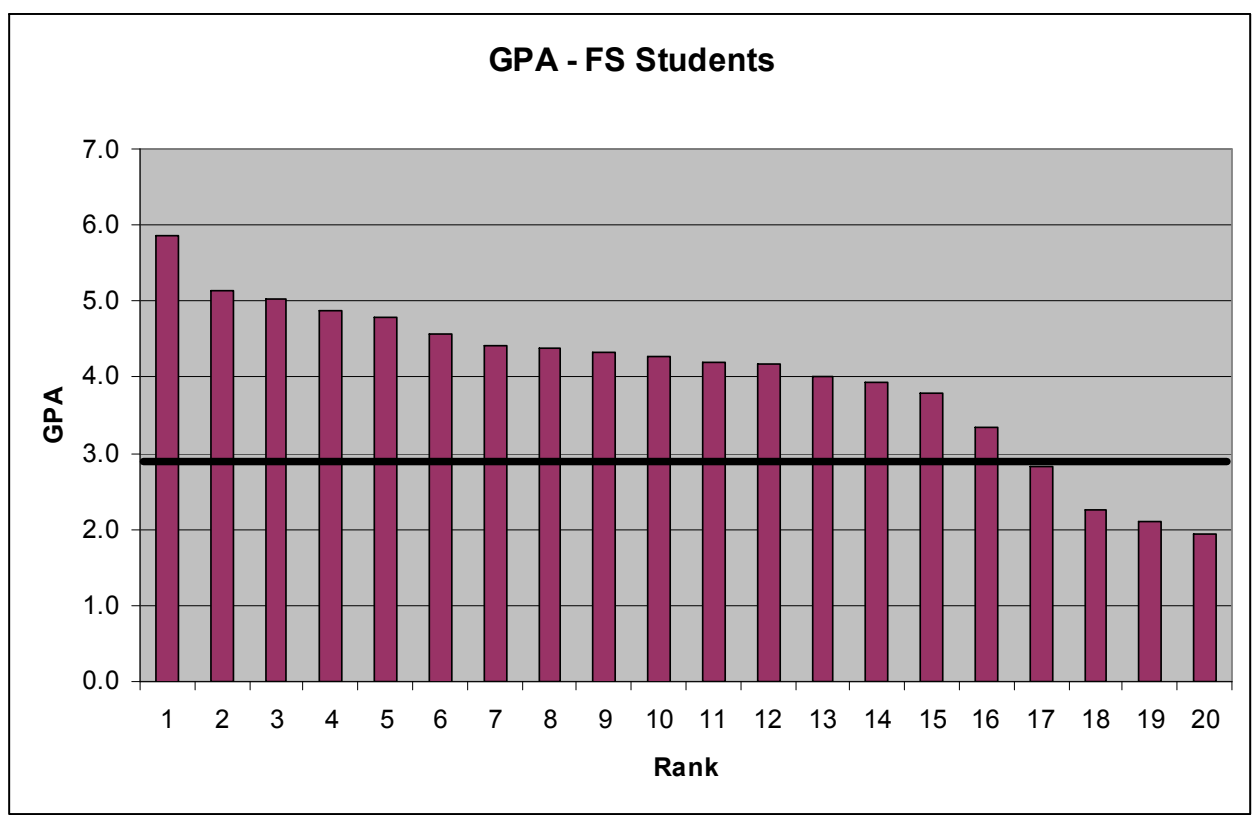

${ }^{5} \mathrm{~A}$ t-test was conducted for both the GPAs and Pass Rates. See Appendix Six for calculations. 
Figure 3 Pass rates for DE students

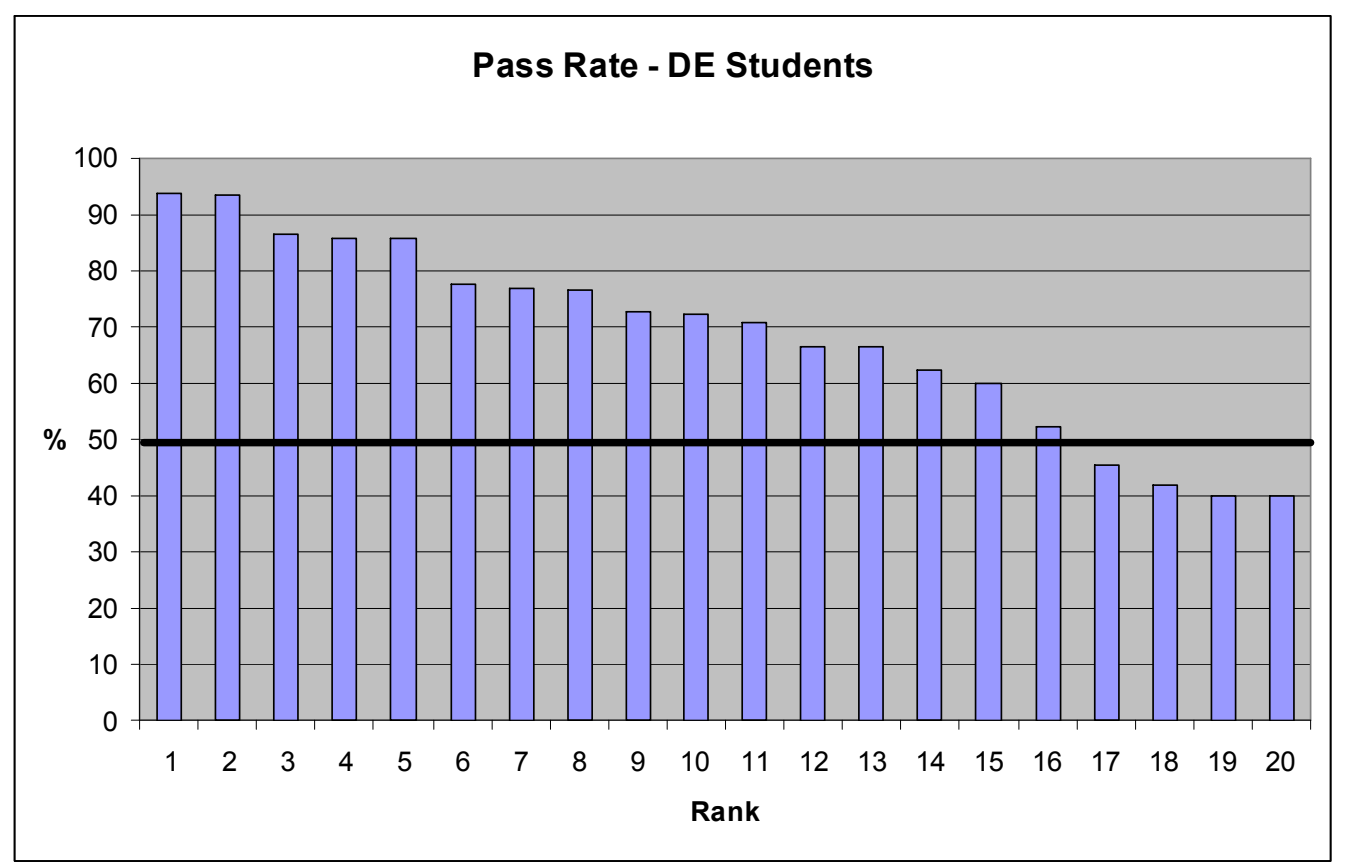

Figure 4 Pass rates for FS students

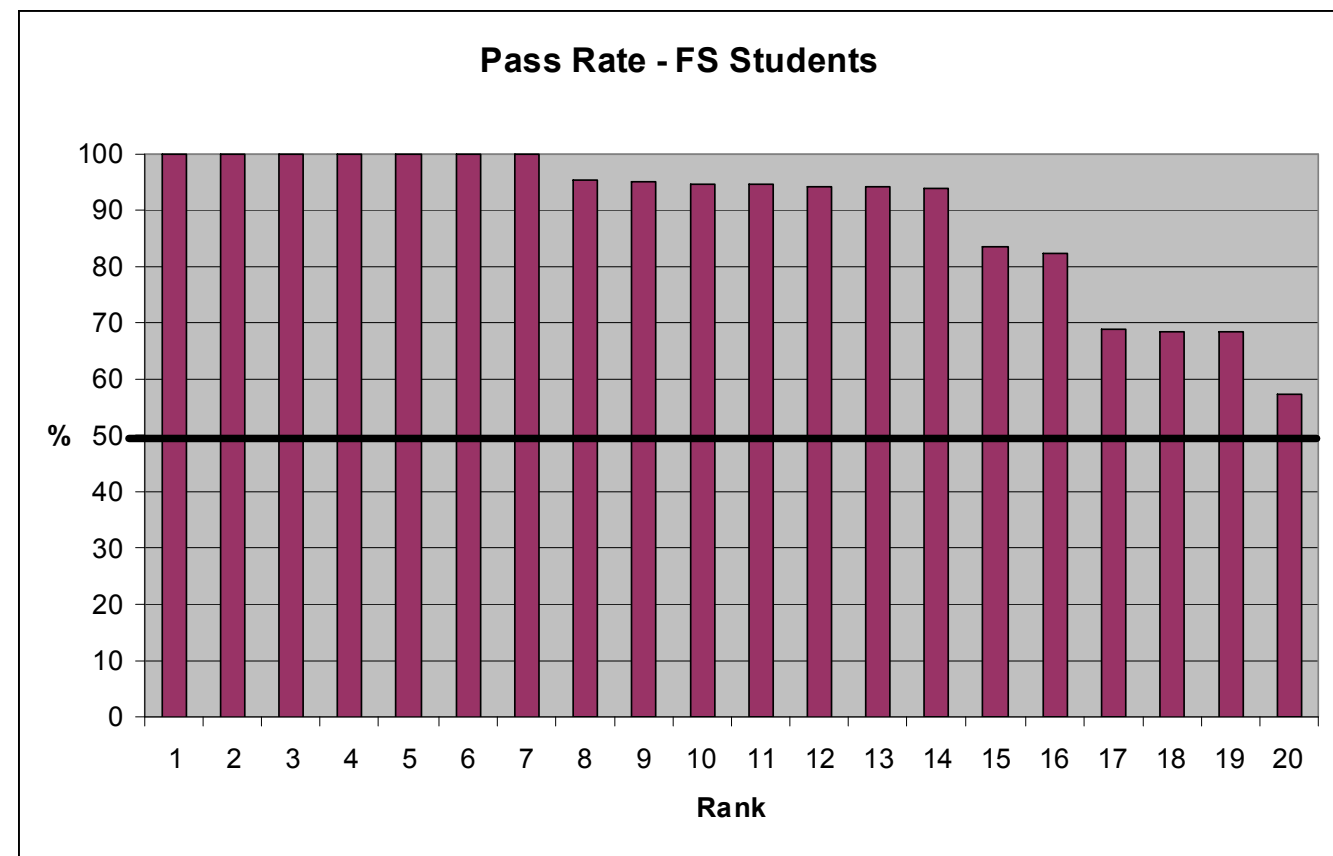

\section{Withdrawal Rate}

In this sample seven DE students withdrew from courses and only one FS student withdrew from a course. These numbers are too small to be of significance. 


\section{Achievement of FS and DE Students Year By Year}

As well as considering the entire course of study undertaken by the students, their GPAs and pass rates were considered on a year by year basis. The mean GPAs and pass rates for both groups of students are shown year by year, for undergraduate courses, in Table 3. This data is also illustrated in Figures 5 and 6. As these graphs show, FS students maintain a higher achievement than DE students throughout their entire undergraduate career. The DE students, rather than begin to catch-up in their second year, actually attain lower grades and a lower pass rate than in their first year, and although their third (and subsequent) year shows an improvement on the second, it is still not as high as their firstyear achievement. The gap between the achievement of FS and DE students increases over the duration of their undergraduate studies.

Table 3 GPAs and pass rates by year

\begin{tabular}{|l|l|l|l|l|l|l|}
\hline & \multicolumn{3}{|l|}{ DE Students } & \multicolumn{2}{l|}{ FS Students } \\
& Year 1 & Year 2 & Year 3+ & Year 1 & Year 2 & Year 3+ \\
\hline Mean GPA & 2.88 & 2.36 & 2.42 & 3.91 & 4.01 & 4.25 \\
\hline Standard deviation & 1.30 & 0.93 & 0.92 & 1.26 & 1.37 & 1.38 \\
\hline Mean pass rate & $70.6 \%$ & $62.3 \%$ & $67.9 \%$ & $88.0 \%$ & $89.9 \%$ & $92.1 \%$ \\
\hline Standard deviation & $28.1 \%$ & $20.4 \%$ & $26.1 \%$ & $18.8 \%$ & $21.0 \%$ & $17.8 \%$ \\
\hline
\end{tabular}


Figure 5 Mean grade point averages per year for FS and DE students

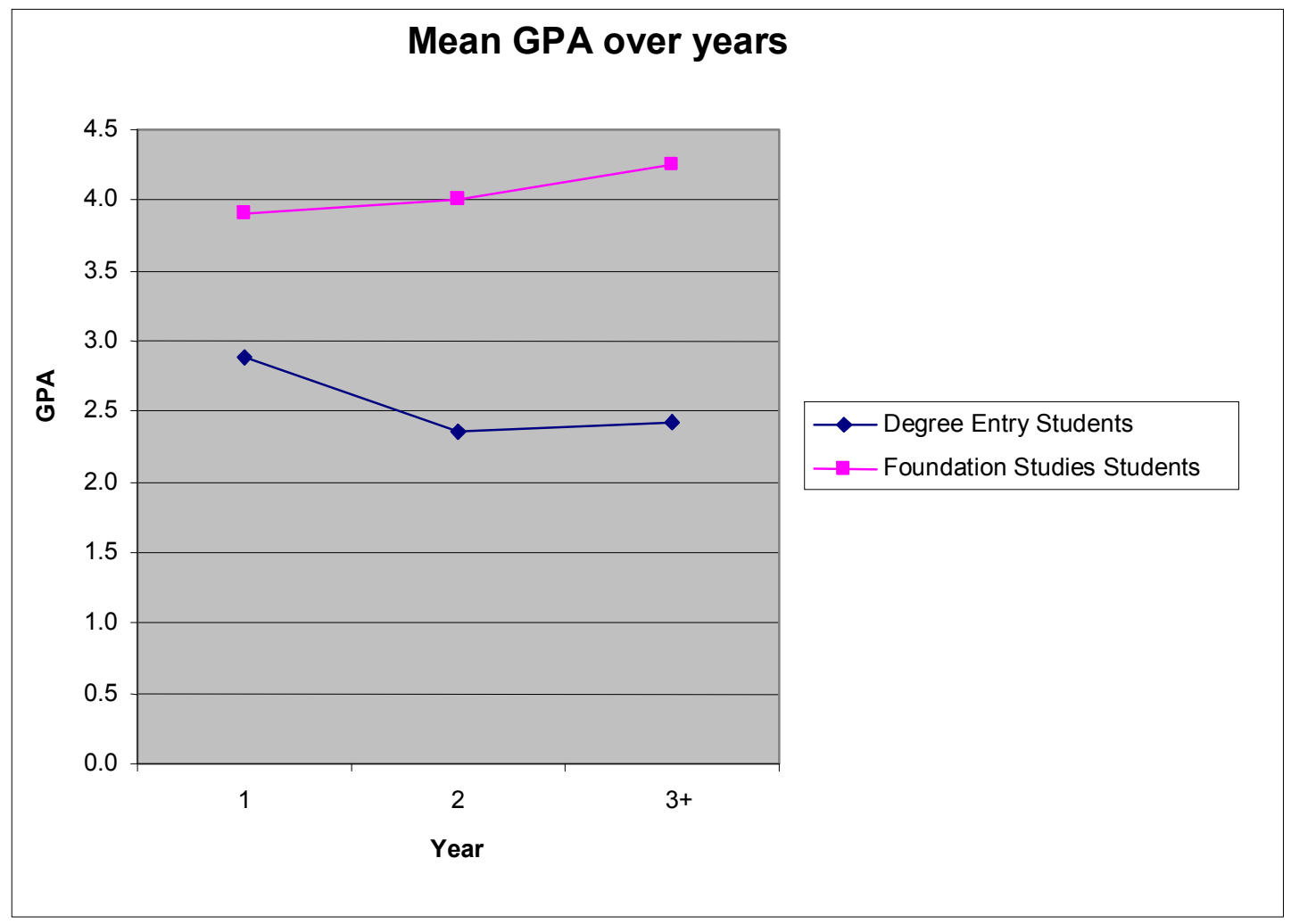

Figure 6 Mean pass rates per year for FS and DE students

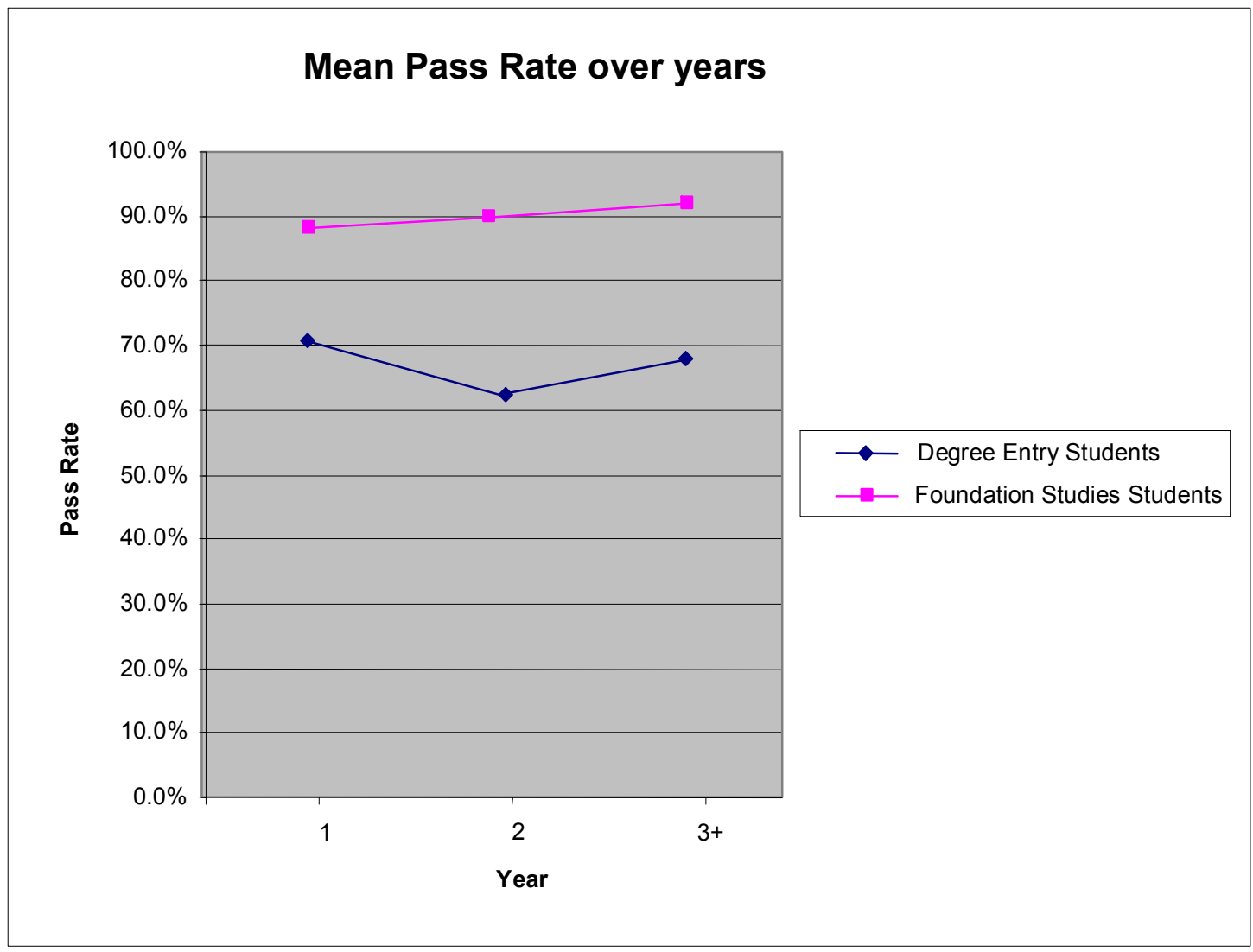




\section{Achievement of FS and DE Students By Specific Subjects}

Some specific courses were reviewed to see how the two groups of students compared. Ten different courses were considered, but the numbers of students from the sample enrolled in many of these courses were too small to be meaningful. Two courses, however, proved popular choices, and therefore were examined in more detail. These courses are ECON130 and INFO101 - a first-year economics course and a first-year information systems course, both of which are compulsory courses for the Bachelor of Commerce and Administration.

In total, 37 of the 40 sample students took ECON130 (18 FS and 19 DE) and 20 students took INFO101 (7 FS and $13 \mathrm{DE}$ ). The number of students gaining each grade in each of these courses is shown in the Table 4, and illustrated in the graphs in Figures 7 to 10. Although no students attained A grades in these courses, a higher percentage of FS students gained B grades than DE students, and a lower percentage of FS students received failing grades. Consistent with the findings across students' entire programme of study, within these two specific courses FS students also out perform DE students.

Table 4 Grades gained by Foundation Studies and Degree Entry students in two courses

\begin{tabular}{|c|c|c|c|c|}
\hline & \multicolumn{2}{|c|}{ ECON130 } & \multicolumn{2}{c|}{ INFO101 } \\
\hline Grade & FS & DE & 1 & DE \\
\hline B+ & 1 & 0 & 2 & 2 \\
\hline B & 3 & 3 & 1 & 5 \\
\hline B- & 4 & 1 & 1 & 0 \\
\hline C+ & 5 & 5 & 1 & 2 \\
\hline C & 4 & 4 & 0 & 1 \\
\hline D & 1 & 5 & 0 & 1 \\
\hline K/Q & 0 & 1 & 1 & 13 \\
\hline Total & 0 & 0 & $\mathbf{7}$ & \\
\hline
\end{tabular}


Figure 7 Grades gained by DE students in ECON130

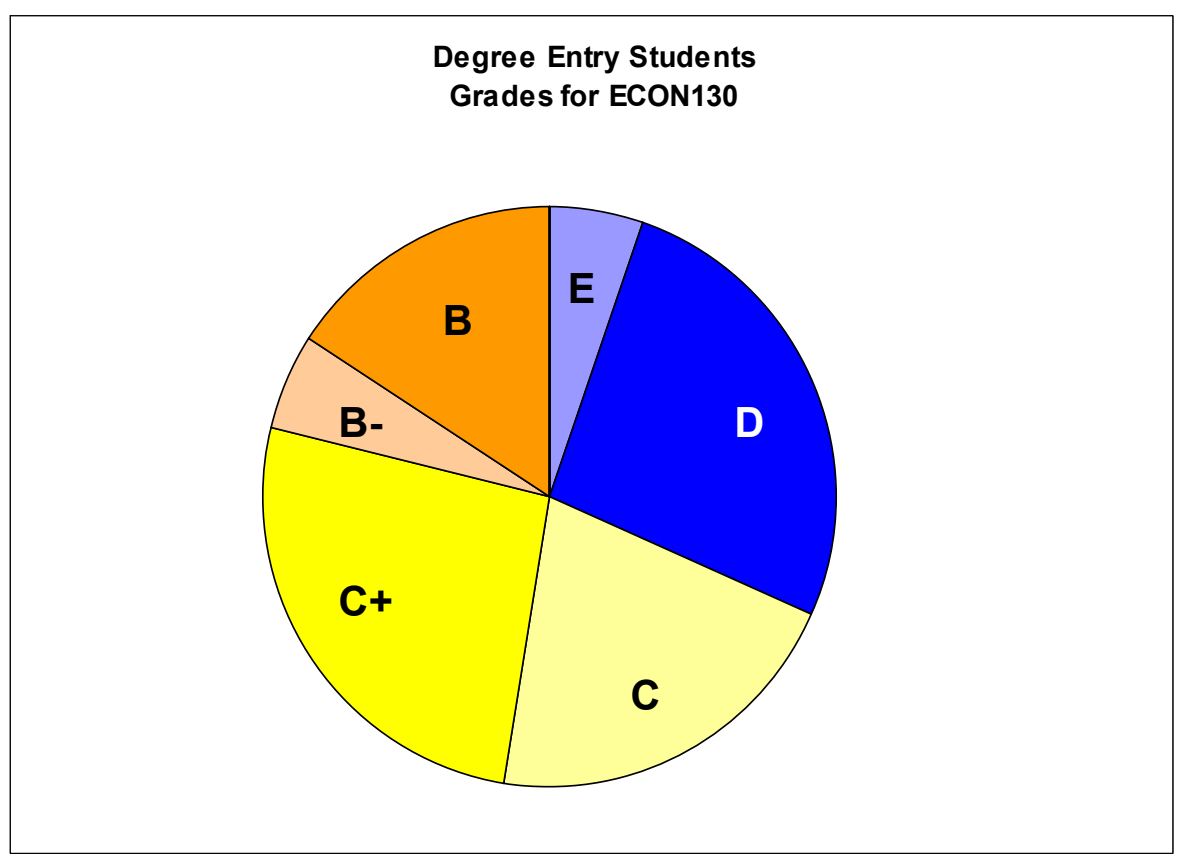

Figure 8 Grades gained by FS students in ECON130

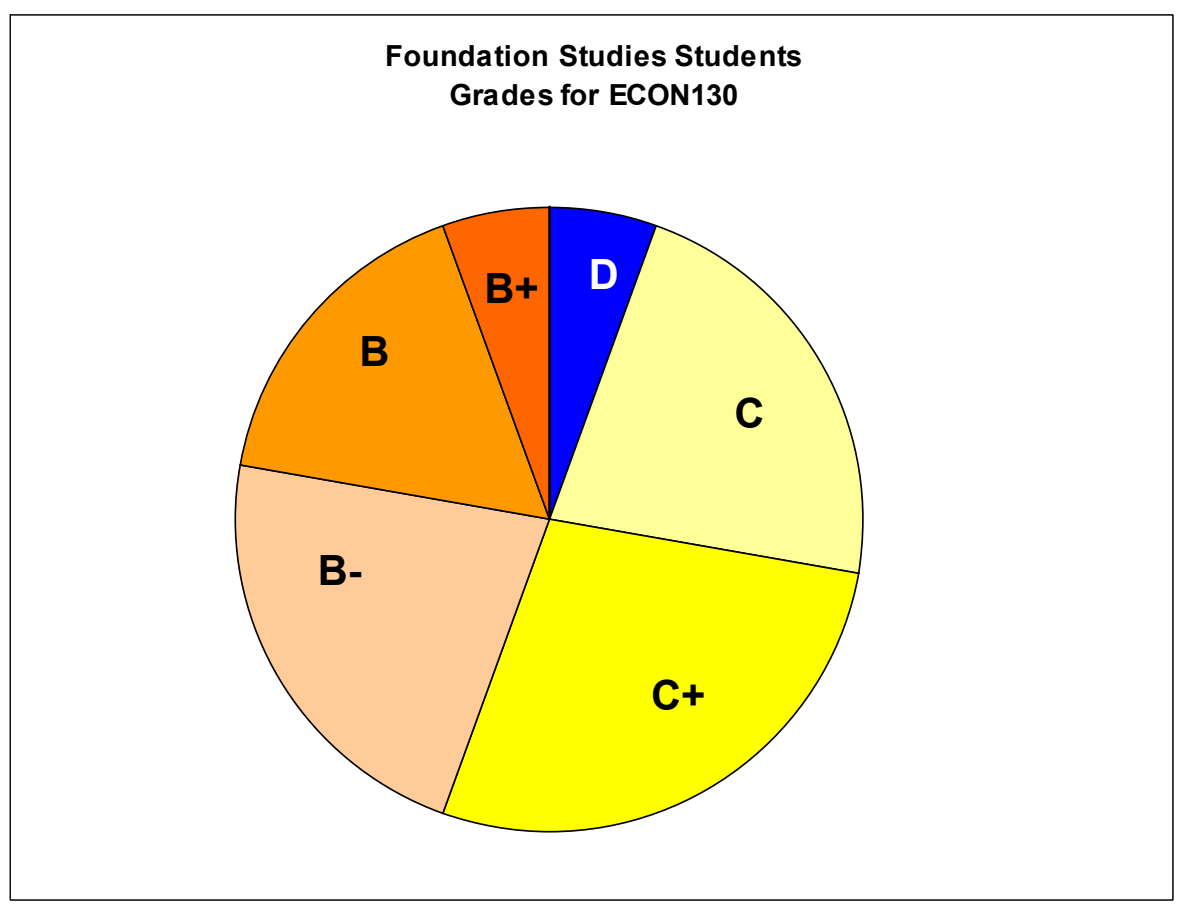


Figure 9 Grades gained by DE students in INFO101

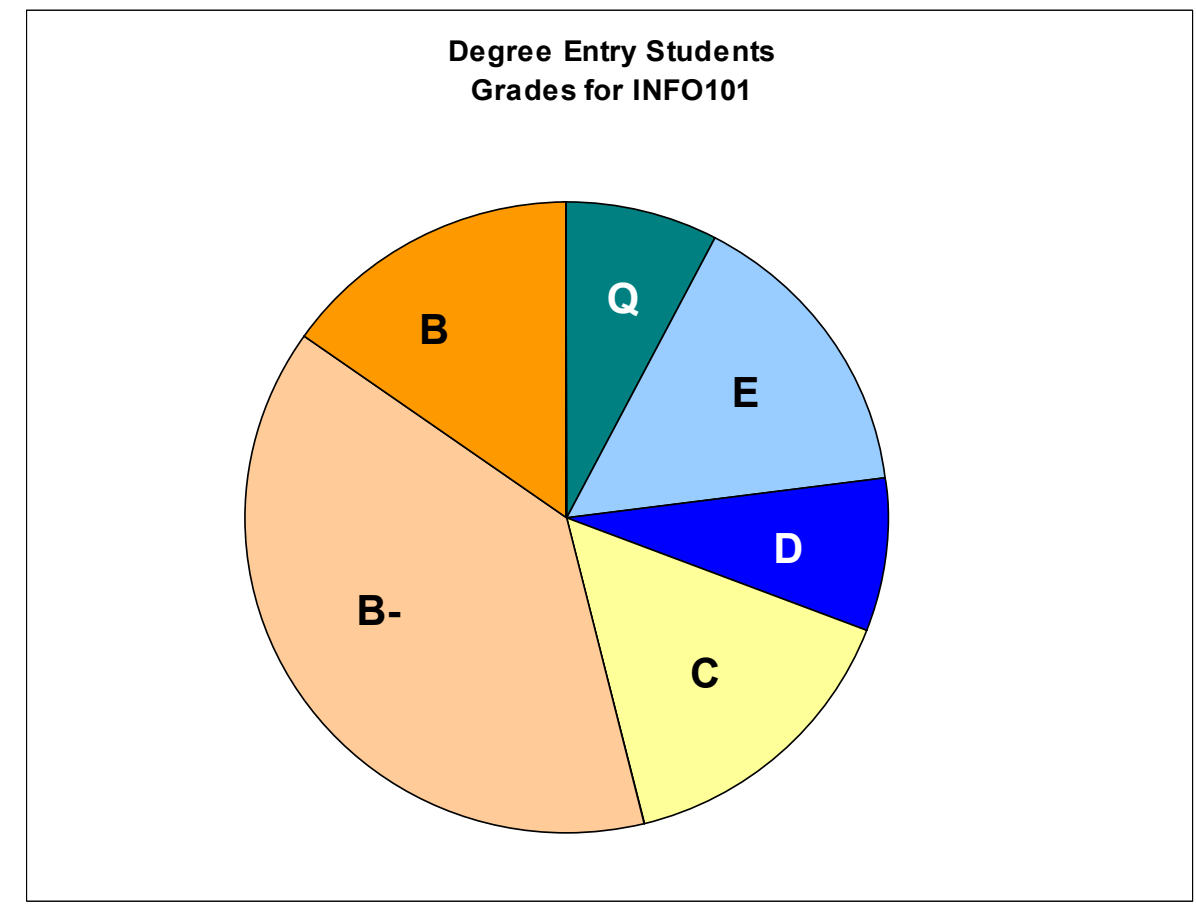

Figure 10 Grades gained by FS students in INFO101

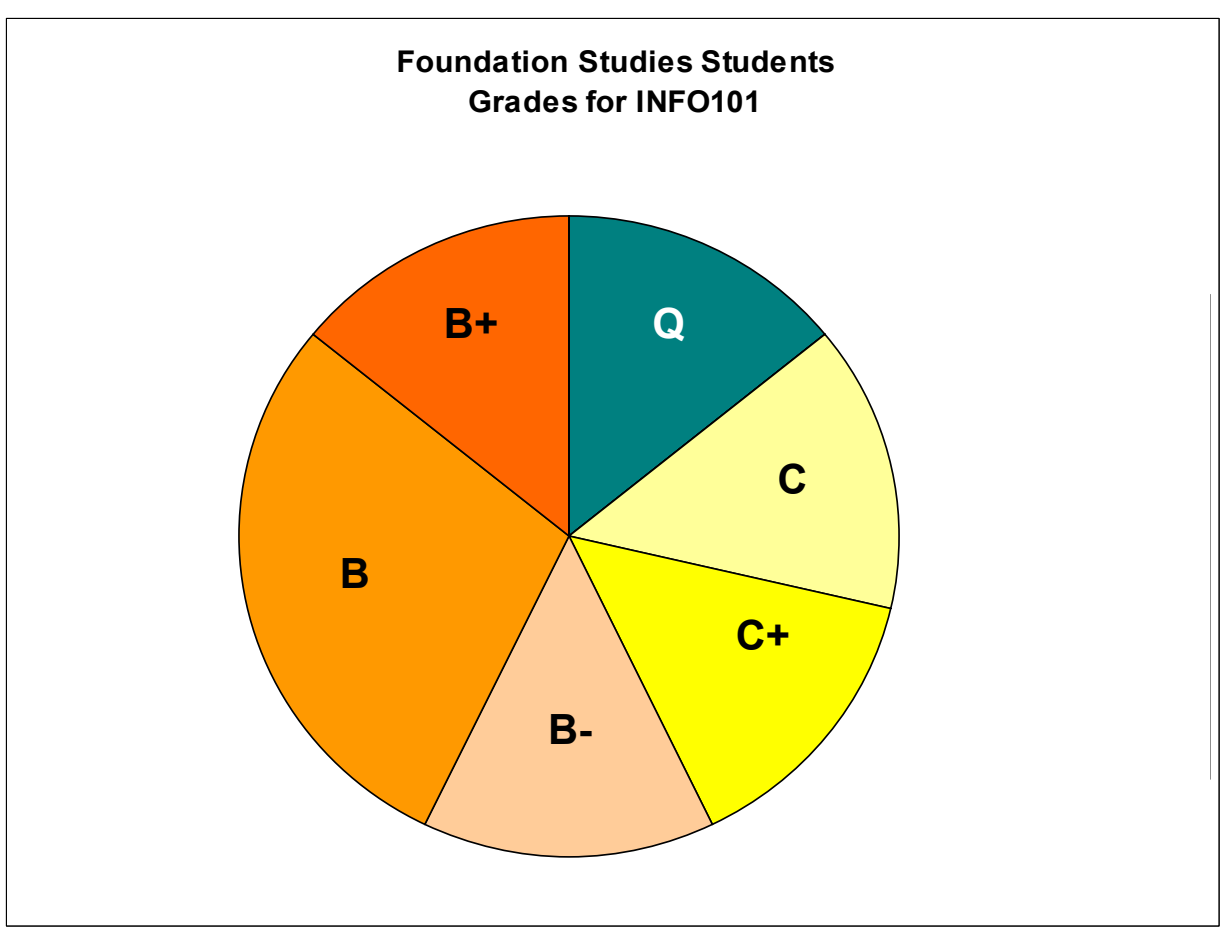




\section{Age}

Another factor considered was age, and whether or not a student's achievement is related to their age. The age of students in this sample ranged from 21 to 27 years. No significant correlation was found between age and achievement.

\section{Gender}

Gender was also considered in regard to students' achievement, as shown in Tables 5 and 6. The mean GPA for female students is 3.6 (4.1 for FS students and 2.9 for DE) and for male students is 3.0 (3.9 for FS and 2.4 for DE).

When considering pass rate, the difference between the means of each gender group is significant at a $5 \%$ level. The GPA comparison between the two gender groups is not statistically significant, but is still an item of interest. ${ }^{6}$ These results show that female students are more successful - in terms of passing undergraduate courses - than male students.

Table 5 GPAs and gender

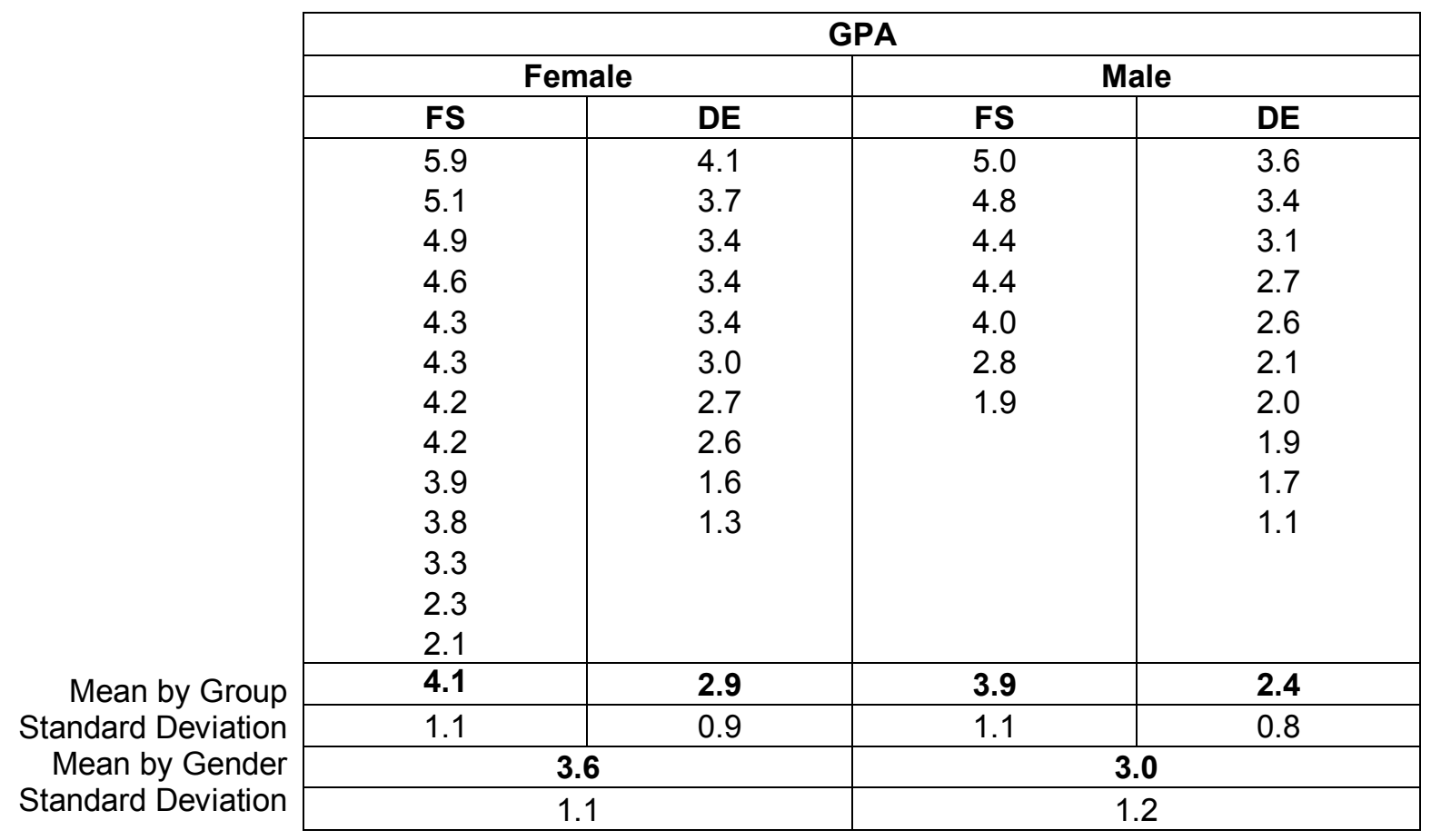

${ }^{6} \mathrm{t}$-Tests were conducted for both the GPAs and Pass Rates, comparing gender groups. Pass rate was tested at a $5 \%$ level, GPA at $10 \%$. See Appendix Six for calculations. 
Table 6 Pass rate and gender

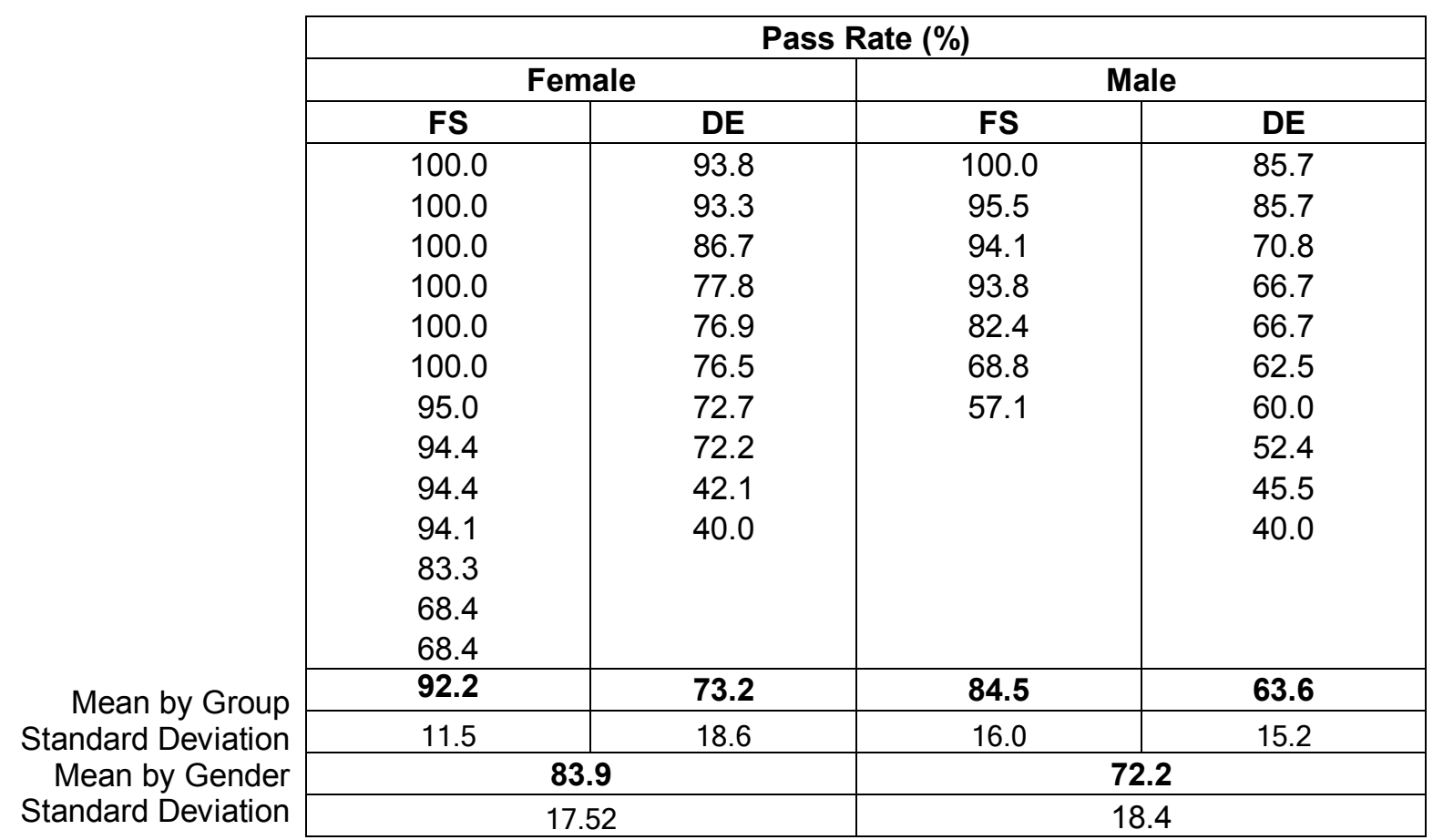

\section{Discussion}

This study shows that Chinese international students who have been through the Foundation Studies programme do better in their subsequent degree study, in terms of grades and pass rates, than those who enter directly into undergraduate degree programmes. The average GPA of FS students is 4.0, which is equivalent to a $B$ - grade, while the average GPA of DE students is only 2.7 - or $\mathrm{C}$ to $\mathrm{C}+$. The average pass rate for FS students is $89.5 \%$; however, the $68.4 \%$ pass rate of DE students is of some concern, indicating that these students have between them failed almost one third of all courses taken.

One possible explanation for Foundation Studies students' advantage over Degree Entry students is that they have an introductory year to the university which gives them a head-start when they reach undergraduate studies. It could be expected then that the DE students would catch up in their second year. However, when GPAs and pass rates were considered on a year by year basis, this did not happen. FS students continued to gain higher results than DE 
students every year of their undergraduate studies, and the gap between FS and DE students' achievement increases over time.

In a case study of two specific courses - ECON130 and INFO101 - the FS students received more high grades ( $\mathrm{B}$ - and higher) and less failing grades than DE students. This is consistent with the findings across students' entire programme of study, showing that FS students out-perform DE students overall, as well as on a year by year basis, and within specific courses.

Another result worth discussing is that DE students withdrew from seven courses after the initial two week cut-off for changing courses, whereas only one FS student withdrew from a course. For the FS student, and four of the DE students, the course they withdrew from was only one of the courses being taken that trimester - they did not withdraw from the other courses, suggesting that the one course may have been dropped because it was too difficult or they were not passing. Another DE student withdrew from two courses in total, but they were in different years. Again, the one course withdrawn from each time was only one of three courses enrolled in - the others were not dropped. The final DE student withdrew from the only one course being studied in that particular trimester, which could indicate that the student had to withdraw completely from study that trimester, as opposed to dropping a course that is too difficult. However, no actual reasons are given for why students withdraw, so these results are open to interpretation.

A second factor the results revealed as having a significant correlation with achievement is gender. Female students pass more courses than male students. This is consistent with the findings of Morrison et al. (2005:328,334), as discussed in Chapter One. They investigated the achievement of students in the UK and found that females outperformed males, for both domestic and international students. The results of this current study show that even though gender and achievement are related, this factor is not as significant as whether or not a student had been through the Foundation Studies programme. ${ }^{7}$ Female FS students were the highest performers, gaining a mean GPA of 4.1

\footnotetext{
${ }^{7}$ The t-tests comparing FS and DE students are significant at a 1\% level, for both GPA and pass rate. The t-tests comparing male and female are significant at a $5 \%$ level for pass rate only.
} 
and a mean pass rate of $92.2 \%$, followed by male FS students on a 3.9 GPA and $84.5 \%$ pass rate. The female DE students came next, with an average GPA of 2.9 and a $73.2 \%$ pass rate. The lowest achieving group was DE males, who had a 2.4 GPA and a pass rate of $63.3 \%$.

The findings of this study show that there is a very significant correlation between completing the Foundation Studies programme and academic achievement in undergraduate courses, with FS students achieving higher GPAs and pass rates than DE students. There is also a significant correlation between gender and achievement, with female students outperforming male students.

\section{Questions Raised}

The first question these results raise is why the FS students outperform the DE students. What is it about the Foundation Studies programme that causes this result? And is it the programme itself or some other factor the FS students have in common that helps them in their further studies? In addition, why do the FS students continue to outperform the DE students as they progress in their undergraduate career? The second stage of this research - the qualitative study - involved interviewing students and seeking to find answers to these questions. The results of this second study are given in the next chapter.

The second question is regarding gender: Why do female students do better than males? Is this the same in China, or is it particular to international students in New Zealand? And is there any explanation for this? Because this research aims to examine the effectiveness of the Foundation Studies programme in preparing students for university study, the question of gender will not be further investigated here. However, future research in this area is recommended. 


\section{Chapter Four: The Students' Perspective (Qualitative study)}

The second phase of research was to interview Chinese international students at Victoria University of Wellington, to gain their perspective on life and education in New Zealand, and to seek similarities or differences between those who had been through the Foundation Studies Programme and those who had not. This chapter presents the findings of these interviews.

Primarily, the two groups - FS students and DE students - are compared. Differences that may explain why one group outperforms the other are sought. Secondary comparisons between a factor identified and the students' academic achievement are also made in some instances to ascertain if these factors directly influence performance.

\section{Findings}

\section{Achievement}

One of the interview questions was regarding achievement. Participants were asked how well their study was going - whether they were passing all of their courses; most (only failed one or two); had failed a few more but were still passing more than half; were passing half and failing just as many; or were failing more courses than passing. Their self-reported achievement is consistent with their academic records, and is shown in Table 7.

Table 7 Achievement in undergraduate courses

\begin{tabular}{|l|c|c|}
\hline \multicolumn{1}{|c|}{ Achievement } & DE students & FS Students \\
\hline Passing all & 0 & 3 \\
\hline Passing most & 2 & 3 \\
\hline Passing more than half & 5 & 3 \\
\hline Passing half & 2 & 0 \\
\hline Passing less than half & 1 & 1 \\
\hline
\end{tabular}


Although in both groups (DE and FS), nine out of ten students are passing at least half of their courses, FS students are doing better with more passing all or most of their courses than DE students, as illustrated in Figures 11 and 12.

Figure 11 Achievement of DE students

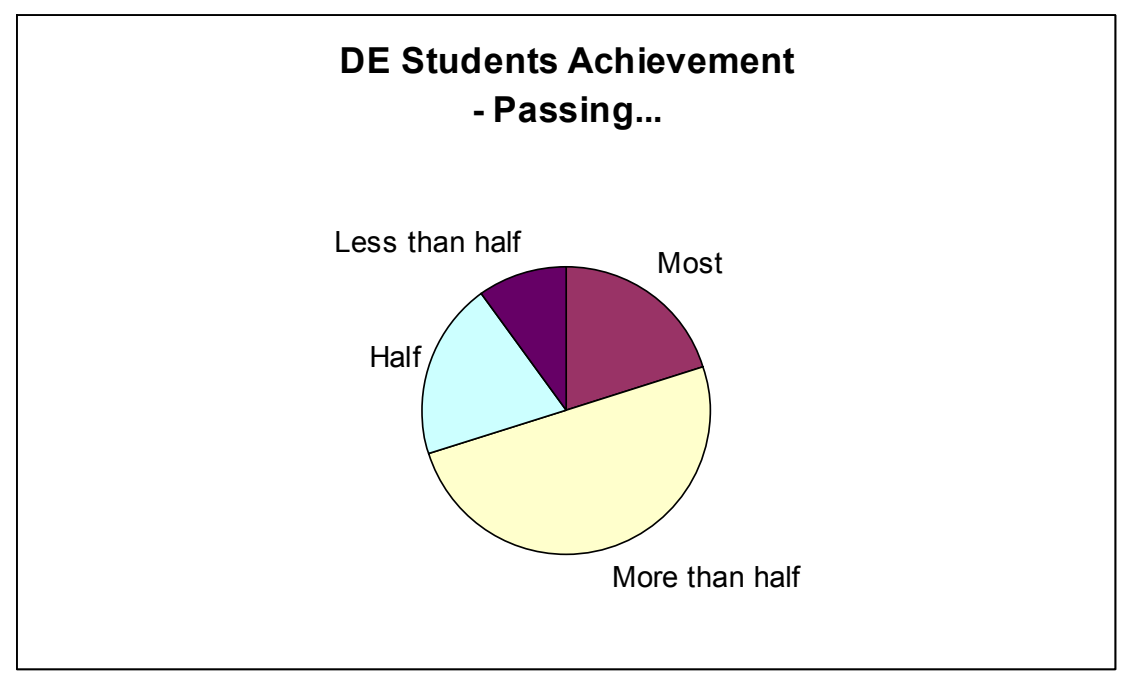

Figure 12 Achievement of FS students

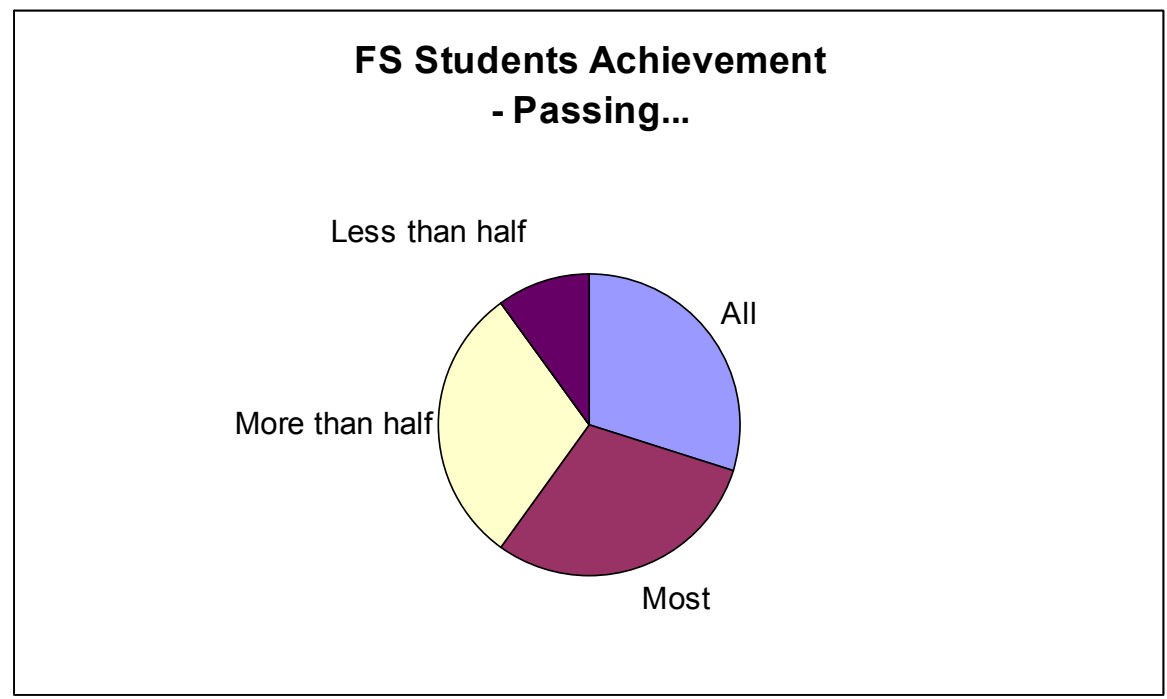

\section{Self-rating: "How Good a Student"}

Students were asked to rate themselves on a scale of $0-5$ according to "how good a student" they were, and were prompted to consider things like whether they attended classes regularly, spent time studying outside of class, their attitude and effort, as well as achievement. Although the scale given was $0-5$, some participants rated themselves half way between points by giving 
themselves scores such as "three and a half". Table 8 shows the rating students gave themselves.

Table 8 Self-rating: "how good a student"

\begin{tabular}{|c|c|c|}
\hline Self rating & DE students & FS students \\
\hline 2 & 3 & \\
\hline 2.5 & 1 & 1 \\
\hline 3 & 4 & 3 \\
\hline 3.5 & 1 & 2 \\
\hline 4 & & 2 \\
\hline 4.5 & 1 & 1 \\
\hline 5 & 1 \\
\hline
\end{tabular}

No student rated themselves as 0 or 1 . Most placed themselves in the middle of the scale (2.5 or 3 ), and many commented that they felt they were average students and were about the middle. Although none were willing to say they were poor students by rating themselves lower than 2, five were confident enough to say they were good, hard-working students and rated themselves from 4 to 5 .

On average DE students have rated themselves lower (mean score of 2.9) than FS students (mean score of 3.6). The one DE student who rated herself 5 did so for effort alone, as she has failed a few of courses but says she works hard, and can not understand why she is failing despite her effort. In general, FS students have a higher opinion of their studiousness or are more confident in their ability than DE students.

Participants were asked to explain why they rated themselves where they did. The reasons given are shown in Table 9. Some students gave two reasons and each is counted separately.

Table 9 Explanations for the rating given

\begin{tabular}{|l|c|c|}
\hline Reason & DE students & FS students \\
\hline Not motivated & 2 & \\
\hline Only does the minimum needed, lazy & 4 & 2 \\
\hline Poor attendance & 1 & \\
\hline Distracted with other things - sports, video games & 1 & \\
\hline Working, so not as much time to study & 2 & 1 \\
\hline Difficulty in lectures - understanding and note taking & 1 & 2 \\
\hline Leaves assignments/study until last minute & & 1 \\
\hline Tries hard, but doesn't do well & 2 & 2 \\
\hline Puts in enough effort to gain Bs, but not an A student & & 4 \\
\hline Studies hard, puts in a lot of effort, determined & 2 & \\
\hline
\end{tabular}


Most students appear to have considered attitude, motivation and effort more than academic achievement when rating themselves. Overall, eight FS and four DE students seem to be hardworking, motivated students, although two of these students (1 FS and $1 \mathrm{DE}$ ) are failing some of their courses despite their efforts and one DE student commented that he put in a lot of effort for some courses, yet failed, and cruised through other courses without trying too hard. Two of these FS students admitted they often left things to the last minute, but then got stuck in and worked hard. Another two (1 FS and $1 \mathrm{DE})$ acknowledged that in the past they were not motivated or were distracted by other things, but now they are working hard. The remaining six DE and two FS students reported themselves as being unmotivated or just doing the minimum amount needed (3 DE, $1 \mathrm{FS}$ ); spending too much time working rather than studying (2 $\mathrm{DE}, 1 \mathrm{FS})$; or finding it hard to understand lectures, take good notes, and therefore learn well $(1 \mathrm{DE})$. These self-evaluations show the same trend as the self-ratings: that FS students have a higher opinion of their studiousness and ability than DE students.

\section{English Language}

As English is the language of instruction in universities in New Zealand, it is essential that students have a high enough level of language to be able to understand and express what they are being taught. For this reason acceptance into undergraduate programmes requires a minimum IELTS (International English Language Testing System) score of 6.0. The entry requirement for the Foundation Studies programme is 5.5 , and students are considered to have reached level 6 by the time they graduate this programme. Therefore all students interviewed in this study will have the same minimum level of English - a level considered adequate for undergraduate study although some may have a higher level.

Participants were not given any formal English test to ascertain their actual level, but they were asked to rate their English language on a scale of $1-5$ (1 being very weak, 5 being very good). Although not instructed to do so, many students gave themselves half marks for this rating also. Eight students placed 
themselves in the middle of the scale (a rating of 3 ). Three students rated themselves highly, with a score of 4 to 5 , and three rated themselves low, on 2 . No student thought their language was less than 2 . The full results are shown in Table 10.

Table 10 English language ability - self-rating

\begin{tabular}{|l|c|c|c|}
\hline Self rating & DE & FS & All \\
\hline 5 & & 1 & 1 \\
\hline 4.5 & & 1 & 1 \\
\hline 4 & & 2 & 2 \\
\hline 3.5 & 2 & 2 & 4 \\
\hline 3 & 5 & 3 & 8 \\
\hline 2.5 & & 1 & 1 \\
\hline 2 & 3 & & 3 \\
\hline \hline Group Mean - rating & 2.8 & 3.6 & 3.2 \\
\hline Standard Deviation & 0.6 & 0.8 & 0.8 \\
\hline
\end{tabular}

FS students tended to rate themselves higher than DE students, with a mean score of 3.6 compared to a mean of 2.8 for DE students. FS students are more confident in their language ability as is clearly seen in figures 13 and 14 .

Figure $13 D E$ students self-rating for English language

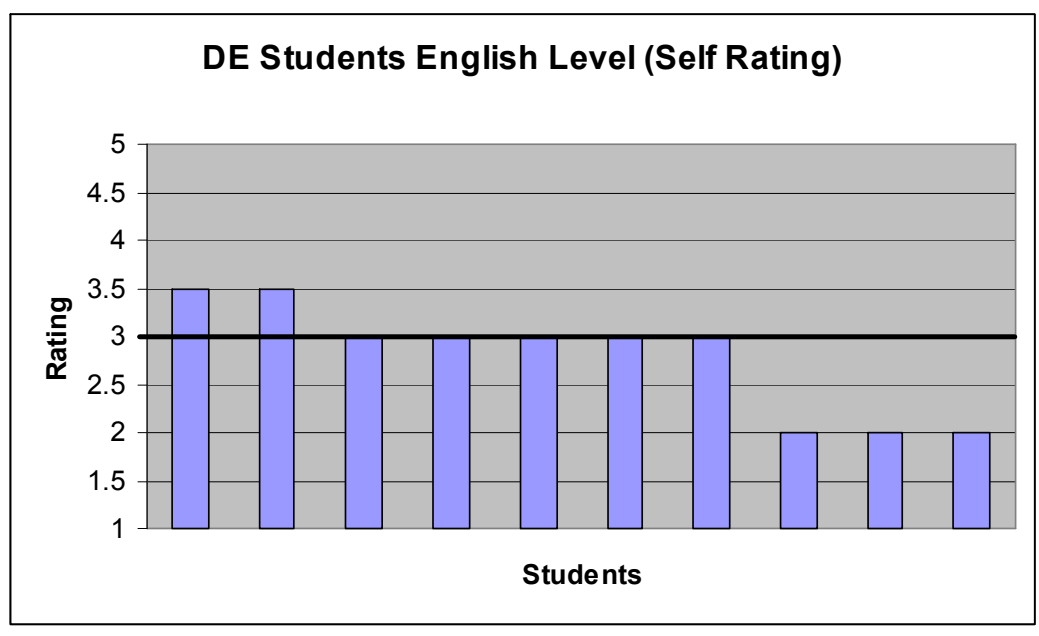

Figure 14 FS students self-rating for English language

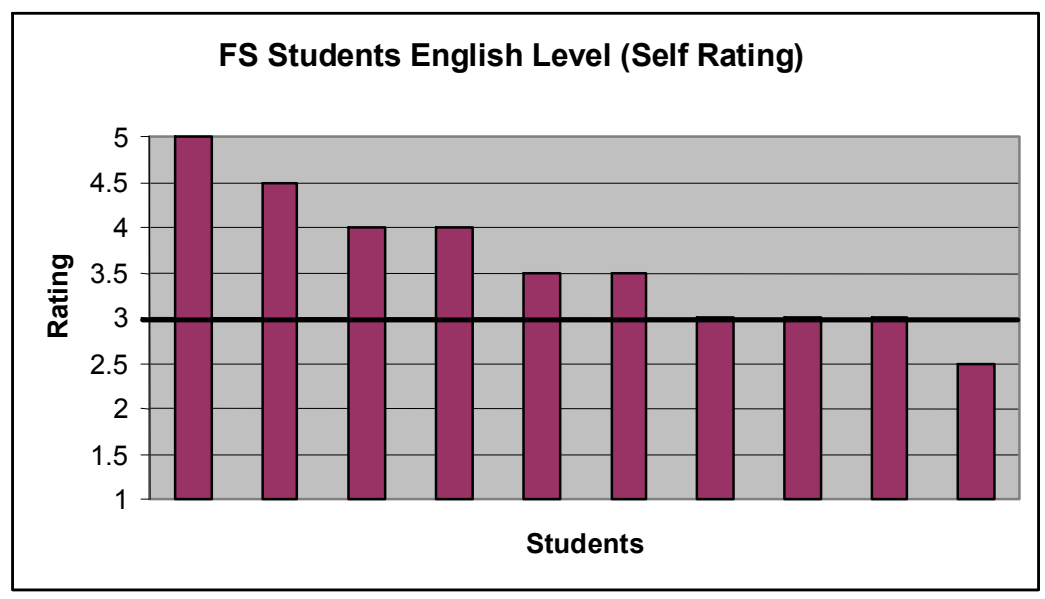


The students' academic achievement was compared with their self-rating of their English language level. Those with high achievement (passing all or most of their courses) rated their language ability in the upper half of the scale $(3-5)$, while the students passing half or less of their courses generally rated themselves lower in English. The comparisons of English level and achievement are shown in Table 11.

Table 11 Achievement and self-rating of English language level

\begin{tabular}{|l|c|c|c|c|c|c|c|}
\hline Achievement & \multicolumn{7}{|c|}{ Self-rating of English Language Level } \\
\hline & $\mathbf{5}$ & $\mathbf{4 . 5}$ & $\mathbf{4}$ & $\mathbf{3 . 5}$ & $\mathbf{3}$ & $\mathbf{2 . 5}$ & $\mathbf{2}$ \\
\hline Passing all & 1 & 1 & & & 1 & & \\
\hline Passing most & & & 1 & 2 & 2 & & \\
\hline Passing more than half & & & 1 & 2 & 4 & 1 & \\
\hline Passing half & & & & & & & 2 \\
\hline Passing less than half & & & & & 1 & & 1 \\
\hline
\end{tabular}

No statistical comparisons can be made as most students considered their language level to be "average" and therefore placed themselves in the middle of the scale - on 3 or 3.5. However, when considering the extremes, two of the three students who are passing all of their courses gave themselves the highest ratings for language -5 and 4.5. The third student rated herself only on 3 for English because she felt disappointed in her current use of English, saying:

"I think my English is better in Foundation than now... because I speak English all the time in Foundation. But now I don't talk with people around campus very much. Only got Chinese friends...I don't have much English speaking friends, so English is not improving. And I think I haven't speak English for ages."

The four students with the lowest achievement - passing half or less of their courses - gave themselves the lowest rating for English language (a score of 2) with the exception of one student, who gave himself a rating of 3 , but also commented "I just can't understand what they say in the lecture, then during the tutorial I just can't talk with the other kiwi students...sometimes I still got problems with English when I reading". His evaluation of his language ability appears to be lower than the score he gave himself, and is likely to be a more accurate reflection of where he sees his language to be at than his first reaction to simply place himself in the middle of the scale. 
The students who are confident in their language ability (rating themselves 4.5 or 5) have passed all of their courses, while the students who rated themselves only 2 for language have passed half or less of their courses.

Participants were also asked if they felt their English language was adequate for their current studies. Nine of the ten FS students felt their English was good enough for their studies but only five out of ten DE students felt their language was adequate. Those who thought their language was adequate made comments such as:

- "I think my English is alright, is prepared for the study"

- "I think it's good enough"

- "It's not good enough for A, but good enough to pass"

- "I don't think my English limits my understanding, I think my English limits my speed"

- "I failed is not because of English...I think the reason I failed just because I don't know how to answer the question...I think maybe I don't know how to study".

Those who felt their language was not sufficient gave reasons such as their essay writing not being good enough (4), lacking vocabulary (2), and difficulty in understanding lectures (2). Some examples are:

- “Not enough for writing, like assignment. I can't do assignment by myself... I feel not good enough in writing"

- "I think the vocabulary's not enough, and grammar, academic words"

- "Not [good enough] for my degree. I still don't think I can understand everything from my lecturers or tutors, just sometimes guess".

Students' achievement was considered against their feelings of language adequacy, and is show in Table 12. All of the students who are passing all of their courses feel their English is sufficient. Of the five students passing most of their courses, four said their language is adequate, and one felt her speaking and listening skills were sufficient but her writing was not good enough so she sought help with her essays. Two students claim their English is adequate but they are passing only half or less of their courses. One participant explained this by describing how he did not study hard enough, but spent more time 
working, playing video games or watching sport. The other participant also admitted that he was not a good student and did not study hard, although he did not give any details. These cases suggest that although having adequate language is important for academic success, it is not the only influencing factor.

Table 12 Achievement and language adequacy

\begin{tabular}{|l|c|c|}
\hline \multicolumn{1}{|c|}{ Achievement } & English Adequate & English Not Adequate \\
\hline Passing all & 3 & 1 \\
\hline Passing most & 4 & 3 \\
\hline Passing more than half & 5 & 1 \\
\hline Passing half & 1 & 1 \\
\hline Passing less than half & 1 & \\
\hline
\end{tabular}

As well as talking about adequacy in general, participants were prompted to talk about the specific areas of language use they felt comfortable in, or struggled with. Altogether five students commented that their essay writing was fine while seven had difficulty with writing. Three participants said their reading was adequate and three said it was not. Six felt their speaking was not very good, and they struggled to make themselves understood at times. Three students thought their oral communication was fine. Six students mentioned their listening was adequate but two felt they did not understand enough. Two felt they were not fast enough, and with better language they could read more material or write more during exams. Only two students thought they had enough vocabulary while six felt they lacked the necessary vocabulary at times, although three of these were not hindered by their lack of vocabulary - they simply checked a dictionary when they got home. Four students mentioned having trouble with grammar, and three found it difficult to understand kiwi slang. The areas students identified themselves as weak in, or felt they were adequate in, are summarized in Table 13.

Table 13 Areas of English language identified as adequate or weak

\begin{tabular}{|l|c|c|c|c|}
\hline Area & \multicolumn{2}{|c|}{ FS Students } & \multicolumn{2}{c|}{ DE Students } \\
\hline & Adequate & Weak & Adequate & Weak \\
\hline Reading & 1 & 2 & 2 & 1 \\
\hline Writing & 4 & 1 & 1 & 6 \\
\hline Speaking & 1 & 3 & 2 & 3 \\
\hline Listening & 2 & & 4 & 2 \\
\hline Grammar & & 1 & & 3 \\
\hline Vocabulary & 2 & 1 & & 5 \\
\hline Slang (understanding) & & 1 & & 2 \\
\hline
\end{tabular}


More DE students reported themselves as weak in writing (6) than FS students (1) while four FS students reported adequate writing skills, compared to only one DE student. DE students appear more confident in their reading skills, with two DE students claiming adequate reading (compared to one FS student) and only one DE student mentioning this as an area of weakness (compared to two FS students). Three DE students and one FS talked about having problems with grammar and five DE students felt their vocabulary was lacking, with only one FS student claiming a lack of vocabulary and two (FS) saying their vocabulary was fine. Overall, DE students mentioned more areas of weakness in their language skills than FS students, again suggesting that FS students are more confident in their English language ability.

Another area participants were asked to comment on was how much they used English in their daily lives. Answers ranged from using English most of the time to hardly using it at all, and are shown in Table 14.

Table 14 English use

\begin{tabular}{|l|l|l|}
\hline Use English... & DE & FS \\
\hline Most of the time, hardly speak Chinese & 1 & 3 \\
\hline Often, at home or with friends, etc & 3 & 1 \\
\hline Everyday (work, uni, etc), but not at home or with friends & 3 & 4 \\
\hline Not often: only use English when essential & 3 & 2 \\
\hline
\end{tabular}

There is no significant difference between the two groups - DE students and FS students - in terms of how much they use English. Students in both groups range from mostly using English to using it very little.

A comparison was made between the participants' self-rating of their English level and how much they use English. Of the four students who use English most of the time, two rated their level high (5 and 4.5) while two gave themselves lower ratings of 3.5 and 2.5. These latter two students both say they have a lot of English-speaking friends and not many Chinese friends, and they compare their language with their English-speaking friends'. The five students who use English very little all rated their language as 3 (the middle of the scale). The results do not show any obvious pattern between the students' language use and their self-rating, but they suggest that students rate 
themselves according to different standards, or label themselves as "average" when they lack a clear standard for measuring.

\section{Life in New Zealand}

Students were asked questions about who their friends are (Chinese, New Zealanders, other Internationals, etc), their living situation, how they feel about life in New Zealand, who they go to for help and what they wish they had known before coming to New Zealand.

\section{Friends}

The majority of participants have Chinese friends. Seven reported having only, or mostly Chinese friends, and seven had a mixture of Chinese and New Zealand friends (including two with New Zealand partners). Another four said their friends were Chinese or international students from other countries, and two said their friends were New Zealanders or other international students, but not Chinese. None had only New Zealand friends. The comparison of DE and FS students is shown in Table 15.

\section{Table 15 Friends}

\begin{tabular}{|l|c|c|c|}
\hline Friends & DE & FS & All \\
\hline Mostly Chinese & 5 & 2 & 7 \\
\hline Chinese and other Internationals & & 4 & 4 \\
\hline Chinese and New Zealanders & 5 & 2 & 7 \\
\hline New Zealanders and other Internationals & & 2 & 2 \\
\hline Mostly New Zealanders & & & \\
\hline
\end{tabular}

Half of DE students have mostly or only Chinese friends and half have both New Zealand and Chinese friends. FS students on the other hand have more international friends - most of which they met during the Foundation Studies Programme. Only two FS students have mainly just Chinese friends. 
Of the twenty participants interviewed, seven live in flats with other Chinese students. One lives in her own apartment in student accommodation, with many other Chinese students around. Six have lived in a home-stay for some time, then moved into Chinese flats. Two are still in home-stays. One lived in a home-stay, then a flat with New Zealanders, and is now living alone. Another lives in a flat with New Zealanders and other internationals. One student is in a boarding house with mostly New Zealanders. The final student has always lived alone in New Zealand. The comparison of DE and FS students is shown in Table 16.

Table 16 Accommodation

\begin{tabular}{|l|c|c|c|}
\hline While in New Zealand, has lived... & DE & FS & All \\
\hline Mostly with New Zealanders & 1 & 3 & 4 \\
\hline With New Zealanders and other Internationals & 1 & & 1 \\
\hline With New Zealanders and Chinese & 1 & 5 & 6 \\
\hline Mostly with Chinese & 6 & 2 & 8 \\
\hline Alone & 1 & & 1 \\
\hline
\end{tabular}

As this table shows, six out of ten DE students live mostly with other Chinese students. FS students, however, have mostly spent some time living with New Zealanders, with five participants having lived in home-stays before moving into Chinese flats, and three still living with New Zealanders. Only two FS students have lived mostly with Chinese friends.

Feelings about life in New Zealand

When asked how they feel about life in New Zealand, participants gave a wide variety of answers. Some of the words that reoccurred were:

- Boring [not exciting/not/interesting/not much to do] (8)

- Clean [fresh air/beautiful/green/blue sky] (7)

- Quiet (4)

- Easy/no pressure/relaxed/comfortable (4)

- Friendly people (3)

- Have to do everything yourself (2) 
Nine participants (5 DE and 4 FS) appear to have adjusted well to life in New Zealand and are happy here. These students made comments such as:

- "I enjoying the life here"

- "It's good, quite relaxed... I like it"

- "I like, I love the life in New Zealand very much"

- "Good, l've been living here many years, for 5 years"

- "Actually it's quite nice... In New Zealand there are lots of nice places... you can do so many things".

Another five students (4 FS and $1 \mathrm{DE}$ ) feel they have become used to New Zealand life, but are dissatisfied to some extent because it is too relaxed, boring, or expensive to live. One student said "I feel comfortable here... not a problem to live here" but also that "life is too easy I think, laid back. I think it's not a good idea to be without pressure...we should live in pressure to push you forward". Another said "life in New Zealand is quite comfortable. It's good for study, and when you're old you can come here, but for young people not many places you can go." A third student said life in New Zealand felt "pretty much normal", but "there's not much to do at times. And prices are too high".

Six students (4 DE and 2 FS) do not appear to have adjusted to or accepted the way of life in New Zealand. Their comments included:

- "I think it's too casual... people are too free and not too much work... here I become lazy",

- "Hard. Because you live by your own, everything you need is by yourself. You need to do many things like you need to control yourself, finance yourself...You need to study, you need to work... So many things"

- "Boring. At first I feel so excited, because first time, yeah. But now I don't think so. I can feel discrimination".

- "Sick of this place, forever. I regret it [coming to New Zealand]. I always thought l'd go back to China. I don't have relationships here, I don't have relatives and friends, so I don't have my social life. And the way of living is totally different, and I like to try it, but it won't be fit me."

Altogether six DE and eight FS students appear to have settled into life in New Zealand reasonably well, despite some dissatisfaction. 
Acculturation is defined by the New Zealand Oxford Dictionary as "adapting to or adopting a different culture" (Deverson 2004). For acculturation to occur on an individual level, a person must have sustained contact with people from another culture. Contact alone is not enough, however, and an acceptance of the new way of life is also needed ("Acculturation" 2006, "Culture Contact" 2009). For the purpose of this study, participants were judged to have acculturated to life in New Zealand if they both claimed to feel settled, happy with or used to life in New Zealand, and had an ongoing relationship with New Zealanders, whether through friendships, living arrangements, or both. Those who claim to be happy with their life in New Zealand, yet surround themselves purely with Chinese friends, completely maintaining their Chinese lifestyle, and having no substantial contact with New Zealanders, lack the cultural exposure needed to acculturate.

One DE and seven FS students met these requirements of having adjusted to life in New Zealand and having ongoing contact with New Zealand culture. The achievement of these students was considered: The three participants who have passed all of their courses are all acculturated to New Zealand. Of the five students passing most of their courses, three also fit this definition of acculturated. A further one of the acculturated students had passed more than half of her courses, but the final one had passed less than half. This last student appears to be happy with life in New Zealand, he claims to be comfortable and he has a good continuing relationship with his first homestay family (New Zealanders), but he is still weak academically.

\section{Help and support}

When asked who they go to for help or support (for personal, daily life, emotional issues), six students mentioned a current or former home-stay parent (3 DE and $3 \mathrm{FS}$ ), another four students turn to their Chinese friends (1 DE and 4 FS), and three students (all DE) have partners who give them help and support. Two students call their mothers in China (1 DE, $1 \mathrm{FS}$ ), while another two (1 DE, 
1 FS) have relatives in New Zealand to look to. Only one student said he had nobody he could go to. There is no significant difference between DE and FS students in this area.

"Wish l'd known"

When asked what they wished they had been told before coming to New Zealand, students gave a variety of answers including knowledge of basic cultural things - such as New Zealanders' passion for rugby, the weather, the size and appearance of Wellington and Victoria University, and a warning that there are some bad people in New Zealand (it is not perfectly safe as some had been led to believe). Three students (1 DE, 2 FS) wished they had been informed more accurately of the cost of living in New Zealand, and that university fees can - and often do - increase each year. Two students (1 DE, 1 FS) wished they had learnt more English before coming, so they would spend less time in language schools in New Zealand before beginning their "real" study. Two students (DE) said they did not realize before coming here how independent they would need to be - they would like to have been taught how to manage on their own and do everything themselves before being thrown into the deep. One student (DE) thought it would have been good to have been told that it was possible to fail. The assumption was made that as long as you pay your fees, go to class, and do what the teacher says, you will pass. She discovered the hard way that this is not the case in New Zealand. There is no significant difference between DE and FS students in this area.

\section{Would Do Differently}

Participants were also asked 'if you could start over, what would you do differently?' The answers are given in Table 17. The noticeable differences are that three FS students would not change anything, but no DE student said this, and five DE students would study harder next time whereas no FS student gave this answer. The three students who said they would not change anything are all doing well academically, passing all or most of their courses. Of the five 
students who said they would study harder if they could start again, one is doing well and passing most of her courses, three are passing more than half, and only one is passing less than half.

Table 17 What participants would do differently if they could start again

\begin{tabular}{|l|l|l|}
\hline Change & DE Students & FS Students \\
\hline Go to Australia instead & 3 & 2 \\
\hline Go to England instead & & 1 \\
\hline Stay in China & 1 & 1 \\
\hline Study harder & 5 & \\
\hline Stay in a home-stay longer & 1 & \\
\hline Learn more English first & & 1 \\
\hline Have a plan / goals & & 1 \\
\hline No change & & 3 \\
\hline Did not answer & & 1 \\
\hline
\end{tabular}

\section{Reasons for Coming to New Zealand to Study}

For many of the participants the choice to study overseas rather than in China was made by their parents - with the student's agreement of course. They often chose an overseas education because the students either did not get entry into a prestigious university, or they did not get into what was considered a good major. In China you can not change your degree or major, but must study what you have gained entry into. One example of this is a student who studied two years of Traditional Chinese Medicine in university in China, but decided it would not be a good career. She wanted to study commerce, but as she could not study this in China, she came to New Zealand.

Where a student is not doing well in the Chinese education system, the student (or parents) may decide their only hope for a degree at all is to study overseas. One of the students interviewed in this study admits:

"In China, to be honest, my study is not that good, not as competitive as other people, that's why I can't qualify for university entrance exam. That's why I chose here, it's more easier to get a degree than in China. Just spend maybe 100 times the money than if I study in China." 
For a few students the decision to study overseas rather than in China was made much earlier than their final year in senior high school, with some coming to New Zealand for high school and some attending an international school or private school in China and then coming to New Zealand for tertiary education.

Once the decision was made to study overseas, the next step was to choose which country. The main reasons New Zealand was chosen by those students interviewed for this study are cost and ease of getting entry. 10 out of 20 students stated these reasons. Other reasons were family connections (2), school connections (2) and friends' recommendations (2). Two students do not know why their parents chose New Zealand, while two students said their parents chose New Zealand because there were less Chinese here than other countries. One student commented that he chose an English speaking country so as to improve his English and specifically chose New Zealand because it was the cheapest of the English speaking countries. No mention was made of academic standards, quality of education or the reputation of specific universities in New Zealand. The results are shown in Table 18.

Table 18 Reasons for choosing New Zealand as the study destination

\begin{tabular}{|l|l|l|}
\hline Reason & DE Students & FS Students \\
\hline Cheaper/easier than other countries & 4 & 6 \\
\hline Not so many Chinese as other countries & 2 & \\
\hline Friends recommended & 2 & \\
\hline High school in China has connection with VUW & & 2 \\
\hline Family connections & 1 & 1 \\
\hline Unknown & 1 & 1 \\
\hline
\end{tabular}

\section{Goals and Plans}

All participants came with the primary goal of gaining a degree. Four said they originally intended to return to China as soon as they finished their degree and another four came with the intention of staying in New Zealand long term, four expected to stay and work for a couple of years to gain valuable work experience before returning to China, one hoped to continue on to do postgraduate study and seven did not mention what they originally intended to do after their undergraduate study. 
Many of these students have changed plans since being in New Zealand: Of the four who came intending to stay in New Zealand for some time, one now wants to return to China as soon as he has finished his degree, one hopes to gain some work experience and then return to China, one plans to work for a few years and then look at further study in the UK or Australia and one is undecided. Of the four originally intending to return to China straight away, one now wants to stay in New Zealand and work for two years before returning to China, one wants to gain some New Zealand work experience and then go to the US, one hopes to do a Masters degree in England, and one intends to go to Australia to do postgraduate study then gain work experience there before returning to China. The four students who had planned to gain work experience in New Zealand before returning to China still intend to do this, but the student who had originally thought she would do post-graduate study in New Zealand has given up this idea as she feels inadequate academically. She now plans to return to China.

One of the students who originally planned to return to China upon completing her undergraduate studies in New Zealand, but now hopes to stay and work for a few years, explains her change:

"The degree, the paper, is very important in China, and now I wish I can have some working experience and now my goal is to get a real accounting job in New Zealand. Then they will become a really valuable working experience in China and I will get good pay. So that will be my goal. I thought [originally] to get degree and go back to China is the first one, but now I wish to get more, I wish to get jobs. I need valuable work experience in New Zealand".

In total, four students now intend to return to China after completing their study, seven want to work for a year or two in New Zealand before returning to China, five would like to go to another country for work or further study and three hope to get work and stay in New Zealand long-term. One student is undecided. Figure 15 shows these plans. 
Figure 15 Plans after completing undergraduate studies

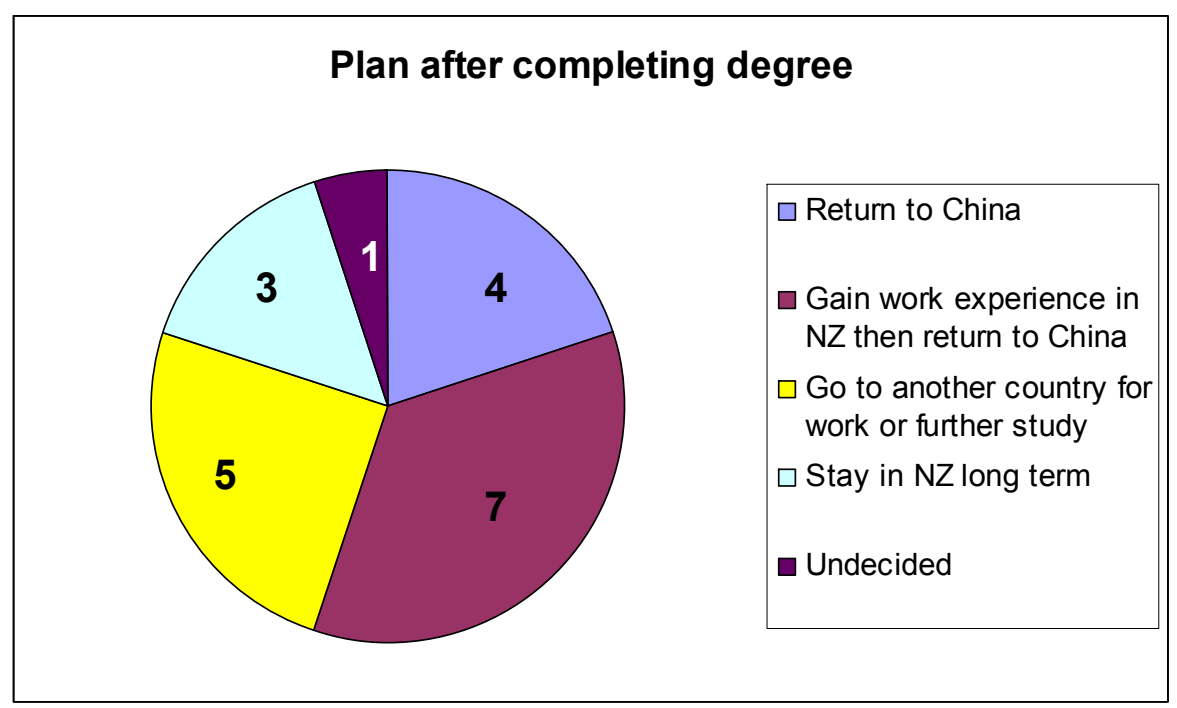

Both groups of participants have similar goals after finishing their degree, although more DE students wanted to return to China straight away (three, compared to one FS). This is shown in Table 19.

Table 19 Plans after completing undergraduate studies - by group

\begin{tabular}{|l|l|l|}
\hline Plans & DE Students & FS Students \\
\hline Stay in NZ & 1 & 2 \\
\hline Work in NZ for a few years then return to China & 3 & 4 \\
\hline Go to another country & 2 & 3 \\
\hline Return to China & 3 & 1 \\
\hline Undecided & 1 & \\
\hline
\end{tabular}

\section{Previous Study}

The education background of students was considered, beginning with their education in China. Two participants did not finish high school in China. Ten finished high school, and another one completed at a vocational school (secondary level). Two students studied for one year at university before coming to New Zealand, one did $1 \frac{1}{2}$ years of university study in China and one finished 2 years at university. One student completed a 3 year diploma a tertiary institution, another completed 1 year of college (tertiary level), and one did half a year at army school after completing high school. In total, two students did not finish high school (1 DE, $1 \mathrm{FS}$ ); twelve completed high school 
or equivalent (4 DE, $8 \mathrm{FS}$ ), but did not have any higher education; and six did one year or more of tertiary study (5 DE, $1 \mathrm{FS})$.

Next, education within New Zealand was considered. Students had a variety of pathways before entering Victoria University. Ten students began with an English language course. Six students attended a New Zealand high school (four for 2 years, one for $3 \frac{1}{2}$ years, one for $4 \frac{1}{2}$ years). Five attended a tertiary institution in New Zealand (four at diploma level, only one began a degree elsewhere then transferred to VUW). Three did a university preparation course other than the VUW Foundation Studies. All students interviewed had done some study in New Zealand - ranging from just a 3 month language course, to just the VUW Foundation Studies programme, to a combination of two or three of the above courses - before beginning their degree study. Of the students interviewed, none went directly into undergraduate study upon arrival from China, although this can and does happen.

As the education background of students is so varied and unique, no correlations or comparisons can be made between the two groups of participants.

\section{Study Techniques and Help Wanted}

Participants were asked how they study and what they do if they need help, as well as what help they would like that they feel they are not getting. The majority - 12 out of 20 students - preferred to study in groups or ask friends and classmates for help. Five students said they preferred to study on their own, using books and notes to help. Two would go to their tutor for help or ask questions during tutorials. One went to Student Learning Support for help. There is very little difference between DE and FS students regarding the ways in which they study, as Table 20 shows. 
Table 20 Study techniques

\begin{tabular}{|l|l|l|}
\hline Preferred way to study & DE Students & FS Students \\
\hline Group study/classmates/friends & 6 & 6 \\
\hline Using books/lecture notes & 2 & 3 \\
\hline Tutor/tutorials & 1 & 1 \\
\hline Student learning support & 1 & \\
\hline
\end{tabular}

When asked what help they would like in their studies, answers were varied, ranging from financial help and free internet access to writing workshops and study groups. There is a desire for group study or tutorials and the availability of someone to help immediately, as seen in these comments:

- "I think there should be a duty tutor, they sit in office for week, then keep doing that. Sometimes I go to the lecturer's office but I won't find anyone there. And email takes time too".

- "Ask some students they learn this paper before, ask for some idea from them."

- "More tutorials. Too many people attend lectures and teacher doesn't know you. I think students need some teacher focus on you".

- "I think the classmates should be the most helpful people for us, because we can discuss something. But I found most classmates they don't like, they just attend the lecture... as soon as the lecture finished, they go home and do their own thing."

- "I'd like more tutorial time, more than lecture time."

- "Something like forced study maybe. Someone have to supervise me, 'cause I'm just lazy."

In total, five students wanted more tutorials or organized group-study times, three students would like a tutor/lecturer available to help them at any time, and one student wanted to be able to get the answers off a student who had already passed the course. Four students did not want or need any other help. One student wanted more practical learning, not just theory. Another thought it would be helpful to be able to re-sit a failed exam, rather than re-sit the whole course. And a further student said a workshop on essay writing was essential for international students. Two students suggested that social help - how to make New Zealand friends, join groups and get involved in extra-mural activities - was more important to them. One student thought financial help was needed, so that students would not have to work and therefore could spend more time 
on study, and one student wanted free internet access, not realizing that internet access is now free on campus for enrolled students. These preferences are outlined in Table 21.

Table 21 Help wanted in university studies

\begin{tabular}{|l|l|l|}
\hline Help wanted & DE Students & FS Students \\
\hline Group-study times & 1 & 2 \\
\hline More tutorials & & 2 \\
\hline Tutor/lecturer available all the time & 2 & 1 \\
\hline Help with writing essays & 1 & \\
\hline Past students to help & 1 & \\
\hline Be able to re-sit exams & & 1 \\
\hline Practical learning, not just theory & 1 & \\
\hline Social - help meeting NZers, joining clubs, etc & \multicolumn{2}{|l|}{} \\
\hline Financial & 1 & 2 \\
\hline Free internet & & 1 \\
\hline No extra help needed & 3 & 1 \\
\hline
\end{tabular}

FS students desired more tutorials and group-study. They also mentioned social aspects, wanting to meet New Zealanders and get involved in extracurricular activities. DE students on the other hand were more likely to say they did not need help.

\section{Differences in Education Systems}

When asked to compare Chinese and New Zealand universities, most participants agreed that they were quite different. Only one student thought the education system in both countries was much the same. Some of the differences that were mentioned are collated and summarized below:

- In China it is hard to get into university, but easy to graduate. Students can not fail, and are much freer. In New Zealand it is easy to get into university but hard to graduate. Students can fail and must work hard.

- In China everybody is in the same class and takes the same subjects. They live together on campus, do their homework together, and help each other. They become very close. In New Zealand, classmates do not study together or do things together. They take different classes and live in different places. It is hard to make friends.

- In China the teacher tells students what they need to know and forces them to learn it. They have to memorize a lot. Students are quiet in class, they 
just sit and listen. In New Zealand the teacher gives suggestions on how to learn, not what to learn. They give surface information but the student needs to go deeper. Students have more freedom to choose what to learn, and have to participate in class and ask questions. They need to motivate themselves to study. They must argue a case, back it up, and think critically.

- Teachers in New Zealand do not care about students' marks - they treat them the same regardless of marks. They treat students as adults. In China the teacher forces students to study and checks up on them every day. They will help with problems, even personal issues, and answer questions.

There were differing opinions as to which system is better. Most students felt the social aspect of the Chinese university is better - they live, study and play together with their classmates and become good friends. Six (4 DE and 2 FS) participants felt that the Chinese university is easier - they are told what they need to know and they simply learn it. There is also more support given, in the form of a teacher checking up on students and always being available to answer questions. In contrast, the apparent unavailability of lecturers and tutors in Victoria University (they are not in their office all day, every day!) was a source of frustration for four of these students, who felt this showed laziness or disinterest on the part of the lecturer. Eight ( 6 FS and $2 \mathrm{DE}$ ) students preferred the New Zealand system because of the flexibility to choose what to study, and the stimulation to investigate, argue and think for themselves. Of the other six students, one did not think there was any difference between the education systems of the two countries, and five recognized differences but were not sure which was better - they liked certain aspects of both.

The participants comments on the New Zealand and Chinese education systems, as well as other remarks about their adjustment to the university environment and study techniques were evaluated in terms of how well the student had grasped and adapted to the required academic conventions. For example, one student identified the differences between the Chinese education system and the New Zealand as: "In China we just use writing, use hand to write. But in New Zealand we just use computer. We can have flatmate, live in home. But in China we must live in school." Although he seems unaware of different teaching and learning styles, he recognizes that essay writing is 
different in the two countries, but his next comment suggests he has not yet learned how to write essays according to western conventions: "I need to improve [essay writing]. Because in China different way, it's confused." He also laments that he tries hard, but does not do very well. These comments all suggest that he has not yet understood how to study successfully under the New Zealand academic conventions. On the other hand, another participant says of the differences between China and New Zealand:

"In New Zealand you need to do it by yourself, and you can find the knowledge during the lecture the teacher give to you is just the surface, just the basic things. And the deep things you need to do study by yourself. Actually I find I can learn more through myself study. And in China the teacher give you what it's like, and why it's going to be like that, and give you all the things and just force you to do that. I like the western way. "

This student also commented that she knows how to write academically and how the examination system works. She appears to have adapted to the New Zealand education system.

This approach was taken in evaluating each participant in regard to their adaptation to the New Zealand academic environment, and in total five DE and seven FS students appear to have adjusted to the New Zealand systems and conventions. The students' adjustment was then compared with their achievement and is shown in Table 22. With the exception of one student who does not appear to have adapted to the way of studying in New Zealand, and yet has still passed most of her courses, there seems to be a clear relationship between adjusting and succeeding academically.

Table 22 Achievement and adjustment to academic conventions

\begin{tabular}{|l|c|c|}
\hline \multicolumn{1}{|c|}{ Achievement } & $\begin{array}{c}\text { Appears to have } \\
\text { adjusted }\end{array}$ & $\begin{array}{c}\text { Does not appear to } \\
\text { have adjusted }\end{array}$ \\
\hline Passing all & 3 & 1 \\
\hline Passing most & 4 & 3 \\
\hline Passing more than half & 5 & 2 \\
\hline Passing half & & 2 \\
\hline Passing less than half & & \\
\hline
\end{tabular}




\section{First Trimester Experience}

When asked what their first trimester of degree study at Victoria University was like, DE students commented on the following areas:

- Found it difficult to write essays (3)

- Did not know how to study or prepare for exams (2)

- Found it difficult in general (2)

- Could not understand everything in the lectures (1)

- Didn't go to classes, wasted time (1)

- Found it ok, smooth (1)

FS students commented:

- Could not understand everything in the lectures (3)

- Found it difficult to take good notes (2)

- Did not know how to use common sense to answer questions (1)

- A lot of new vocabulary to learn (1)

- Did not enjoy at first (1)

- Found it different from Foundation Studies, but still felt better prepared than others (1)

- Found it similar to Foundation Studies (3)

The top two areas the DE students struggled with - essay writing and study techniques - were not issues to FS students. Rather, FS students reported more difficulty with listening to lectures and taking notes. Four FS students referred to Foundation Studies as a good preparation, though one student said undergraduate study was much harder and he did not feel prepared enough.

\section{What FS Students Say About the Foundation Studies Programme}

Participants who have been through the Foundation Studies Programme were asked to comment on the programme - both positive and negative aspects, how it prepared them for degree study, and how they felt about it. Nine out of ten students were positive about their Foundation Studies experience and thought it was worthwhile. One student said it was not very useful, but still good 
because of all the support given for the personal issues he was facing at the time.

Some of the positive aspects students mentioned are as follows:

- Make good friends, keep these friends during degree study (5)

- Teachers are helpful (3)

- Good preparation for degree (2)

- Helps you discover your strengths and interests and what to study in future (2)

- Good support for personal issues (1)

Some of the negative comments students made are:

- The days are long, a lot of classes (1)

- Some Foundation Studies rules are not the same as degree courses (1)

- It does not prepare you for undergraduate study, it is completely different (1)

Some of the ways in which Foundation Studies prepared students for undergraduate study are:

- Getting to know the university system, library, services (6)

- Learn how to study (3)

- Writing essays (3)

- Subject specific knowledge (especially economics and accounting) (2)

- Help with choosing the right degree to study (2)

- Confidence (1)

- Improving English (1)

Overall, most FS students felt that Foundation Studies was a positive and worthwhile experience that prepared them for undergraduate study by helping them become familiar with the university system and facilities, learn essay writing and study skills, choose the right degree to study, and make friends. 


\section{Summary of Results}

The results of this study show that FS students have a higher achievement in their degree study than DE students, with six students passing all or most of their undergraduate courses, compared to two DE students. This is consistent with the results of the first study, which also showed FS students outperformed DE students academically.

By examining the issues relating to language, cultural adjustment, and adaptation to different academic conventions, this study finds that FS students are more confident in their English language ability than DE students, with most $(9 / 10)$ saying their language is adequate for their studies, compared to only half of DE students. More FS students have lived with New Zealanders than DE students, although FS students report slightly less New Zealand friends than DE students: DE students have mostly Chinese, but also some New Zealand friends, whereas FS students have more international friends. Eight FS and six DE students appeared to have settled into New Zealand life and feel comfortable or accustomed to living here, but only seven FS and one DE student appear to have acculturated to New Zealand. In considering their study experience in New Zealand, six FS students and two DE students prefer the New Zealand education system to the Chinese, but seven FS and five DE students appear to have adjusted to the New Zealand conventions, regardless of their preference. Nine out of ten FS students felt that Foundation Studies was a positive and worthwhile experience that prepared them for undergraduate study by helping them become familiar with the university system and facilities, learning essay writing and study skills, helping them choose the right degree to study, and making friends. In their first trimester of undergraduate study, DE students typically struggled with essay writing and study techniques, whereas FS students found it harder to listen to lectures and take good notes.

Despite their differences, DE and FS students also have much in common: they have similar demographics, reasons for choosing New Zealand, study techniques, and feelings about life in New Zealand. They face the same challenges in studying and living in New Zealand, but FS students are better equipped to face those challenges. 


\section{Chapter Five: Discussion}

This chapter considers the two studies and how they combine to give a fuller picture of the effects of the Foundation Studies programme on undergraduate achievement. The results of the second study are then discussed, examining in particular English language, adjusting to life in New Zealand, and adapting to different academic systems. Finally the issues raised by this study are presented.

The findings of the first phase of study show that there is a significant correlation between completing the Foundation Studies Programme and academic achievement in undergraduate courses, with FS students achieving higher GPAs and pass rates than DE students. There is also a correlation between gender and achievement, with female students outperforming male students. The second phase focused on the primary finding of the first study that students who complete the Foundation Studies programme prior to their undergraduate study outperform students who enter directly into degree programmes - and sought to identify factors that may account for the differing level of achievement between these two groups.

Consistent with the first study, the results of the second phase also show that FS students outperform DE students. Furthermore, the results from the interview data reveal some differences between the two groups, giving insight into what factors contribute to the higher achievement of FS students. Three main themes emerged from the findings presented in the previous chapter. These themes are: confidence using English; New Zealand life; and academic adjustment and preparedness. The results from the second study are discussed here within the context of these three themes.

\section{Confidence in English}

One of the findings of this study is that FS students are more confident in their English language ability, rating themselves on average higher than DE students. 
These ratings were based only on the student's self-perception, so can not be considered as actual skill levels, but rather an indication of the student's feelings about their language ability. The score each student gave themselves could have been influenced by a variety of things - their self-esteem, modesty, their environment, and who they compare themselves to - and these influencing factors are likely to vary from student to student. This means that students with a similar language level may have given themselves quite different ratings. Some of the comments made by participants that show how they rated themselves, or who they compared themselves to are listed below:

- "Because they using, Kiwis speak slang. Sometimes I can't really get that. And their punctuations and the tones between different age of people, like teenagers, they speaking like...It's really hard to understand them."

- "I still find like in my interview, sometimes I still can't understand employer ask me questions. And I'm afraid to ask him to explain something because employer might think your communication is not good."

- "If I compare myself with other Chinese students I know, maybe I'm better. But when I talk with my kiwi friends, sometime they say 'I'm sorry I can't understand'."

- "Compared to most of my friends around me, my English is much better than them."

- "Still have a long way to go. Although I have learned English for 5, 6 years, level still a bit, not as good as my expectation. Still got a long way to go."

- "When I talk to someone I feel sometimes I want to say something but I can not express it."

- "I know what I want to say, but I couldn't find the right words to use, so sometimes I feel a little frustrated. But normally we can understand what others say. Understanding is easier than your own speaking." 
- "I can normally communicate with people in the social life, I can do that. But in academic, like writing, it's not that good enough."

- "I think my English still got a problem especially for the normal talking, conversation, but I think for study or just lectures or some topics I will handle that, but for the daily life, talking, the words, I don't know the words, or something slang."

Although the students' actual English level can not be gauged by their selfrating, the score they gave themselves offers insight into their confidence and how they feel about their language ability. The results show that the students who rated their language ability highly (giving themselves a score of 4.5 or 5) have passed all of their courses, while the students who only gave themselves a rating of 2 for English language have passed half or less of their courses. These results suggest that confidence in English language influences academic achievement. However, the results could also be considered in the opposite way - that is, a student's achievement influences their confidence in their language ability. Taking this approach, a student who is doing well academically will feel more confident in their ability and therefore rate themselves more highly, while a student who is struggling in their studies will feel less confident and rate themselves lower. Of the three students who are passing all of their courses, only two rated themselves highly (5 and 4.5). The third student rated herself 3 for language ability, although this can be accounted for as she gave the reason for her rating as being an awareness that she was not using English as much as she used to and therefore was worried her language was no longer improving. Likewise, of the four students passing half or less of their courses, three rated themselves low (a score of 2). The fourth rated his English as 3 although his comments about his language ability did not support this score but rather suggested he felt his language was weaker.

Although there is a link between confidence in language ability and academic performance, it is not clear which is affecting which. According to Choi (1997:269-270), international students often feel inadequate in using English and are unsure of how to address teachers and classmates, which causes them to avoid asking for help. If students are not comfortable asking for help, it is 
likely to affect their achievement. On the other hand, someone who is confident with their communication skills is more likely to ask questions in class, engage in discussion with classmates, approach lecturers or tutors for help, as well as feel more socially adequate in everyday life. This confidence is therefore likely to have a positive impact upon their academic performance, supporting the view that it is confidence in language that influences achievement.

Participants also commented on the adequacy of their language for the study they were undertaking. As shown in the results, nine of the ten FS students felt their English was good enough but only five of the ten DE students felt they had adequate language skills. All of the students who have passed all of their courses felt their English was sufficient. Of the five students who passed most of their courses, four claimed their language was adequate. Two students who said their English was adequate had passed half or less of their courses; however, their low achievement can be explained by other factors such as lack of time and effort spent on studying. In general, the students who are successful in their study - passing all or most of their courses - feel their language is sufficient for their studies. Whether it is their adequate language that contributes to their academic success or their achievement that causes their feelings of adequacy is uncertain.

Although half of DE students (five out of ten) felt their language was inadequate for undergraduate study, only one FS student (out of ten) thought this. The other nine believed their language ability was good enough. This is somewhat surprising considering the FS students often have a lower English language level when they begin their Foundation Studies programme than the DE students have when they begin their degree. The English requirement for entrance to Foundation Studies is an IELTS score of 5.5, compared to 6.0 for undergraduate entrance. Many students do the Foundation Studies programme because they only gained an IELTS score of 5.5 and therefore could not get entry into undergraduate programmes. Successful completion of the Foundation Studies programme is considered equivalent to gaining 6.0 in IELTS, 
but no higher. ${ }^{8}$ So the FS students and the DE students begin their undergraduate studies with a level of English considered to be equivalent, and most FS students feel their language is fine but only half of the DE students feel adequate linguistically.

Two of the specific areas of language that the participants comment on feeling adequate or weak in show a difference between FS and DE students. These areas are writing and vocabulary. Four FS students mentioned they felt their writing skills were adequate while one said she still had some problems with essay writing, but six DE students felt their writing was weak and only one thought this skill was adequate. Five DE students also said their vocabulary was a problem, but only one FS student talked about lacking vocabulary and two FS students specifically noted having sufficient vocabulary for the subjects they studied. As previously mentioned, students who are not native English speakers often score lower in written work due to poor vocabulary, grammar mistakes, and lack of cohesion throughout an essay, showing that writing skills and vocabulary are important factors for success (McKay 2000). This may explain why FS students, who claim to feel more adequate in their writing skills and vocabulary knowledge than DE students, gain higher grades and pass rates than $\mathrm{DE}$ students.

The question as to why FS students feel more adequate in their language skills remains. One answer may be that their English level is higher than the predicted outcome of the Foundation Studies programme, although as already mentioned, this is unlikely given the length and breadth of the course. It may be simply a feeling of confidence the FS students gain during their foundational courses, which is reflected in their higher self-rating - as commented on above. It may also be that the specific academic language and skills such as essay writing taught in Foundation Studies give them an advantage over the DE students. Although their general language level may not increase, their academic language and skills increase, and these academic factors may be more important to success than simple language level. McKay (2000) claims

\footnotetext{
${ }^{8}$ One of the highly experienced ESOL teachers who developed the core English language component of the Foundation Studies programme and who is also an IELTS examiner confirms that the 8 month Foundation Studies programme should increase a student's English level from 5.5 to 6.0 on the IELTS scale, but is not long enough or intensive enough to increase their level more than this.
} 
that cultural understanding plays a factor in achievement, with international students scoring lower than domestic students not only because of language difficulties, but also because of not knowing the way things should be done. According to this view, FS students achieve higher grades than DE students because they have been introduced to essay writing and other academic language skills during their Foundation Studies programme, along with an introduction to New Zealand culture, giving them an advantage over those students who may not have been taught these essential skills. This area will be further discussed later in this chapter.

New Zealand Life

\section{Acculturation}

Fox (2004), Zhang (2004) and Volet (1999) all agree that the more a student has adjusted to the host country, the better their academic achievement. Zhang (2004:48-49) claims that Chinese students in New Zealand who interact socially with New Zealanders are more satisfied with the education they receive than students who do not interact with New Zealanders. Similarly, Ho et al. (2007:33-39) suggest that international students who find it difficult to fit into New Zealand culture and make friends with host nationals feel dissatisfied with their New Zealand education.

The findings of this study show that more FS than DE students (seven FS versus one DE) are acculturated to New Zealand - where acculturation is both having a relationship with New Zealanders (whether through friendships, living arrangements, or both) and feeling settled or happy with life in this country. Acculturation has a positive effect on achievement, as the results show that all three of the students who are passing all of their courses are acculturated, as are three of the five students passing most of their courses. Of the two remaining students judged to be acculturated, one is passing more than half and one less than half. The latter student claims to be comfortable living in New Zealand, has a good relationship with his first home-stay family, would like to stay in New Zealand after graduating as he enjoys the life here, but is not doing 
well academically. He says himself "I'm not really a good student, not study so hard". He also talked about his study path in China before coming to New Zealand. Although he sat the university entrance exam, he did not do well enough to enter one of the top universities, but instead went to an army school. After six months he left the army school to come to New Zealand in the hope of earning a degree here. So although acculturated to life in New Zealand, this student is not strong academically, suggesting that acculturation on its own is not enough to enable a student to succeed in university. It does, however, still appear to have a positive effect on achievement, as the rest of the results and previous research - as discussed earlier - show.

However, this correlation between acculturation and achievement could also be working in reverse. Rather than acculturation affecting achievement positively, it could be claimed that achievement affects acculturation, with those students who are doing well academically feeling happy and open to accepting a new way of life, while those students who are not achieving well in their studies, for whatever reason, are not happy with their life in New Zealand therefore do not feel settled, are more negative about life here, and are also less inclined to seek out friendships with New Zealanders, preferring to stay in the more familiar Chinese circles.

\section{Contact with New Zealanders}

As well as acculturation, other factors concerning the students' life in New Zealand were considered. One of these is contact with New Zealanders. Although this was taken into account as part of acculturation, it is also worth considering on its own.

International students need contact with host nationals in order to gain cultural knowledge (Andrade 2006:131). Without an understanding of how to respond appropriately to situations and what is socially acceptable, students may feel uncomfortable and unhappy with the country they are living in. Gu and Schweifurth (2006:82-85) claim that Chinese students in the UK face their biggest challenge in simply living a different lifestyle than they are accustomed 
to and they often feel marginalized because of cultural differences and communication problems. Bai (2008b:123-136) found a similar situation with Chinese students in New Zealand. She suggests that some Chinese students' negative experience in New Zealand and feelings of racism or discrimination are due to the cultural dilemmas faced. Similarly, Choi (1997) found that Korean students in Australia felt dissatisfied with their relationships with Australians. They found it difficult to make Australian friends, saying that most of their relationships with Australians seemed superficial and did not go beyond a surface friendliness. They also felt misunderstood. More interaction with host nationals could help students cross some of the cultural and communication barriers and feel more comfortable and settled in the country they are living in.

The current study considered students' contact with New Zealanders in friendships and living arrangements. None of the participants claimed to have mostly New Zealand friends. Five of the DE students said they had some New Zealand and some Chinese friends, and four of the FS students had some New Zealand friends along with Chinese or other international student friends. Regarding accommodation, eight FS and three DE students have lived with New Zealanders for a reasonable period - some are still living in New Zealand home-stays while some have moved into flats with friends (mostly Chinese). In total, five DE and eight FS students have relationships with New Zealanders either through friendships or living situations, or both. These students have more opportunity to learn about New Zealand culture than those students who have little or no contact with New Zealanders, and are therefore more likely to adjust to New Zealand life.

\section{Feelings about Life in New Zealand}

Another factor considered in the discussion on acculturation, but also worth examining on its own, is how the students feel about life in New Zealand.

The results of this study show that overall eight FS students and six DE students appeared to have settled into New Zealand life, claiming that they felt 
happy, comfortable, or used to living here. The results also show, however, that four of the FS students and one DE student who are, on the whole, settled and happy also talked about areas in which they were dissatisfied or critical of. These were things such as the cost of living, quietness, lack of things to do and lack of pressure. All other participants were completely positive or clearly negative about living in this country.

It is likely that most people would have both positive and negative things to say about their life and the country or city they live in, so it is not surprising that six participants had both positive and negative things to say when talking about life in New Zealand. It is possibly more surprising that the other twelve participants were more focused one way or the other. This may be because those students who were not happy with life in New Zealand wanted to make it clear they were dissatisfied, therefore only talked of the negative aspects, while those students who were content did not want to show any discontent for fear of giving the wrong impression. Of the six students who expressed both positive and negative aspects of life in New Zealand, five were FS students. It seems that FS students felt more comfortable expressing some negative opinions while still claiming to be happy and settled in their life, which may show - as previously seen - that FS students are more confident in themselves and in their ability to communicate their thoughts and ideas. This also suggests that FS students have learned to look at issues from different perspectives and present a fuller picture, rather than focusing on just one aspect. This may indicate that FS students are developing their analytical and critical thinking skills - skills which are encouraged in the university environment.

\section{Help and Support}

One of the issues international students face in studying abroad is that they leave behind their family, friends and support networks. Andrade (2006) identifies this problem, claiming that international students have little support in the country they are studying in, as their main support networks are in their home country. Gu and Schweisfurth (2006:82-85) similarly found in their study 
of Chinese students in the UK that they lacked the friendships and social networks they had back home, and as a result often felt lonely and bored.

Although some of the participants in this current study mentioned that they felt lonely or found New Zealand boring, most of them claimed to have a good group of friends, and all but three had someone in New Zealand they went to for help and support. Two students still called their mothers in China first for help. Only one student felt he had no one to go to at all. This shows that although students leave behind their social circles and support networks, they are able to make new ones in their host country rather than go without. They find help primarily from local families - where they have lived with a local family, from relatives in the same country, or from co-national friends.

There is no significant difference between the two groups of DE and FS students in this area - both groups find help and support in the same ways.

\section{Would Do Differently}

The answers participants gave to the question "if you could start over, what would you do differently?" gives some insight into their feelings of satisfaction with their studies and their life in New Zealand. A total of eight of the twenty participants said they would not come to New Zealand at all, given what they now know. For most, this is to do with the perceived value of the qualification they will gain, and the cost in getting it. Although an interesting finding, this is outside of the scope of this current discussion, which is focusing on the achievement of DE and FS students and seeking explanations for the higher achievement of FS students. The value Chinese students place on their New Zealand degree is a subject that has been investigated recently by Limin Bai (2008a) and would be worth further research.

A further three participants said they would not change a thing. These were all FS students and they appear to be well adjusted to and happy with life in New Zealand. Five participants - all DE students - said they would study harder if they could start again. Of these five students, one is passing most of her 
courses, three are passing more than half, and only one is passing less than half. This response may indicate that these students are not happy about having failed some of their courses, and ideally they would work harder so as not to fail any at all. Or it may simply be a convenient answer, one which they consider to be the right response, as there is always room for improvement.

\section{Reasons for Choosing New Zealand}

The main reasons New Zealand was chosen by the students interviewed for this study are cost and ease of getting entry, with half of the participants stating these reasons. In a study done by Bai (2008a:216-217) on Chinese students in New Zealand, over $80 \%$ of respondents gave the most important reason for choosing New Zealand as "cheap tuition fees" and "cheapest country". Although in this current study only $50 \%$ have given cost and ease of entry as the main factors, this is still the singularly most important factor. Other reasons included family connections, friends' recommendations and an existing relationship between a high school in China and Victoria University of Wellington. There is no significant difference between DE and FS students in regard to their reasons for choosing New Zealand. Very few, if any, students chose New Zealand for the merits of the country or the quality of education, and none came because of a desire to immigrate permanently to this country. As their reasons are generally of a practical rather than emotional nature, it is not surprising that there is no correlation between a student's reason for choosing New Zealand and their subsequent adjustment to life in this country.

\section{Future Goals}

Nine of the participants interviewed in this study say they have changed their plans - from their original intention - about what they will do when they finish their undergraduate studies. In particular, more students now hope to work in New Zealand for a few years before returning to China, and more students plan to go to another country (Australia, USA or England) for further study or work. 
The change of plan of these students may be due to several factors. One is the changing attitudes in China regarding overseas education and the increasing problem of graduate unemployment in China (Bai 2006). As unemployment increases, a student needs more than a degree from a good university to secure a job, but also suitable work experience. Therefore some students choose to stay in New Zealand to gain this in the hope that it will make them more employable when they return to China. Alternatively, some of the students who originally intended to return to China are now considering going elsewhere for further study or work, as the prospect of finding a good job upon their return to China is diminishing.

Another reason for the change in plans may be the changes in the thoughts and attitudes of the students themselves. Most come to New Zealand as young dependant teenagers who follow their parents' choices and advice. By the time they have finished their degree they are independent adults who have learned more about who they are and what they desire. Through the experience of traveling and living in another culture, some catch the travel bug, and want to continue to experience more of the world, others embrace the new culture and find they want to stay, while others realize that their roots run deep and long to return home.

\section{Academic Adjustment and Preparedness}

A third area to be discussed is that of academic adjustment and preparedness. The findings of this study show that FS students are more prepared for undergraduate study and have better adjusted to the conventions of the New Zealand academic system than DE students. This adjustment and preparedness contributes towards their achievement in undergraduate courses.

\section{Confidence}

As previously discussed, FS students are more confident in their English language ability and more comfortable in expressing negative along with 
positive feelings about life in New Zealand. Furthermore, this study shows that FS students also have more confidence in their academic ability, giving themselves higher scores, on average, than their DE peers when assessing their studiousness. This confidence in their academic ability may be due to the fact that they are gaining good grades and passing most of their courses. It may also be because they feel equipped and able to complete the academic tasks they are faced with. Nine out of ten FS students felt that Foundation Studies was good preparation for further university study as it helped them become familiar with the university system and services available, as well as teaching them essay writing and study skills. It was also an opportunity for them to make good friends, many of whom they kept over the following years. These feelings of being academically prepared, being in a familiar environment and having friends for support are sure to give students more confidence as well as practically helping them in their studies.

\section{Previous Study}

The results of the interviews show how unique and varied each student's educational background is. Although the majority of students (12 out of 20) completed high school or equivalent in China and then came to New Zealand, the other eight had varying levels of education - some did not finish high school while others completed one or more years at tertiary level. Once in New Zealand their study pathways were even more varied. All students interviewed had done some study in New Zealand prior to beginning their undergraduate courses. This ranged from just a 3 month language course, to just the VUW Foundation Studies programme, to a combination of two or three avenues including language schools, high schools, foundation programmes and other tertiary providers such as polytechnics. Of the students interviewed, none went directly into degree study upon arrival from China. This is in line with findings of Merwood $(2007: 6,31)$, who notes that Chinese students commonly have multiple pathways to degree study. Among the Chinese participants in his survey, while in New Zealand $82 \%$ had studied English language, 32\% had attended high school and $70 \%$ continued on to tertiary institutions. 
It is reasonable to expect a student's academic background to play a factor in how they approach learning and how well they do in their undergraduate study. As the participants' backgrounds are so varied, the effects of the different levels of previous education can not be measured. It is clear that doing the Foundation Studies programme prior to beginning an undergraduate degree has a positive effect, but the effects of other levels of education - either in China or New Zealand - are unknown in this current study. This is an area that needs further investigation.

\section{Differences in Education Systems}

Different countries have different education systems. Any international student or study-abroad student is faced with the challenge of having to learn about and adjust to the academic conventions in the country they go to. For some countries, the differences are minor and the adjustment is made effortlessly, but for others - especially for Asian students coming to a "western" system such as in New Zealand, the differences are greater and the adjustment more difficult. The results of the interviews for this study offer insight into what the participants recognize as the differences between studying in China and New Zealand, how they feel about the education system here and how they have adjusted or not adjusted to the New Zealand academic conventions.

Common sense says that students who understand what is required of them are more likely to succeed than those who do not know what they need to do. Gu and Schweisfurth (2006), Borland and Pearce (2002), Holmes (2004), Choi (1997) and Zamel and Spack (2006) all agree that for students to succeed they must understand the education system they are studying within and know what is required of them. The first step in adjusting to a new system is to understand the differences between the former and the target practices.

Some of the differences between the Chinese and New Zealand educational styles noted by Holmes (2004) are that the Chinese systems requires more memorization, rote learning and repetition, while the New Zealand system emphasizes questioning, problem solving and critical thinking. Inside the 
classroom, Chinese students are used to sitting quietly while the teacher does all of the talking, whereas in New Zealand universities, discussion-oriented tutorials, and even asking questions during lectures, are common. In China, the teacher tells students everything they need to know, but in New Zealand the student is expected to read widely and pull information together themselves. The writing style in the Chinese context varies from the New Zealand style of essay writing: in Chinese indirect references to traditions and traditional texts, and allowing the reader to make inferences is preferred, whereas in New Zealand an essay must be direct, explanatory, critical or analytical and most importantly all references are explicit and acknowledged. Often these conventions, especially relating to plagiarism, are not clearly expressed and Chinese students are caught out because of ignorance. Bai (2008a:232-235) explains that there is a different focus in the two countries: the focus in China is on examinations and learning the "right" answers, often through memorization, whereas in New Zealand the emphasis is on independent learning, research and problem solving.

The results of the interviews for this current study show that most participants recognized differences between the education systems of China and New Zealand. Only one student did not think there were any differences. Some of the areas mentioned agree with the differences identified by Holmes and Bai, as described above. These were to do with teaching and learning styles - how they are accustomed to being told what to learn by the Chinese teachers, and simply having to remember it, whereas in New Zealand they need to dig deeper themselves, learn to argue, present a case from different perspectives and think critically, and participate in class discussions. Participants also talked about the relationship with teachers: they felt that New Zealand lecturers did not care about students' grades, did not force them to study, were not available at all times to answer their questions, but treated them as adults; Chinese teachers, however, forced students to study, were always available to answer questions and tell them what they needed to learn, checked up on them regularly and helped with personal issues as well as academic issues. They were treated more like children still. Another difference that stood out to many students was that in Chinese universities once you are in it is hard to fail, where as in New Zealand it is quite possible to fail courses. Failing courses and having to spend 
more time and money than originally intended to complete their degree requirements is an area that surprised and frustrated some students.

As already suggested, students who are able to identify the differences between the academic conventions in China and New Zealand are more likely to be able to adapt to the new system and therefore be successful. The results of this study show that five DE and seven FS students understand these differences. The other eight participants appeared less aware of the learning approach needed to succeed in a New Zealand university, recognizing the main differences as social and structural, or not seeing a difference at all.

Some of the other differences identified by participants in this current study go beyond the teaching and learning differences, and relate more to student life and relationships. Most students felt that the Chinese university was friendlier, there was more interaction between classmates, more social activity, and a sense of living and learning together. In New Zealand, on the other hand, students do their own thing and go their own way, and it is much more individualistic. Although some students said they preferred the New Zealand system in general, some liked the Chinese way better, and some liked certain aspects of both and would ideally blend the two. In particular, the aspects of the Chinese university life students preferred were to do with community living and learning, and support from teachers. The positive features of the New Zealand system were identified as the encouragement to think for oneself, develop independent learning and research skills and the flexibility to choose from a range of courses.

The way in which participants preferred to study and the ways in which they would like help with their studies also reveal areas in which students sought a more Chinese approach to their learning. The majority of students like to study in groups - they get together, usually with their Chinese classmates, to discuss lectures and assignments and come to agreement about what has been taught and what the answers are. This preferred way to study is in agreement with one of the aspects of the Chinese system that many students liked - that is the interaction between classmates and the concept of learning together. 
Participants also mentioned, when asked what help they would like, that group study times and more tutorials would be useful.

Bai (2008a:230-235) asked Chinese students in New Zealand to compare the education systems of New Zealand and China and found that the majority of students rated New Zealand as "better" or "much better" than China. Most students felt the quality of education in New Zealand was higher than in China and also more internationalised - because many lecturers in New Zealand universities come from or have been educated in other countries. New materials are also available quickly in New Zealand. Another advantage of the education system in New Zealand is the ability to choose electives and study a broad range of subjects. Similarly, Doherty and Singh (2005) found that Asian students at an Australian university tended to view the Australian system as better than the methods of their home country and Andrade (2006:137-138) also found that many students in her study reported a preference for the "western" style of education. Although the results of the research conducted for this current thesis did not show a majority preference for the New Zealand system, as in the above-mentioned studies - the reasons for preferring the New Zealand academic system are similar to these studies, and in most cases where the Chinese way was preferred it related to the social aspect of university life or group study.

\section{Adjusting to New Zealand Academic Conventions}

Gu and Schweisfurth (2006:81-87) found that Chinese students in the UK made a conscious effort to adjust to the new academic conventions. Similarly, Doherty and Singh (2005) found, when considering Asian students at an Australian university, that although the students initially had some difficulties with the different conventions they soon learnt what was needed and adapted to it. Zamel and Spack (2006:130) also acknowledge that students learn what is expected of them but they suggest that they ought not to be left to learn it on their own. 
This study also found that many students have adjusted to the New Zealand academic conventions, although some still displayed a desire to do things the Chinese way. Included in the twelve students (7 FS and 5 DE) who appear to have adapted to the requirements of university study in New Zealand are the three who have passed all of their courses, four of the five passing most, and five of the eight students passing over half of all courses taken. Those who have passed only half or less than half of their courses do not seem to have grasped and conformed to the western academic conventions. The curious case in these results is the student who does not appear to have recognized and adapted fully to the academic conventions, yet is still passing most of her courses. When comparing the different education systems, this student talks of the different living arrangements, the social aspect and the availability of teachers to answer questions, but does not seem aware of differences in the way of teaching and learning, the need to develop critical thinking and research skills, and other pedagogical issues. She seeks help from classmates and tutors, and says about essay writing "I can't do assignment by myself. I have to search some sentence, some points from internet, from other articles. I feel not good enough in writing." It may be that this student has in fact understood the requirements and adjusted to the way of learning in New Zealand despite not showing this explicitly through the interview, or that the help she gets from classmates, tutors, the internet and other articles is enough for her to succeed.

Participants' comments, when asked about their experience as a new student in undergraduate courses, gives some insight into the adjustment that occurred. They talked about finding it difficult to write essays, not knowing how to study or prepare for exams, and struggling to understand lectures and take good notes. In particular, the DE students have more difficulty with essay writing and study techniques, while the FS students found the lecture setting more of a challenge to adjust to. This is likely to be because during the Foundation Studies Programme, students are taught explicitly about essay writing - how to structure an academic essay and how to reference correctly and avoid plagiarism - as well as learning good study habits. So when they begin their undergraduate studies they are already prepared in these areas. The DE students, on the other hand, must begin to learn these skills during their undergraduate study. While FS students are prepared for essays, they feel less 
comfortable in the lecture setting. This may be because of the small classes and tutorial-style teaching in the Foundation Studies programme that does not expose them to large lectures and the need to take good notes. That only one of the DE students mentioned difficulty in this area could suggest that DE students struggled less with understanding lectures and note-taking. Perhaps it is because their listening skills are better than the FS students - although as previously mentioned in discussing English language ability, more DE than FS students claimed to have poor listening skills. Another explanation may be that they did not mention this area as much as the FS students because they are more aware of problems with essay writing and general study skills, and lectures are a less important issue to them.

Nine out of ten FS students claimed that the Foundation Studies Programme was useful in preparing them for their undergraduate courses. The main factor appears to be getting to know the university system, the library and other resources and services available. Some of the other ways in which they were also helped included essay writing, study skills, specific subject knowledge and help with choosing the right degree to study. These answers suggest the FS students adjust to the New Zealand university setting largely during their Foundation Studies Programme, so that when they begin their undergraduate studies they feel comfortable and familiar with the environment, and they have developed important essay writing and study skills. DE students have not had this opportunity to adjust before commencing their undergraduate courses, but must learn about the differences and change accordingly as they go.

Overall, FS students are more prepared for undergraduate study in New Zealand than DE students. They have more confidence and they are familiar with many of the academic conventions, especially in regards to essay writing and general study skills. They also are more familiar with the university systems and resources. Much of their adjustment takes place during the Foundation Studies Programme, while DE students are learning about the new rules and making the necessary adjustments during their undergraduate study. The majority of both groups of students appear to adjust to the New Zealand system eventually, and many favour it over the Chinese way, although most students still regard the social aspect of Chinese universities as superior. 


\section{Issues Raised}

There are a number of issues raised by this study. The main issue is the need for international students, and in particular Chinese students in New Zealand, to be better prepared for their university study - academically, socially and culturally. Students especially need to be taught the academic conventions they are expected to abide by. Coming from different education systems with different rules, different ways of writing academic essays, different teaching and learning styles, they should not be expected to suddenly know what to do without being told, nor should they have to work it out the hard way - through trial and error. Social and cultural adjustment is also important for academic success; therefore international students should be given help and support in learning the cultural differences and adjusting to life in New Zealand. Providing an environment where students can make friends and interact with other international students as well as New Zealanders would be beneficial in aiding this adjustment.

Another matter this study revealed is that Chinese students do not expect to fail at university. Their general perception - based on the Chinese university system - is that once a student is accepted into university, they simply need to spend the required years, learn the required information, and receive their degree. Many students are dismayed to find that in New Zealand they spend more time and money than originally expected to gain their degree, because they fail and have to repeat courses. Students need to be better informed that it is possible to fail courses, and that it is not unusual to take more than the minimum time to complete a degree. They should also be better prepared by education institutions in New Zealand before starting on undergraduate courses, as this study shows that the average pass rate among DE students is just $68 \%$, but for FS students it is $90 \%$.

The issue of English language is also raised by the DE students feeling that their English is not adequate for their studies despite having gained a score of 6.0 or higher in the IELTS test. This raises the question of whether 6.0 is high enough, or if international students in fact need a higher level of English to be successful in undergraduate study. 
The final question raised by this study is why the FS students increase their advantage over DE students as they continue through their degree study. Some explanations for the FS students' higher achievement have been given and discussed, but none of these explanations completely account for why the FS students continue to outperform DE students, and why the DE students although they show evidence of also learning and adapting to the required academic conventions, and adjusting culturally and socially - never catch up. 


\section{Conclusion}

Chinese international students in New Zealand face many challenges as they pursue their overseas education. They must not only master another language, but also adjust to a new culture and a different academic environment. All three areas have an effect on a student's success. Education providers should, therefore, assist international students in all of these areas in order to produce successful graduates and compete in the international education market.

The aim of this research project was to evaluate the effectiveness of the Foundation Studies Programme at Victoria University of Wellington and to identify factors that contribute to Chinese students' success in a New Zealand university. The questions being considered were:

- Does the Foundation Studies Programme help Chinese international students to succeed in their undergraduate study in a New Zealand university?

- In what ways does the programme prepare students?

- What factors influence a Chinese international student's success in the New Zealand academic environment?

As Chinese international students can not go directly from high school in China to university in New Zealand, the Foundation Studies Programme is a necessary step for many. One of its purposes is to bridge the gap between high school and university and prepare students for undergraduate study, so it is important to evaluate whether or not it does this successfully. The findings from this study will also be valuable in helping to identify what areas Chinese students struggle with in moving from the Chinese to the New Zealand education system, and to discover what factors contribute to successful undergraduate study.

A mixed methods approach was taken for this research and data was collected in two phases. The first phase was a quantitative study comparing the academic achievement, at undergraduate level, of students who had taken the Foundation Studies Programme with students who had not. This was done by 
comparing the academic records of 40 Chinese international students enrolled in their second or subsequent year of undergraduate courses at Victoria University of Wellington, 20 of whom had been through the Foundation Studies Programme prior to beginning their degree study (FS) and 20 who had not (DE). The second phase was a qualitative study. 20 Chinese international students who were studying towards, or had recently completed, an undergraduate degree at Victoria University of Wellington were interviewed. Again half had taken the Foundation Studies Programme prior to their undergraduate courses and half had not. Participants were asked about their experience as an international student in New Zealand and areas they struggled with, succeeded in, appreciated, felt frustrated with, valued, regretted, understood and adjusted to all emerged. Students who had taken Foundation Studies were asked to comment on whether or not they felt the programme was valuable, and in what ways.

The results of this research show that there is a significant correlation between completing the Foundation Studies Programme and subsequent achievement in undergraduate studies. Chinese international students who have been through the Foundation Studies Programme outperform, in their undergraduate study, those who have not. This is revealed in the higher average GPA and pass rate of Foundation Studies graduates compared to the students who did not do the programme. As well as the average GPA and pass rate of FS students being higher than DE students across all courses taken, FS students also outperformed DE students in the two specific courses considered. A year by year analysis of performance showed that FS students not only surpass DE students in their first year of study, but they continue to do better each subsequent year.

Three main factors influencing success emerged through the analysis of the interviews. These factors are confidence in language, acculturation to New Zealand and academic adjustment. These three areas were discussed in chapter one when exploring previous studies on international students, and in particular what aspects affect their achievement. The results of this research are consistent with the literature, agreeing that these factors are important for academic success. 
The first of these factors is confidence in using English. This research finds that those with high English self-ratings were also the high achievers, while those with low ratings were not doing as well academically (passing half or less of their courses). FS students generally rated themselves higher than DE students. Nine out of ten FS students also felt their English was adequate for undergraduate study while only five out of ten DE students felt adequate. FS students are more confident in their English language, which may contribute to their outperforming DE students in undergraduate study.

Acculturation also has an effect on achievement. This research finds that all of the students who had passed all of their courses, and most of those who had passed most of their courses are acculturated to New Zealand. The students who had passed half or less of their courses, apart from one exception are not acculturated. The results show that more FS than DE students have acculturated to New Zealand. This may be attributed in part to the Foundation Studies Programme providing students exposure to aspects of New Zealand culture through the courses with a New Zealand focus.

The third aspect - adapting to the New Zealand academic system - is also important if students are to succeed within that system. Again this research shows a positive relationship between academic adjustment and achievement: Those students who passed all of their courses, and all but one student who passed most have adapted to the required academic conventions, but those who have passed half or less of their courses have not learned and adapted to the New Zealand system. The results also show that more FS than DE students have adjusted to the way of learning in a New Zealand university. This adaptation is made easy for the FS students through the explicit teaching of essay writing techniques, how to avoid plagiarism and study skills during the Foundation Studies Programme.

This research has shown that Chinese international students benefit from being properly prepared for academic study in New Zealand. Students who take the Foundation Studies Programme of Victoria University of Wellington receive this preparation and are more successful in their subsequent undergraduate studies than students who do not take the programme. In the three areas identified as 
important for success - confidence in the English language, acculturation and adjusting to the academic conventions - FS students rate higher than DE students. This demonstrates the effectiveness of the Victoria University Foundation Studies Programme in preparing Chinese international students for further study, particularly in these areas.

This study also calls for further research in this area. The findings answer the initial questions posed for this project; however, in investigating this area several other questions arise. The first is the effectiveness of other preparation courses. If similar studies were conducted on other foundation courses offered in New Zealand it would give more insight into the factors that contribute to academic success. Comparisons could then be made between programmes to find which aspects benefit students most and which are the aspects that are less important. Another question is the effect of students' previous study on their achievement at undergraduate level. The participants in this study had varied academic backgrounds, but the only comparisons made were between those who had taken the Victoria University Foundation Studies programme and those who had not. The effects of students taking preparation courses at other institutions or studying to different levels within New Zealand or China are unknown, but need to be investigated in future research. The final question that could be considered further is why the FS students continue to outperform the DE students in their second and third year. The results of this study show that FS students begin their undergraduate courses with an advantage in that they are familiar with the university, they have learned how to write academic essays and reference correctly, and they have gained confidence in their language and academic ability. However, further research in this area on a larger scale than that in the current study is required to determine how and to what extent this initial advantage benefits students throughout their undergraduate career.

As already mentioned, the findings in this study are supported by the previous studies discussed in the introduction. However, this research also covers new ground, as the effectiveness of foundation programmes is an area that has had little previous investigation. This study fills this gap and highlights the need for educational institutions in New Zealand to prepare all Chinese international students for their academic pursuits here. If this is done, students will benefit by 
greater achievement in their study, less failed courses and less time spent repeating courses. Educational institutions will also benefit through having students who are more equipped to succeed in their studies, and students will be more satisfied with the education they receive and their experience in New Zealand, taking positive reports back to other potential students. 


\section{References}

"Acculturation". 2006. In Encyclopedia of Multicultural Psychology. Retrieved 12 May 2009 from SAGE Publications: http://www.sageereference.com/multiculturalpsychology/Article_n3.html.

Andrade, M. S. 2006. International students in English-speaking universities: Adjustment factors. Journal of Research in International Education 5 (2): 131-154.

Bai, L. 2006. Graduate unemployment: dilemmas and challenges in China's move to mass higher education. The China Quarterly, 2006:128-144.

Bai, L. 2008 (a). The influence of Chinese perceptions of modernization on the value of education: A case study of Chinese students in New Zealand. China: An International Journal 6(2):208-236.

Bai, L. 2008 (b). Meeting the Challenges: Chinese Students' Experience in New Zealand. Shanghai: East China Normal University Press.

Borland, H. and A. Peace. 2002. Identifying key dimension of language and cultural disadvantage at university. Australian Review of Applied Linguistics 25 (2): 101-127.

Choi, M. 1997. Korean students in Australian universities: Intercultural issues. Higher Education Research and Development 16(3):263-282.

Creswell, J. 2003. Qualitative, Quantitative and Mixed Methods Approaches $\left(2^{\text {nd }} E d\right.$.). Thousand Oaks, CA: Sage Publications.

Creswell, J. 2007. Qualitative Inquiry and Research Design: Choosing Among Five Approaches ( $2^{\text {nd }} E d$.). Thousand Oaks, CA: Sage Publications.

Creswell, J. and V. Plano Clark. 2007. Designing and Conducting Mixed Methods Research. Thousand Oaks, CA: Sage Publications.

"Culture Contact". 2009. In Encyclopedia Britannica. Retrieved 12 May 2009 from Encyclopedia Britannica Online: http://www.search.eb.com/eb/article9472156 .

Deverson, T. 2004. "Acculturate v." In The New Zealand Oxford Dictionary. Oxford University Press. Retrieved 12 May 2009 from Oxford Reference Online, Oxford University Press, Victoria University of Wellington: http://www.oxfordreference.com/views/ENTRY.html?subview=Main\&entry=t 186.e340 
Doherty, C. and P. Singh. 2005. International student subjectivities: biographical investments for liquid times. Paper presented at AARE Education Research Conference, University of Western Sydney, Parramatta Campus, Australia, 'Creative Dissent: Constructive Solutions'; $27^{\text {th }}$ November $-1^{\text {st }}$ December 2005.

Fox, J. 2004. Test decisions over time: tracking validity. Language Testing 21(4):437-465.

$\mathrm{Gu}, \mathrm{Q}$. and M. Schweisfurth. 2006. Who adapts? Beyond cultural models of 'the' Chinese learner. Language, Culture and Curriculum. 19 (1): 74-89.

Ho, E. S., W. W. Li, J. Cooper and P. Holmes. 2007. The experiences of Chinese International students in New Zealand. Report for Education New Zealand, March 2007. University of Waikato.

Hofstede, G. 1986. Cultural differences in teaching and learning. International Journal of Intercultural Relations 10: 301-320.

Holmes, P. 2004. Negotiating differences in learning and intercultural communication: ethnic Chinese students in a New Zealand University. Business Communication Quarterly 67 (3): 294-307.

Holmes, J. 1992. An Introduction to Sociolinguistics. London and New York: Longman.

James, M. A. 2006. Transfer of learning from a university content-based EAP course. TESOL Quarterly 40 (4): 783 - 806.

Katzer, J., K. Cook and W. Crouch. 1998. Evaluating Information: A Guide for Users of Social Science Research (4 ${ }^{\text {th }}$ Ed.). Boston MA: McGraw-Hill.

Light, R., M. Xu, and J. Mossop. 1987. English proficiency and academic performance of international students. TESOL Quarterly, 21(2):251-261.

Mangen, S. 2007. Qualitative research methods in cross-national settings. In L. Hantrais and S Mangen (Eds), Cross-National Research Methodology and Practice. Oxon: Rougledge, 19-34.

McKay, P. 2000. On ESL standards for school-age learners. Language Testing 17(2):185-214.

McKenzie, K., and R. Schweitzer. 2001. Who succeeds at university? Factors predicting academic performance in first year Australian university students. Higher Education Research and Development 20 (1): 21-33.

Mertens, D. 2005. Research and Evaluation in Education and Psychology: Integrating Diversity with Quantitative, Qualitative and Mixed Methods $\left(2^{\text {nd }}\right.$ Ed.). Thousand Oaks, CA: Sage Publications. 
Merwood, P. 2007. International Students: Studying and Staying on in New Zealand. A report for Education New Zealand and Department of Labour. Wellington: Department of Labour.

Ministry of Education, International Division. 2008. International Student Enrolments in New Zealand 2001-2007. Retrieved 3 April 2009 from http://www.educationcounts.govt.nz/publications/international/15260/28332/ 24707

Morrison, J., B. Merrick, S. Higgs and J. Le Métais. 2005. Researching the performance of international students in the UK. Studies in Higher Education 30 (3): 327-337.

Robinson, R. 2004. Pathways to completion: Patterns of progression through a university degree. Higher Education 47(1):1-20.

Skyrme, G. 2007. Entering university: the differentiated experience of two Chinese international students in a New Zealand university. Studies in Higher Education 32 (3): 357-372.

Stroven, C. 2003. Foundation Year Study. Unpublished report done for Otago University Foundation Year programme.

Volet, S. 1999. Learning across cultures: appropriateness of knowledge transfer. International Journal of Educational Research 31:625-643.

Ward, C. and A. Masgoret. 2004. The Experience of International Students in New Zealand: Report on the Results of the National Survey. Wellington: Ministry of Education.

Zamel, V. and R. Spack. 2006. Teaching multilingual learners across the curriculum: Beyond the ESOL classroom and back again. Journal of Basic Writing 25 (2): 126-152.

Zhang, Z. 2004. The Experiences and Perceptions of a Sample of Chinese International Students in New Zealand. Research report, Department of Management and International Business. Albany: Massey University. 


\section{Appendices}

Appendix One: Student Achievement Data

\section{Degree Entry Students}

\begin{tabular}{|c|c|c|c|c|c|c|}
\hline STUDENT & GENDER & AGE & TERM & PTRM & COURSE & GRADE \\
\hline \multirow{18}{*}{1} & $\mathrm{~F}$ & 23 & 200401 & 2 & INF0101 & B \\
\hline & $\mathrm{F}$ & 23 & 200401 & 1 & TOUR101 & B- \\
\hline & $F$ & 23 & 200401 & 1 & TOUR104 & $\mathrm{C}+$ \\
\hline & $\mathrm{F}$ & 23 & 200401 & 1 & JAPA111 & $A+$ \\
\hline & $\mathrm{F}$ & 23 & 200401 & 2 & JAPA112 & $A+$ \\
\hline & $\mathrm{F}$ & 23 & 200401 & 2 & TOUR108 & C \\
\hline & $\mathrm{F}$ & 23 & 200501 & 1 & ECON130 & $\mathrm{C}+$ \\
\hline & $\mathrm{F}$ & 23 & 200501 & 1 & QUAN102 & $E$ \\
\hline & $\mathrm{F}$ & 23 & 200501 & $\mathrm{~F}$ & JAPA104 & $\mathrm{B}+$ \\
\hline & $\mathrm{F}$ & 23 & 200501 & 2 & TOUR230 & $D$ \\
\hline & $F$ & 23 & 200501 & 1 & TOUR240 & $\mathrm{C}$ \\
\hline & $\mathrm{F}$ & 23 & 200501 & 2 & TOUR250 & $Q$ \\
\hline & $\mathrm{F}$ & 23 & 200601 & $\mathrm{~F}$ & JAPA201 & $E$ \\
\hline & $\mathrm{F}$ & 23 & 200601 & 2 & TOUR230 & C \\
\hline & $\mathrm{F}$ & 23 & 200601 & A & MARK101 & B \\
\hline & $\mathrm{F}$ & 23 & 200601 & 2 & TOUR250 & B- \\
\hline & $\mathrm{F}$ & 23 & 200701 & 1 & TOUR301 & B- \\
\hline & $\mathrm{F}$ & 23 & 200701 & 1 & TOUR390 & $\mathrm{C}$ \\
\hline \multirow{19}{*}{2} & $\mathrm{~F}$ & 24 & 200501 & 2 & STAT131 & B \\
\hline & $\mathrm{F}$ & 24 & 200501 & 2 & QUAN111 & A \\
\hline & $\mathrm{F}$ & 24 & 200501 & 2 & MGMT101 & $\mathrm{C}+$ \\
\hline & $\mathrm{F}$ & 24 & 200601 & 1 & ECON130 & B \\
\hline & $\mathrm{F}$ & 24 & 200601 & $A$ & ACCY223 & $E$ \\
\hline & $\mathrm{F}$ & 24 & 200601 & 1 & ACCY001 & $\mathrm{F}$ \\
\hline & $\mathrm{F}$ & 24 & 200601 & 2 & ACCY001 & $\mathrm{F}$ \\
\hline & $\mathrm{F}$ & 24 & 200601 & $A$ & ACCY001 & $\mathrm{F}$ \\
\hline & $\mathrm{F}$ & 24 & 200601 & $A$ & ACCY231 & $\mathrm{C}$ \\
\hline & $\mathrm{F}$ & 24 & 200601 & 2 & STAT193 & $A$ \\
\hline & $\mathrm{F}$ & 24 & 200601 & 1 & FCOM110 & $\mathrm{C}+$ \\
\hline & $\mathrm{F}$ & 24 & 200601 & 1 & JAPA111 & $\mathrm{C}+$ \\
\hline & $\mathrm{F}$ & 24 & 200601 & $A$ & COML203 & WD \\
\hline & $\mathrm{F}$ & 24 & 200601 & 1 & ACCY111 & B- \\
\hline & $\mathrm{F}$ & 24 & 200601 & 2 & ECON140 & B- \\
\hline & $\mathrm{F}$ & 24 & 200601 & 2 & INF0101 & B- \\
\hline & $\mathrm{F}$ & 24 & 200701 & 1 & MOFI201 & $\mathrm{C}+$ \\
\hline & $F$ & 24 & 200701 & 1 & QUAN201 & $\mathrm{C}$ \\
\hline & $\mathrm{F}$ & 24 & 200701 & 1 & IBUS201 & $\mathrm{K}$ \\
\hline \multirow[t]{8}{*}{3} & $M$ & 26 & 200301 & 2 & PHYS131 & $D$ \\
\hline & $M$ & 26 & 200301 & 2 & ARCH172 & $\mathrm{C}$ \\
\hline & $M$ & 26 & 200301 & 2 & $\mathrm{ARCH} 111$ & $B$ \\
\hline & $M$ & 26 & 200401 & 2 & $\mathrm{ARCH} 102$ & B- \\
\hline & $M$ & 26 & 200401 & 2 & $\mathrm{ARCH} 112$ & B- \\
\hline & $M$ & 26 & 200401 & 1 & PHYS130 & $\mathrm{C}+$ \\
\hline & $M$ & 26 & 200401 & 1 & $\mathrm{ARCH} 171$ & $\mathrm{C}$ \\
\hline & $M$ & 26 & 200401 & 2 & $\mathrm{ARCH} 181$ & $Q$ \\
\hline
\end{tabular}




\begin{tabular}{|c|c|c|c|c|c|c|}
\hline & $M$ & 26 & 200401 & 1 & ARCH101 & $\mathrm{C}+$ \\
\hline & $M$ & 26 & 200501 & 2 & ARCH181 & $\mathrm{C}$ \\
\hline & $M$ & 26 & 200501 & 1 & DESN104 & $Q$ \\
\hline & $M$ & 26 & 200501 & 2 & BBSC231 & WD \\
\hline & $M$ & 26 & 200501 & 1 & BBSC241 & $Q$ \\
\hline & $M$ & 26 & 200501 & 2 & BBSC251 & Q \\
\hline & $\mathrm{M}$ & 26 & 200501 & 1 & BBSC261 & Q \\
\hline & $M$ & 26 & 200601 & 1 & DESN104 & $\mathrm{D}$ \\
\hline & $M$ & 26 & 200601 & 2 & BBSC231 & $\mathrm{C}$ \\
\hline & $\mathrm{M}$ & 26 & 200601 & 1 & BBSC241 & $\mathrm{C}+$ \\
\hline & $\mathrm{M}$ & 26 & 200601 & 2 & BBSC251 & $D$ \\
\hline & $M$ & 26 & 200601 & $A$ & DESN114 & A- \\
\hline & $\mathrm{M}$ & 26 & 200701 & 1 & BBSC303 & $E$ \\
\hline & $\mathrm{M}$ & 26 & 200701 & 1 & BBSC331 & $\mathrm{D}$ \\
\hline \multirow{21}{*}{4} & $\mathrm{M}$ & 23 & 200401 & 2 & INF0101 & $E$ \\
\hline & M & 23 & 200401 & $A$ & ACCY001 & $\mathrm{F}$ \\
\hline & $M$ & 23 & 200401 & 2 & QUAN111 & $B-$ \\
\hline & $M$ & 23 & 200401 & 2 & STAT193 & $\mathrm{C}+$ \\
\hline & $\mathrm{M}$ & 23 & 200401 & A & ACCY111 & $E$ \\
\hline & $\mathrm{M}$ & 23 & 200401 & A & ECON130 & $\mathrm{D}$ \\
\hline & $\mathrm{M}$ & 23 & 200501 & 1 & ECON130 & $\mathrm{C}$ \\
\hline & $\mathrm{M}$ & 23 & 200501 & 1 & ACCY001 & Q \\
\hline & $\mathrm{M}$ & 23 & 200501 & 2 & WRIT151 & WD \\
\hline & $\mathrm{M}$ & 23 & 200501 & 2 & ACCY111 & $E$ \\
\hline & $M$ & 23 & 200501 & 2 & ECON140 & $\mathrm{D}$ \\
\hline & $\mathrm{M}$ & 23 & 200501 & A & ECON140 & B- \\
\hline & $\mathrm{M}$ & 23 & 200601 & 1 & MOFI201 & B \\
\hline & $\mathrm{M}$ & 23 & 200601 & 1 & ACCY001 & $\mathrm{P}$ \\
\hline & $\mathrm{M}$ & 23 & 200601 & 2 & ACCY111 & $\mathrm{C}+$ \\
\hline & $\mathrm{M}$ & 23 & 200601 & 2 & MOFI202 & $\mathrm{C}+$ \\
\hline & $\mathrm{M}$ & 23 & 200601 & 2 & MOFI302 & $\mathrm{D}$ \\
\hline & $\mathrm{M}$ & 23 & 200601 & 1 & MARK101 & $\mathrm{C}+$ \\
\hline & $M$ & 23 & 200701 & 1 & ACCY231 & $\mathrm{C}$ \\
\hline & $\mathrm{M}$ & 23 & 200701 & 1 & ACCY223 & $\mathrm{C}$ \\
\hline & $\mathrm{M}$ & 23 & 200701 & 1 & MOFI305 & $\mathrm{C}$ \\
\hline \multirow{15}{*}{5} & $\mathrm{~F}$ & 22 & 200501 & 1 & ECON130 & $\mathrm{D}$ \\
\hline & $\mathrm{F}$ & 22 & 200501 & 1 & JAPA111 & $\mathrm{C}+$ \\
\hline & $\mathrm{F}$ & 22 & 200501 & 1 & QUAN102 & B \\
\hline & $\mathrm{F}$ & 22 & 200501 & 2 & QUAN111 & B- \\
\hline & $\mathrm{F}$ & 22 & 200501 & 2 & ACCY111 & Q \\
\hline & $\mathrm{F}$ & 22 & 200501 & A & MARK101 & $\mathrm{C}$ \\
\hline & $\mathrm{F}$ & 22 & 200501 & A & ECON130 & $\mathrm{D}$ \\
\hline & $\mathrm{F}$ & 22 & 200601 & 2 & QUAN203 & $\mathrm{D}$ \\
\hline & $\mathrm{F}$ & 22 & 200601 & 2 & MARK202 & $E$ \\
\hline & $\mathrm{F}$ & 22 & 200601 & $\mathrm{~F}$ & MATH114 & $E$ \\
\hline & $\mathrm{F}$ & 22 & 200601 & 1 & FCOM110 & $\mathrm{C}$ \\
\hline & $\mathrm{F}$ & 22 & 200601 & 1 & INF0101 & $\mathrm{D}$ \\
\hline & $\mathrm{F}$ & 22 & 200601 & 2 & MARK204 & $E$ \\
\hline & $\mathrm{F}$ & 22 & 200701 & 1 & ECON130 & $\mathrm{C}+$ \\
\hline & $\mathrm{F}$ & 22 & 200701 & 1 & MARK211 & $\mathrm{D}$ \\
\hline \multirow[t]{7}{*}{6} & $\mathrm{~F}$ & 23 & 200501 & 2 & DESN112 & $\mathrm{C}+$ \\
\hline & $\mathrm{F}$ & 23 & 200501 & 1 & DESN101 & B- \\
\hline & $\mathrm{F}$ & 23 & 200501 & 1 & DESN111 & $\mathrm{C}+$ \\
\hline & $\mathrm{F}$ & 23 & 200501 & 2 & DESN171 & B- \\
\hline & $\mathrm{F}$ & 23 & 200501 & 1 & GEOG111 & $\mathrm{D}$ \\
\hline & $\mathrm{F}$ & 23 & 200501 & A & DESN104 & $B+$ \\
\hline & $\mathrm{F}$ & 23 & 200501 & 2 & DESN131 & $\mathrm{C}$ \\
\hline
\end{tabular}




\begin{tabular}{|c|c|c|c|c|c|c|}
\hline & $\mathrm{F}$ & 23 & 200601 & 2 & LADN232 & $\mathrm{D}$ \\
\hline & $\mathrm{F}$ & 23 & 200601 & 1 & LADN201 & $\mathrm{C}$ \\
\hline & $\mathrm{F}$ & 23 & 200601 & 1 & GEOG111 & $\mathrm{C}$ \\
\hline & $\mathrm{F}$ & 23 & 200601 & 1 & LADN211 & B- \\
\hline & $\mathrm{F}$ & 23 & 200601 & 2 & LADN212 & B- \\
\hline & $\mathrm{F}$ & 23 & 200601 & 2 & LADN271 & $\mathrm{C}$ \\
\hline & $\mathrm{F}$ & 23 & 200601 & A & PASI101 & $\mathrm{C}$ \\
\hline & $\mathrm{F}$ & 23 & 200701 & 1 & LADN341 & $E$ \\
\hline & $\mathrm{F}$ & 23 & 200701 & 1 & LADN371 & $\mathrm{D}$ \\
\hline & $\mathrm{F}$ & 23 & 200701 & 1 & LADN311 & $\mathrm{C}+$ \\
\hline \multirow{24}{*}{7} & $\mathrm{M}$ & 22 & 200401 & 2 & QUAN111 & $A-$ \\
\hline & $\mathrm{M}$ & 22 & 200401 & 2 & STAT193 & B- \\
\hline & $M$ & 22 & 200401 & 2 & MGMT101 & $\mathrm{D}$ \\
\hline & $\mathrm{M}$ & 22 & 200501 & 1 & ECON130 & $\mathrm{D}$ \\
\hline & $\mathrm{M}$ & 22 & 200501 & 1 & MARK101 & $\mathrm{C}$ \\
\hline & $\mathrm{M}$ & 22 & 200501 & A & MGMT202 & B \\
\hline & $M$ & 22 & 200501 & 1 & SPAN111 & $\mathrm{D}$ \\
\hline & $M$ & 22 & 200501 & 2 & PSYC122 & $D$ \\
\hline & $\mathrm{M}$ & 22 & 200501 & 2 & MARK202 & B- \\
\hline & $\mathrm{M}$ & 22 & 200501 & 1 & ACCY111 & $\mathrm{D}$ \\
\hline & $\mathrm{M}$ & 22 & 200501 & 2 & MGMT101 & $\mathrm{C}$ \\
\hline & $\mathrm{M}$ & 22 & 200601 & 2 & MARK302 & B \\
\hline & $\mathrm{M}$ & 22 & 200601 & 1 & FCOM110 & $\mathrm{C}+$ \\
\hline & $\mathrm{M}$ & 22 & 200601 & A & ACCY111 & $\mathrm{C}+$ \\
\hline & $\mathrm{M}$ & 22 & 200601 & 2 & ECON140 & B- \\
\hline & $\mathrm{M}$ & 22 & 200601 & 1 & MARK211 & $E$ \\
\hline & $\mathrm{M}$ & 22 & 200601 & 1 & MGMT205 & $\mathrm{C}+$ \\
\hline & $\mathrm{M}$ & 22 & 200601 & 1 & MGMT206 & B- \\
\hline & $M$ & 22 & 200601 & 2 & MGMT314 & $B$ \\
\hline & $\mathrm{M}$ & 22 & 200601 & 2 & MGMT315 & B \\
\hline & $\mathrm{M}$ & 22 & 200701 & 1 & MOFI305 & $\mathrm{C}+$ \\
\hline & $\mathrm{M}$ & 22 & 200701 & 1 & MOFI201 & A- \\
\hline & $M$ & 22 & 200701 & 1 & MARK211 & $\mathrm{C}+$ \\
\hline & $\mathrm{M}$ & 22 & 200701 & 1 & MARK301 & $\mathrm{K}$ \\
\hline \multirow{20}{*}{8} & M & 26 & 200301 & 2 & TECH102 & $E$ \\
\hline & M & 26 & 200301 & 2 & COMP202 & Q \\
\hline & $\mathrm{M}$ & 26 & 200301 & 2 & COMP203 & $Q$ \\
\hline & $\mathrm{M}$ & 26 & 200401 & 2 & STAT193 & $\mathrm{C}$ \\
\hline & M & 26 & 200401 & 1 & MATH214 & Q \\
\hline & M & 26 & 200401 & A & COMP103 & $\mathrm{C}$ \\
\hline & M & 26 & 200401 & 1 & COMP204 & $E$ \\
\hline & $\mathrm{M}$ & 26 & 200401 & 2 & TECH102 & $\mathrm{C}+$ \\
\hline & $\mathrm{M}$ & 26 & 200401 & 1 & COMP201 & Q \\
\hline & $\mathrm{M}$ & 26 & 200401 & 2 & COMP102 & $\mathrm{C}$ \\
\hline & M & 26 & 200501 & 1 & COMP205 & $\mathrm{D}$ \\
\hline & $M$ & 26 & 200501 & 2 & COMP206 & $\mathrm{Q}$ \\
\hline & M & 26 & 200501 & 1 & MATH214 & $E$ \\
\hline & $\mathrm{M}$ & 26 & 200501 & 2 & COMP202 & $\mathrm{C}$ \\
\hline & M & 26 & 200501 & 1 & COMP203 & $\mathrm{C}$ \\
\hline & M & 26 & 200601 & 1 & COMP205 & $\mathrm{D}$ \\
\hline & M & 26 & 200601 & 2 & COMP206 & $\mathrm{D}$ \\
\hline & $\mathrm{M}$ & 26 & 200601 & 1 & MATH214 & $\mathrm{C}$ \\
\hline & $\mathrm{M}$ & 26 & 200601 & 1 & COMP302 & $\mathrm{C}+$ \\
\hline & $\mathrm{M}$ & 26 & 200701 & 1 & COMP205 & $\mathrm{D}$ \\
\hline \multirow[t]{3}{*}{9} & $\mathrm{M}$ & 22 & 200501 & 1 & INF0101 & $\mathrm{C}$ \\
\hline & $\mathrm{M}$ & 22 & 200501 & 2 & STAT131 & $\mathrm{C}+$ \\
\hline & $M$ & 22 & 200501 & 1 & STAT193 & $\mathrm{D}$ \\
\hline
\end{tabular}




\begin{tabular}{|c|c|c|c|c|c|c|}
\hline & $M$ & 22 & 200501 & 2 & STAT193 & B \\
\hline & $M$ & 22 & 200501 & $\mathrm{~F}$ & MATH114 & $\mathrm{C}+$ \\
\hline & $M$ & 22 & 200501 & 1 & COMP102 & $E$ \\
\hline & $M$ & 22 & 200601 & 1 & ECON130 & $\mathrm{C}+$ \\
\hline & $M$ & 22 & 200601 & $A$ & COMP101 & $\mathrm{C}+$ \\
\hline & $\mathrm{M}$ & 22 & 200601 & 2 & STAT291 & $E$ \\
\hline & $M$ & 22 & 200601 & 2 & MATH207 & $E$ \\
\hline & $M$ & 22 & 200601 & $\mathrm{~F}$ & MATH113 & $\mathrm{C}+$ \\
\hline & $\mathrm{M}$ & 22 & 200601 & 1 & MATH206 & $\mathrm{G}$ \\
\hline & $\mathrm{M}$ & 22 & 200601 & A & MARK101 & B- \\
\hline & $M$ & 22 & 200701 & 1 & STAT231 & $E$ \\
\hline & $M$ & 22 & 200701 & 1 & MATH214 & $E$ \\
\hline & $\mathrm{M}$ & 22 & 200701 & 1 & OPRE251 & B- \\
\hline \multirow{21}{*}{10} & $\mathrm{~F}$ & 26 & 200401 & 1 & ECON130 & $\mathrm{C}$ \\
\hline & $\mathrm{F}$ & 26 & 200401 & 2 & ECON140 & $D$ \\
\hline & $\mathrm{F}$ & 26 & 200401 & 2 & INF0101 & B- \\
\hline & $\mathrm{F}$ & 26 & 200401 & 1 & MARK101 & $Q$ \\
\hline & $\mathrm{F}$ & 26 & 200401 & 1 & FCOM110 & B- \\
\hline & $\mathrm{F}$ & 26 & 200401 & 2 & ACCY111 & $\mathrm{Q}$ \\
\hline & $\mathrm{F}$ & 26 & 200401 & 2 & MGMT101 & $Q$ \\
\hline & $\mathrm{F}$ & 26 & 200501 & 2 & ECON140 & B- \\
\hline & $\mathrm{F}$ & 26 & 200501 & 1 & MARK101 & $\mathrm{C}+$ \\
\hline & $\mathrm{F}$ & 26 & 200501 & 1 & INFO201 & $\mathrm{C}$ \\
\hline & $\mathrm{F}$ & 26 & 200501 & 1 & ACCY001 & $Q$ \\
\hline & $\mathrm{F}$ & 26 & 200501 & 2 & ACCY001 & $Q$ \\
\hline & $F$ & 26 & 200501 & A & ACCY001 & $\mathrm{F}$ \\
\hline & $\mathrm{F}$ & 26 & 200501 & 1 & QUAN102 & $\mathrm{C}$ \\
\hline & $\mathrm{F}$ & 26 & 200501 & 2 & ACCY111 & $Q$ \\
\hline & $\mathrm{F}$ & 26 & 200501 & $A$ & ACCY111 & Q \\
\hline & $\mathrm{F}$ & 26 & 200601 & 2 & INFO301 & $D$ \\
\hline & $\mathrm{F}$ & 26 & 200601 & 2 & ACCY001 & $\mathrm{F}$ \\
\hline & $\mathrm{F}$ & 26 & 200601 & 2 & ACCY111 & $\mathrm{C}$ \\
\hline & $\mathrm{F}$ & 26 & 200701 & 1 & ACCY001 & WD \\
\hline & $\mathrm{F}$ & 23 & 200501 & 2 & INFO102 & $\mathrm{C}+$ \\
\hline \multirow{12}{*}{11} & $\mathrm{~F}$ & 23 & 200501 & 2 & INF0101 & B \\
\hline & $\mathrm{F}$ & 23 & 200501 & 2 & TOUR108 & $\mathrm{C}$ \\
\hline & $\mathrm{F}$ & 23 & 200601 & 1 & FCOM110 & B- \\
\hline & $\mathrm{F}$ & 23 & 200601 & 2 & ELCM251 & B- \\
\hline & $\mathrm{F}$ & 23 & 200601 & 2 & QUAN111 & A- \\
\hline & $\mathrm{F}$ & 23 & 200601 & 1 & TOUR101 & $\mathrm{C}+$ \\
\hline & $\mathrm{F}$ & 23 & 200601 & 1 & ACCY111 & $\mathrm{D}$ \\
\hline & $\mathrm{F}$ & 23 & 200601 & 2 & COMM101 & B \\
\hline & $\mathrm{F}$ & 23 & 200601 & 2 & ASIA102 & B- \\
\hline & $\mathrm{F}$ & 23 & 200701 & 1 & ECON130 & $\mathrm{D}$ \\
\hline & $\mathrm{F}$ & 23 & 200701 & 1 & ELCM211 & B \\
\hline & $\mathrm{F}$ & 23 & 200701 & 1 & IBUS201 & $\mathrm{K}$ \\
\hline \multirow[t]{11}{*}{12} & $\mathrm{~F}$ & 22 & 200501 & 2 & MGMT101 & B- \\
\hline & $\mathrm{F}$ & 22 & 200501 & 2 & ACCY001 & $\mathrm{P}$ \\
\hline & $\mathrm{F}$ & 22 & 200501 & 2 & WRIT151 & B- \\
\hline & $\mathrm{F}$ & 22 & 200501 & 2 & ACCY111 & B- \\
\hline & $\mathrm{F}$ & 22 & 200601 & 1 & ECON130 & B \\
\hline & $\mathrm{F}$ & 22 & 200601 & 1 & ACCY231 & B \\
\hline & $\mathrm{F}$ & 22 & 200601 & 2 & ACCY232 & B- \\
\hline & $\mathrm{F}$ & 22 & 200601 & 2 & QUAN111 & $\mathrm{B}+$ \\
\hline & $\mathrm{F}$ & 22 & 200601 & 2 & ECON140 & B- \\
\hline & $\mathrm{F}$ & 22 & 200601 & 1 & INF0101 & B- \\
\hline & $\mathrm{F}$ & 22 & 200601 & 1 & COML203 & $B$ \\
\hline
\end{tabular}




\begin{tabular}{|c|c|c|c|c|c|c|}
\hline & $\mathrm{F}$ & 22 & 200601 & 2 & COML303 & $\mathrm{D}$ \\
\hline & $\mathrm{F}$ & 22 & 200701 & 1 & QUAN102 & A- \\
\hline & $\mathrm{F}$ & 22 & 200701 & 1 & ACCY223 & C \\
\hline & $\mathrm{F}$ & 22 & 200701 & 1 & ACCY308 & $\mathrm{C}+$ \\
\hline & $\mathrm{F}$ & 21 & 200401 & 1 & ECON130 & $\mathrm{C}$ \\
\hline & $\mathrm{F}$ & 21 & 200401 & 2 & ECON140 & B \\
\hline & $\mathrm{F}$ & 21 & 200401 & 1 & STAT193 & $\mathrm{Q}$ \\
\hline & $\mathrm{F}$ & 21 & 200401 & 2 & STAT193 & $\mathrm{C}+$ \\
\hline & $\mathrm{F}$ & 21 & 200401 & 2 & QUAN111 & $\mathrm{B}+$ \\
\hline & $\mathrm{F}$ & 21 & 200401 & 2 & ACCY111 & D \\
\hline & $\mathrm{F}$ & 21 & 200401 & 1 & INET101 & C \\
\hline & $\mathrm{F}$ & 21 & 200501 & 1 & ECON201 & $\mathrm{C}+$ \\
\hline & $\mathrm{F}$ & 21 & 200501 & 2 & ECON202 & D \\
\hline & $\mathrm{F}$ & 21 & 200501 & 1 & QUAN201 & $B$ \\
\hline 13 & $\mathrm{~F}$ & 21 & 200501 & 2 & ACCY111 & $\mathrm{D}$ \\
\hline & $\mathrm{F}$ & 21 & 200501 & 1 & MOFI201 & $\mathrm{C}+$ \\
\hline & $\mathrm{F}$ & 21 & 200501 & 2 & MOFI202 & $\mathrm{D}$ \\
\hline & $\mathrm{F}$ & 21 & 200601 & 2 & ECON202 & $C$ \\
\hline & $\mathrm{F}$ & 21 & 200601 & 2 & ECON309 & $\mathrm{C}+$ \\
\hline & $\mathrm{F}$ & 21 & 200601 & 1 & ECON333 & B- \\
\hline & $\mathrm{F}$ & 21 & 200601 & 1 & MOFI305 & $\mathrm{E}$ \\
\hline & $\mathrm{F}$ & 21 & 200601 & 2 & MOFI302 & $\mathrm{C}$ \\
\hline & $\mathrm{F}$ & 21 & 200601 & 1 & JAPA111 & $B$ \\
\hline & $\mathrm{F}$ & 21 & 200701 & 1 & FCOM110 & $\mathrm{C}$ \\
\hline & $\mathrm{F}$ & 21 & 200701 & 1 & QUAN371 & B- \\
\hline & $\mathrm{F}$ & 21 & 200701 & 1 & ACCY111 & $\mathrm{B}$ \\
\hline & $\mathrm{F}$ & 23 & 200501 & 2 & ARCH102 & B- \\
\hline & $\mathrm{F}$ & 23 & 200501 & 2 & ARCH112 & B- \\
\hline & $\mathrm{F}$ & 23 & 200501 & 2 & ARCH172 & $\mathrm{C}$ \\
\hline & $\mathrm{F}$ & 23 & 200501 & 2 & ARCH181 & $\mathrm{C}+$ \\
\hline & $\mathrm{F}$ & 23 & 200501 & 1 & JAPA111 & $\mathrm{C}+$ \\
\hline & $\mathrm{F}$ & 23 & 200501 & 1 & ARCH111 & $\mathrm{B}+$ \\
\hline & $\mathrm{F}$ & 23 & 200501 & 1 & $\mathrm{ARCH} 101$ & $\mathrm{~B}+$ \\
\hline 14 & $\mathrm{~F}$ & 23 & 200601 & 1 & WRIT151 & B- \\
\hline & $\mathrm{F}$ & 23 & 200601 & 2 & BBSC231 & B- \\
\hline & $\mathrm{F}$ & 23 & 200601 & 1 & BBSC241 & $\mathrm{C}+$ \\
\hline & $\mathrm{F}$ & 23 & 200601 & 2 & BBSC251 & B- \\
\hline & $\mathrm{F}$ & 23 & 200601 & 1 & BBSC261 & $C$ \\
\hline & $\mathrm{F}$ & 23 & 200601 & 2 & $\mathrm{ARCH} 222$ & $\mathrm{C}+$ \\
\hline & $\mathrm{F}$ & 23 & 200701 & 1 & BBSC303 & $\mathrm{B}$ \\
\hline & $\mathrm{F}$ & 23 & 200701 & 1 & BBSC331 & $\mathrm{C}$ \\
\hline & $\mathrm{F}$ & 23 & 200701 & 1 & BBSC351 & $\mathrm{K}$ \\
\hline 15 & $\mathrm{~F}$ & 21 & 200501 & 2 & STAT131 & $B$ \\
\hline & $\mathrm{F}$ & 21 & 200501 & A & COMP103 & $\mathrm{C}+$ \\
\hline & $\mathrm{F}$ & 21 & 200501 & 2 & TECH102 & B- \\
\hline & $\mathrm{F}$ & 21 & 200501 & 2 & COMP102 & B \\
\hline & $\mathrm{F}$ & 21 & 200601 & 1 & COMP101 & A \\
\hline & $\mathrm{F}$ & 21 & 200601 & 1 & COMP205 & D \\
\hline & $\mathrm{F}$ & 21 & 200601 & 2 & COMP206 & $\mathrm{C}+$ \\
\hline & $\mathrm{F}$ & 21 & 200601 & 2 & CHEM104 & C \\
\hline & $\mathrm{F}$ & 21 & 200601 & A & QUAN102 & B \\
\hline & $\mathrm{F}$ & 21 & 200601 & 2 & MATH114 & $\mathrm{C}+$ \\
\hline & $\mathrm{F}$ & 21 & 200601 & 1 & TECH203 & C \\
\hline & $\mathrm{F}$ & 21 & 200601 & 2 & COMP202 & B- \\
\hline & $\mathrm{F}$ & 21 & 200701 & 1 & MATH214 & $\mathrm{D}$ \\
\hline & $\mathrm{F}$ & 21 & 200701 & 1 & COMP203 & B \\
\hline
\end{tabular}




\begin{tabular}{|c|c|c|c|c|c|c|}
\hline & $\mathrm{F}$ & 21 & 200701 & 1 & COMP302 & B- \\
\hline \multirow{12}{*}{16} & $\mathrm{M}$ & 23 & 200501 & $A$ & INFO102 & $D$ \\
\hline & $\mathrm{M}$ & 23 & 200501 & $A$ & INFO101 & $Q$ \\
\hline & $M$ & 23 & 200601 & 1 & ECON130 & $\mathrm{C}+$ \\
\hline & $M$ & 23 & 200601 & 2 & INF0101 & $\mathrm{C}$ \\
\hline & $\mathrm{M}$ & 23 & 200601 & 2 & INF0102 & $\mathrm{B}+$ \\
\hline & $M$ & 23 & 200601 & 1 & QUAN102 & $D$ \\
\hline & $M$ & 23 & 200601 & 2 & MARK202 & $E$ \\
\hline & $M$ & 23 & 200601 & 2 & ACCY111 & $\mathrm{C}+$ \\
\hline & $\mathrm{M}$ & 23 & 200601 & 1 & ACCY111 & $\mathrm{D}$ \\
\hline & $\mathrm{M}$ & 23 & 200701 & 1 & ELCM211 & $E$ \\
\hline & $\mathrm{M}$ & 23 & 200701 & 1 & QUAN102 & $\mathrm{C}$ \\
\hline & $\mathrm{M}$ & 23 & 200701 & 1 & MARK211 & WD \\
\hline \multirow{14}{*}{17} & $M$ & 22 & 200501 & 1 & FCOM110 & $\mathrm{C}$ \\
\hline & $M$ & 22 & 200501 & 1 & QUAN102 & $\mathrm{C}+$ \\
\hline & $\mathrm{M}$ & 22 & 200501 & 2 & QUAN111 & B \\
\hline & $\mathrm{M}$ & 22 & 200501 & 1 & ECON130 & $\mathrm{C}+$ \\
\hline & $M$ & 22 & 200501 & 2 & ECON140 & $\mathrm{B}+$ \\
\hline & $\mathrm{M}$ & 22 & 200501 & 2 & IBUS202 & $\mathrm{C}$ \\
\hline & $M$ & 22 & 200601 & 1 & ECON201 & $\mathrm{B}+$ \\
\hline & $M$ & 22 & 200601 & 2 & ECON202 & $\mathrm{D}$ \\
\hline & $M$ & 22 & 200601 & 2 & ACCY111 & $\mathrm{D}$ \\
\hline & $M$ & 22 & 200601 & 1 & IBUS201 & B- \\
\hline & $\mathrm{M}$ & 22 & 200601 & 2 & IBUS301 & B- \\
\hline & $M$ & 22 & 200701 & 1 & IBUS309 & B- \\
\hline & $M$ & 22 & 200701 & 1 & ECON305 & $\mathrm{C}+$ \\
\hline & $\mathrm{M}$ & 22 & 200701 & 1 & IBUS305 & B- \\
\hline \multirow{14}{*}{18} & $\mathrm{M}$ & 25 & 200501 & 1 & ECON130 & B \\
\hline & $\mathrm{M}$ & 25 & 200501 & 2 & ECON140 & $\mathrm{B}+$ \\
\hline & $\mathrm{M}$ & 25 & 200501 & 1 & FCOM110 & $\mathrm{C}+$ \\
\hline & $\mathrm{M}$ & 25 & 200501 & 1 & QUAN102 & $\mathrm{B}+$ \\
\hline & $M$ & 25 & 200501 & 2 & QUAN111 & $\mathrm{B}+$ \\
\hline & $M$ & 25 & 200501 & 2 & ACCY111 & C \\
\hline & $M$ & 25 & 200601 & 1 & MOFI201 & $\mathrm{B}+$ \\
\hline & $\mathrm{M}$ & 25 & 200601 & 1 & ECON201 & $\mathrm{C}$ \\
\hline & $\mathrm{M}$ & 25 & 200601 & 2 & ECON202 & $\mathrm{D}$ \\
\hline & $\mathrm{M}$ & 25 & 200601 & 1 & QUAN201 & $\mathrm{C}+$ \\
\hline & $M$ & 25 & 200601 & 2 & MOFI202 & $D$ \\
\hline & $\mathrm{M}$ & 25 & 200701 & 1 & MOFI305 & $\mathrm{C}$ \\
\hline & $M$ & 25 & 200701 & 1 & QUAN371 & $\mathrm{C}+$ \\
\hline & $\mathrm{M}$ & 25 & 200701 & 1 & QUAN304 & B- \\
\hline \multirow[t]{15}{*}{19} & $M$ & 24 & 200401 & 1 & ECON130 & $\mathrm{C}$ \\
\hline & $M$ & 24 & 200401 & 2 & INFO101 & $E$ \\
\hline & $\mathrm{M}$ & 24 & 200401 & 1 & FCOM110 & $\mathrm{C}$ \\
\hline & $M$ & 24 & 200401 & 1 & QUAN103 & $A-$ \\
\hline & $M$ & 24 & 200401 & 2 & QUAN111 & $\mathrm{C}+$ \\
\hline & $\mathrm{M}$ & 24 & 200401 & 2 & CHIN213 & $\mathrm{C}+$ \\
\hline & $\mathrm{M}$ & 24 & 200501 & 2 & ECON140 & $\mathrm{C}+$ \\
\hline & $M$ & 24 & 200501 & $\mathrm{~F}$ & CHIN313 & $\mathrm{C}+$ \\
\hline & $M$ & 24 & 200501 & 1 & ACCY111 & $E$ \\
\hline & $M$ & 24 & 200501 & 1 & IBUS201 & $E$ \\
\hline & $\mathrm{M}$ & 24 & 200501 & 2 & IBUS202 & $\mathrm{D}$ \\
\hline & $M$ & 24 & 200601 & 2 & INFO101 & B- \\
\hline & $M$ & 24 & 200601 & 1 & ECON201 & $\mathrm{C}$ \\
\hline & $\mathrm{M}$ & 24 & 200601 & 2 & ECON202 & $E$ \\
\hline & $\mathrm{M}$ & 24 & 200601 & 2 & ECON314 & WD \\
\hline
\end{tabular}




\begin{tabular}{|llllll|}
\hline$M$ & 24 & 200601 & 1 & GERM103 & B \\
$M$ & 24 & 200601 & A & ACCY111 & E \\
$M$ & 24 & 200601 & 1 & IBUS201 & D \\
$M$ & 24 & 200601 & A & CHIN314 & B+ \\
$M$ & 24 & 200701 & 1 & ECON333 & WD \\
$M$ & 24 & 200701 & 1 & WRIT151 & B \\
$M$ & 24 & 200701 & 1 & QUAN102 & B \\
$M$ & 24 & 200701 & 1 & ACCY111 & B- \\
\hline$M$ & 21 & 200501 & 1 & ECON130 & E \\
$M$ & 21 & 200501 & 1 & QUAN102 & E \\
$M$ & 21 & 200501 & 2 & QUAN111 & B+ \\
$M$ & 21 & 200501 & 2 & ACCY111 & C \\
$M$ & 21 & 200501 & 1 & FCOM110 & E \\
$M$ & 21 & 200601 & 1 & ECON130 & B- \\
$M$ & 21 & 200601 & 2 & MGMT101 & D \\
$M$ & 21 & 200601 & 2 & INFO101 & B- \\
$M$ & 21 & 200601 & 2 & ACCY001 & P \\
$M$ & 21 & 200601 & 1 & QUAN102 & B+ \\
$M$ & 21 & 200601 & 1 & FCOM110 & E \\
$M$ & 21 & 200601 & 2 & ECON140 & C+ \\
$M$ & 21 & 200701 & 1 & MOFI201 & B \\
$M$ & 21 & 200701 & 1 & ACCY231 & C \\
$M$ & 21 & 200701 & 1 & ACCY223 & C+ \\
\hline$M$ & & & & \\
\hline
\end{tabular}

\section{Foundation Studies Students}

\begin{tabular}{|c|c|c|c|c|c|c|}
\hline STUDENT & GENDER & AGE & TERM & PTRM & COURSE & GRADE \\
\hline \multirow{23}{*}{1} & $M$ & 27 & 200401 & 1 & FNDN001 & B- \\
\hline & M & 27 & 200401 & 1 & FNDN002 & $B+$ \\
\hline & M & 27 & 200401 & 1 & FNDN005 & B- \\
\hline & M & 27 & 200401 & 2 & FNDN020 & A \\
\hline & M & 27 & 200401 & 2 & FNDN023 & $\mathrm{A}^{+}$ \\
\hline & M & 27 & 200401 & 2 & FNDN024 & B- \\
\hline & M & 27 & 200401 & B & FNDN898 & $\mathrm{P}$ \\
\hline & M & 27 & 200501 & 2 & ARCH102 & $\mathrm{Q}$ \\
\hline & M & 27 & 200501 & 2 & ARCH 112 & Q \\
\hline & M & 27 & 200501 & 1 & $\mathrm{ARCH} 171$ & D \\
\hline & M & 27 & 200501 & 2 & ARCH172 & Q \\
\hline & M & 27 & 200501 & 2 & ARCH181 & Q \\
\hline & M & 27 & 200501 & 1 & ARCH111 & B \\
\hline & M & 27 & 200501 & 1 & ARCH101 & B \\
\hline & M & 27 & 200601 & 1 & ECON130 & B \\
\hline & M & 27 & 200601 & 1 & FCOM110 & $C+$ \\
\hline & M & 27 & 200601 & 1 & QUAN102 & $A^{+}$ \\
\hline & M & 27 & 200601 & 2 & QUAN111 & $A^{+}$ \\
\hline & M & 27 & 200601 & 2 & ACCY111 & B- \\
\hline & M & 27 & 200601 & 2 & ECON140 & $B+$ \\
\hline & M & 27 & 200701 & 1 & ECON201 & $B+$ \\
\hline & M & 27 & 200701 & 1 & QUAN201 & B \\
\hline & M & 27 & 200701 & 1 & MOFI201 & $B+$ \\
\hline \multirow[t]{5}{*}{2} & $\mathrm{~F}$ & 22 & 200301 & 5 & ELIN933 & $P$ \\
\hline & $\mathrm{F}$ & 22 & 200401 & 1 & FNDN001 & B- \\
\hline & $\mathrm{F}$ & 22 & 200401 & 1 & FNDN002 & $B+$ \\
\hline & $\mathrm{F}$ & 22 & 200401 & 2 & FNDN021 & B- \\
\hline & $\mathrm{F}$ & 22 & 200401 & 2 & FNDN023 & A- \\
\hline
\end{tabular}




\begin{tabular}{|c|c|c|c|c|c|c|}
\hline & $\mathrm{F}$ & 22 & 200401 & 2 & FNDN025 & $\mathrm{C}+$ \\
\hline & $\mathrm{F}$ & 22 & 200401 & 1 & FNDN003 & B- \\
\hline & $\mathrm{F}$ & 22 & 200401 & $B$ & FNDN898 & $\mathrm{P}$ \\
\hline & $\mathrm{F}$ & 22 & 200501 & 1 & ECON130 & B- \\
\hline & $\mathrm{F}$ & 22 & 200501 & 2 & ECON140 & B- \\
\hline & $\mathrm{F}$ & 22 & 200501 & 1 & MARK101 & B- \\
\hline & $\mathrm{F}$ & 22 & 200501 & $A$ & ACCY223 & $\mathrm{C}$ \\
\hline & $\mathrm{F}$ & 22 & 200501 & 2 & ACCY001 & $\mathrm{P}$ \\
\hline & $\mathrm{F}$ & 22 & 200501 & $A$ & ACCY231 & B- \\
\hline & $\mathrm{F}$ & 22 & 200501 & 1 & QUAN102 & $A$ \\
\hline & $\mathrm{F}$ & 22 & 200501 & 2 & QUAN111 & $A+$ \\
\hline & $\mathrm{F}$ & 22 & 200501 & 2 & ACCY111 & $\mathrm{C}+$ \\
\hline & $\mathrm{F}$ & 22 & 200501 & $A$ & COML203 & $\mathrm{D}$ \\
\hline & $\mathrm{F}$ & 22 & 200601 & 1 & MOFI201 & $B$ \\
\hline & $\mathrm{F}$ & 22 & 200601 & 1 & ACCY232 & $\mathrm{C}+$ \\
\hline & $\mathrm{F}$ & 22 & 200601 & 2 & ACCY302 & $\mathrm{C}$ \\
\hline & $\mathrm{F}$ & 22 & 200601 & 2 & ACCY306 & B- \\
\hline & $\mathrm{F}$ & 22 & 200601 & 1 & FCOM110 & $\mathrm{C}+$ \\
\hline & $\mathrm{F}$ & 22 & 200601 & 2 & MOFI202 & B- \\
\hline & $\mathrm{F}$ & 22 & 200601 & $A$ & COML203 & B- \\
\hline & $\mathrm{F}$ & 22 & 200601 & $A$ & INFO101 & $\mathrm{C}+$ \\
\hline & $\mathrm{F}$ & 22 & 200701 & 1 & ACCY308 & $\mathrm{C}$ \\
\hline & $\mathrm{F}$ & 22 & 200701 & 1 & MOFI303 & $\mathrm{C}+$ \\
\hline \multirow{27}{*}{3} & $\mathrm{~F}$ & 23 & 200301 & 4 & ELIN932 & $\mathrm{P}$ \\
\hline & $\mathrm{F}$ & 23 & 200401 & 1 & FNDN001 & $\mathrm{C}$ \\
\hline & $\mathrm{F}$ & 23 & 200401 & 1 & FNDN004 & $\mathrm{C}+$ \\
\hline & $\mathrm{F}$ & 23 & 200401 & 2 & FNDN020 & $\mathrm{C}+$ \\
\hline & $\mathrm{F}$ & 23 & 200401 & 2 & FNDN021 & $\mathrm{C}+$ \\
\hline & $\mathrm{F}$ & 23 & 200401 & 2 & FNDN024 & $\mathrm{C}$ \\
\hline & $\mathrm{F}$ & 23 & 200401 & 1 & FNDN003 & $\mathrm{C}+$ \\
\hline & $\mathrm{F}$ & 23 & 200401 & B & FNDN898 & $\mathrm{P}$ \\
\hline & $\mathrm{F}$ & 23 & 200501 & 1 & ECON130 & B- \\
\hline & $\mathrm{F}$ & 23 & 200501 & 2 & ECON140 & $\mathrm{C}$ \\
\hline & $\mathrm{F}$ & 23 & 200501 & 1 & QUAN102 & $\mathrm{C}+$ \\
\hline & $\mathrm{F}$ & 23 & 200501 & 1 & WRIT151 & $\mathrm{C}+$ \\
\hline & $\mathrm{F}$ & 23 & 200501 & 2 & QUAN111 & B \\
\hline & $\mathrm{F}$ & 23 & 200501 & 2 & ACCY111 & $\mathrm{C}$ \\
\hline & $\mathrm{F}$ & 23 & 200501 & A & COML203 & $E$ \\
\hline & $\mathrm{F}$ & 23 & 200601 & 2 & MGMT101 & $\mathrm{D}$ \\
\hline & $\mathrm{F}$ & 23 & 200601 & 1 & MOFI201 & $\mathrm{D}$ \\
\hline & $\mathrm{F}$ & 23 & 200601 & 1 & ECON201 & $\mathrm{D}$ \\
\hline & $\mathrm{F}$ & 23 & 200601 & 2 & ECON202 & $\mathrm{D}$ \\
\hline & $\mathrm{F}$ & 23 & 200601 & 2 & QUAN203 & $\mathrm{C}$ \\
\hline & $\mathrm{F}$ & 23 & 200601 & 1 & FCOM110 & $\mathrm{C}$ \\
\hline & $\mathrm{F}$ & 23 & 200601 & A & INF0101 & $\mathrm{C}$ \\
\hline & $\mathrm{F}$ & 23 & 200601 & A & PSYC101 & $\mathrm{D}$ \\
\hline & $\mathrm{F}$ & 23 & 200701 & 1 & KORE111 & B \\
\hline & $\mathrm{F}$ & 23 & 200701 & 1 & ECON201 & B- \\
\hline & $\mathrm{F}$ & 23 & 200701 & 1 & QUAN201 & $\mathrm{C}$ \\
\hline & $\mathrm{F}$ & 23 & 200701 & 1 & JAPA111 & $\mathrm{C}$ \\
\hline \multirow[t]{7}{*}{4} & $\mathrm{M}$ & 23 & 200401 & 1 & FNDN001 & B- \\
\hline & $\mathrm{M}$ & 23 & 200401 & 1 & FNDN004 & B \\
\hline & $\mathrm{M}$ & 23 & 200401 & 2 & FNDN020 & B \\
\hline & $M$ & 23 & 200401 & 2 & FNDN021 & $\mathrm{B}+$ \\
\hline & $\mathrm{M}$ & 23 & 200401 & 2 & FNDN023 & $\mathrm{B}+$ \\
\hline & $\mathrm{M}$ & 23 & 200401 & 1 & FNDN003 & B- \\
\hline & $M$ & 23 & 200401 & B & FNDN898 & $\mathrm{P}$ \\
\hline
\end{tabular}




\begin{tabular}{|c|c|c|c|c|c|c|}
\hline & $M$ & 23 & 200501 & 1 & FCOM110 & B \\
\hline & M & 23 & 200501 & 1 & QUAN102 & $A$ \\
\hline & M & 23 & 200501 & 2 & QUAN111 & $A$ \\
\hline & $M$ & 23 & 200501 & 2 & ACCY111 & B- \\
\hline & $M$ & 23 & 200501 & 1 & ECON130 & B \\
\hline & $M$ & 23 & 200501 & 2 & ECON140 & B \\
\hline & M & 23 & 200601 & 1 & MOFI201 & B- \\
\hline & $M$ & 23 & 200601 & 1 & ACCY001 & $P$ \\
\hline & $M$ & 23 & 200601 & 1 & ACCY231 & B- \\
\hline & $M$ & 23 & 200601 & 2 & ACCY306 & $\mathrm{C}+$ \\
\hline & M & 23 & 200601 & 2 & MOFI202 & B- \\
\hline & $M$ & 23 & 200601 & 2 & MOFI301 & $\mathrm{C}+$ \\
\hline & $M$ & 23 & 200601 & 1 & COML203 & $\mathrm{C}$ \\
\hline & M & 23 & 200701 & 1 & MOFI305 & $\mathrm{D}$ \\
\hline & $M$ & 23 & 200701 & 1 & QUAN371 & $\mathrm{B}+$ \\
\hline & $M$ & 23 & 200701 & 1 & MOFI303 & $\mathrm{B}-$ \\
\hline \multirow{25}{*}{5} & $F$ & 24 & 200401 & 1 & FNDN001 & $C$ \\
\hline & $F$ & 24 & 200401 & 1 & FNDN004 & B- \\
\hline & $F$ & 24 & 200401 & 2 & FNDN020 & $B$ \\
\hline & $F$ & 24 & 200401 & 2 & FNDN021 & $\mathrm{C}+$ \\
\hline & $F$ & 24 & 200401 & 2 & FNDN023 & $B$ \\
\hline & $F$ & 24 & 200401 & 1 & FNDN003 & B- \\
\hline & $F$ & 24 & 200401 & $B$ & FNDN898 & $P$ \\
\hline & $F$ & 24 & 200501 & 2 & MGMT101 & C \\
\hline & $F$ & 24 & 200501 & 2 & ACCY001 & $P$ \\
\hline & $F$ & 24 & 200501 & $A$ & ACCY231 & $\mathrm{B}+$ \\
\hline & $F$ & 24 & 200501 & 1 & QUAN102 & A- \\
\hline & $F$ & 24 & 200501 & 2 & QUAN111 & $A+$ \\
\hline & $F$ & 24 & 200501 & $A$ & COML203 & $\mathrm{C}+$ \\
\hline & $F$ & 24 & 200501 & 1 & ACCY111 & $\mathrm{C}$ \\
\hline & $F$ & 24 & 200501 & 1 & ECON130 & $\mathrm{C}$ \\
\hline & $F$ & 24 & 200501 & 2 & ECON140 & $B$ \\
\hline & $F$ & 24 & 200601 & 1 & MOFI201 & A- \\
\hline & $F$ & 24 & 200601 & 1 & ACCY232 & $\mathrm{D}$ \\
\hline & $F$ & 24 & 200601 & 1 & ACCY223 & $\mathrm{C}+$ \\
\hline & $F$ & 24 & 200601 & 2 & ACCY302 & $D$ \\
\hline & $F$ & 24 & 200601 & 2 & ACCY306 & $B-$ \\
\hline & $F$ & 24 & 200601 & 2 & MOFI202 & $D$ \\
\hline & $F$ & 24 & 200701 & 1 & ACCY308 & $\mathrm{C}+$ \\
\hline & $F$ & 24 & 200701 & 1 & QUAN371 & A- \\
\hline & $\mathrm{F}$ & 24 & 200701 & 1 & MOFI303 & B- \\
\hline \multirow[t]{16}{*}{6} & $M$ & 22 & 200401 & 1 & FNDN001 & $B-$ \\
\hline & $M$ & 22 & 200401 & 1 & FNDN004 & $\mathrm{C}+$ \\
\hline & $M$ & 22 & 200401 & 2 & FNDN021 & B- \\
\hline & $M$ & 22 & 200401 & 2 & FNDN024 & $\mathrm{C}+$ \\
\hline & $M$ & 22 & 200401 & 2 & FNDN025 & B- \\
\hline & $M$ & 22 & 200401 & 1 & FNDN003 & $\mathrm{C}+$ \\
\hline & M & 22 & 200401 & $B$ & FNDN898 & $P$ \\
\hline & $M$ & 22 & 200501 & 1 & ECON130 & $B-$ \\
\hline & $M$ & 22 & 200501 & 2 & ECON140 & B- \\
\hline & $M$ & 22 & 200501 & 1 & MARK101 & B- \\
\hline & $M$ & 22 & 200501 & 1 & QUAN102 & A- \\
\hline & $M$ & 22 & 200501 & 2 & QUAN111 & A- \\
\hline & $M$ & 22 & 200501 & 2 & ACCY111 & $\mathrm{D}$ \\
\hline & M & 22 & 200501 & $A$ & ACCY111 & $\mathrm{B}+$ \\
\hline & $M$ & 22 & 200601 & 1 & FCOM110 & B- \\
\hline & $M$ & 22 & 200601 & 1 & MOFI201 & $\mathrm{C}+$ \\
\hline
\end{tabular}




\begin{tabular}{|c|c|c|c|c|c|c|}
\hline & M & 22 & 200601 & 2 & MARK202 & $\mathrm{C}+$ \\
\hline & M & 22 & 200601 & 2 & MARK203 & $\mathrm{C}+$ \\
\hline & M & 22 & 200601 & 2 & MARK302 & B \\
\hline & M & 22 & 200601 & 1 & MARK211 & C \\
\hline & M & 22 & 200601 & A & CHIN314 & A- \\
\hline & M & 22 & 200701 & 1 & MARK304 & B \\
\hline & M & 22 & 200701 & 1 & MARK306 & $B+$ \\
\hline & M & 22 & 200701 & 1 & MARK301 & B- \\
\hline & $\mathrm{F}$ & 21 & 200401 & 1 & FNDN001 & $C+$ \\
\hline & $\mathrm{F}$ & 21 & 200401 & 1 & FNDN004 & B \\
\hline & $\mathrm{F}$ & 21 & 200401 & 2 & FNDN020 & B \\
\hline & $\mathrm{F}$ & 21 & 200401 & 2 & FNDN021 & B- \\
\hline & $\mathrm{F}$ & 21 & 200401 & 2 & FNDN023 & $\mathrm{A}^{+}$ \\
\hline & $\mathrm{F}$ & 21 & 200401 & 1 & FNDN003 & $\mathrm{C}+$ \\
\hline & $\mathrm{F}$ & 21 & 200401 & B & FNDN898 & $P$ \\
\hline & $\mathrm{F}$ & 21 & 200501 & 1 & ECON130 & $\mathrm{C}+$ \\
\hline & $\mathrm{F}$ & 21 & 200501 & 2 & ECON140 & $\mathrm{D}$ \\
\hline & $\mathrm{F}$ & 21 & 200501 & A & ACCY223 & A- \\
\hline & $\mathrm{F}$ & 21 & 200501 & A & ACCY001 & $P$ \\
\hline & $\mathrm{F}$ & 21 & 200501 & A & ACCY231 & A- \\
\hline 7 & $\mathrm{~F}$ & 21 & 200501 & 1 & QUAN102 & $B$ \\
\hline & $\mathrm{F}$ & 21 & 200501 & 1 & WRIT151 & B- \\
\hline & $\mathrm{F}$ & 21 & 200501 & 2 & QUAN111 & $B+$ \\
\hline & $\mathrm{F}$ & 21 & 200501 & 2 & ACCY111 & C \\
\hline & $\mathrm{F}$ & 21 & 200601 & 2 & ACCY232 & C \\
\hline & $\mathrm{F}$ & 21 & 200601 & 1 & ACCY308 & B \\
\hline & $\mathrm{F}$ & 21 & 200601 & 1 & JAPA111 & A- \\
\hline & $\mathrm{F}$ & 21 & 200601 & A & MGMT101 & $\mathrm{C}+$ \\
\hline & $\mathrm{F}$ & 21 & 200601 & 2 & ECON140 & $B+$ \\
\hline & $\mathrm{F}$ & 21 & 200601 & 2 & INFO101 & $B+$ \\
\hline & $\mathrm{F}$ & 21 & 200601 & 1 & COML203 & B \\
\hline & $\mathrm{F}$ & 21 & 200701 & 1 & ACCY305 & B- \\
\hline & $\mathrm{F}$ & 21 & 200701 & 1 & COML305 & $\mathrm{B}$ \\
\hline & $\mathrm{F}$ & 23 & 200401 & 1 & FNDN001 & $\mathrm{C}+$ \\
\hline & $\mathrm{F}$ & 23 & 200401 & 1 & FNDN004 & $B$ \\
\hline & $\mathrm{F}$ & 23 & 200401 & 1 & FNDN005 & B \\
\hline & $\mathrm{F}$ & 23 & 200401 & 2 & FNDN022 & $B+$ \\
\hline & $\mathrm{F}$ & 23 & 200401 & 2 & FNDN023 & $B$ \\
\hline & $\mathrm{F}$ & 23 & 200401 & 2 & FNDN024 & B- \\
\hline & $\mathrm{F}$ & 23 & 200401 & B & FNDN898 & $P$ \\
\hline & $\mathrm{F}$ & 23 & 200501 & 2 & GERM114 & B \\
\hline & $\mathrm{F}$ & 23 & 200501 & 1 & GERM103 & $\mathrm{B}+$ \\
\hline & $\mathrm{F}$ & 23 & 200501 & 2 & GERM104 & B- \\
\hline & $\mathrm{F}$ & 23 & 200501 & 1 & SPAN111 & B- \\
\hline 8 & $\mathrm{~F}$ & 23 & 200501 & 2 & ENGL114 & $C$ \\
\hline & $\mathrm{F}$ & 23 & 200501 & 1 & MDIA101 & $B+$ \\
\hline & $\mathrm{F}$ & 23 & 200501 & A & CHIN314 & $B+$ \\
\hline & $\mathrm{F}$ & 23 & 200601 & 2 & ENGL215 & $\mathrm{C}+$ \\
\hline & $\mathrm{F}$ & 23 & 200601 & 1 & ENGL224 & B \\
\hline & $\mathrm{F}$ & 23 & 200601 & 1 & LING211 & B \\
\hline & $\mathrm{F}$ & 23 & 200601 & 2 & LING221 & C+ \\
\hline & $\mathrm{F}$ & 23 & 200601 & 1 & LING223 & $B+$ \\
\hline & $\mathrm{F}$ & 23 & 200601 & 2 & LING322 & $\mathrm{C}+$ \\
\hline & $\mathrm{F}$ & 23 & 200601 & 2 & LING325 & $B$ \\
\hline & $\mathrm{F}$ & 23 & 200701 & 1 & ENGL315 & $\mathrm{C}+$ \\
\hline & $\mathrm{F}$ & 23 & 200701 & 1 & ENGL308 & B- \\
\hline & $\mathrm{F}$ & 23 & 200701 & 1 & ENGL231 & C+ \\
\hline
\end{tabular}




\begin{tabular}{|c|c|c|c|c|c|c|}
\hline \multirow{22}{*}{9} & $\mathrm{~F}$ & 21 & 200401 & 1 & FNDN001 & $\mathrm{C}+$ \\
\hline & $\mathrm{F}$ & 21 & 200401 & 1 & FNDN002 & $\mathrm{B}$ \\
\hline & $\mathrm{F}$ & 21 & 200401 & 2 & FNDN020 & B \\
\hline & $\mathrm{F}$ & 21 & 200401 & 2 & FNDN021 & $\mathrm{B}+$ \\
\hline & $\mathrm{F}$ & 21 & 200401 & 2 & FNDN025 & $B-$ \\
\hline & $\mathrm{F}$ & 21 & 200401 & 1 & FNDN003 & $\mathrm{B}+$ \\
\hline & $\mathrm{F}$ & 21 & 200401 & $B$ & FNDN898 & $\mathrm{P}$ \\
\hline & $\mathrm{F}$ & 21 & 200501 & 2 & MGMT101 & $\mathrm{C}$ \\
\hline & $\mathrm{F}$ & 21 & 200501 & $A$ & INFO102 & A- \\
\hline & $\mathrm{F}$ & 21 & 200501 & 2 & ACCY111 & $\mathrm{C}+$ \\
\hline & $\mathrm{F}$ & 21 & 200501 & 1 & TOUR101 & $\mathrm{C}+$ \\
\hline & $\mathrm{F}$ & 21 & 200501 & 1 & TOUR104 & B \\
\hline & $F$ & 21 & 200501 & 1 & MARK101 & $B$ \\
\hline & $\mathrm{F}$ & 21 & 200501 & 1 & INFO101 & B \\
\hline & $\mathrm{F}$ & 21 & 200501 & 2 & TOUR108 & $\mathrm{C}+$ \\
\hline & $\mathrm{F}$ & 21 & 200601 & 1 & INFO201 & $\mathrm{B}+$ \\
\hline & $\mathrm{F}$ & 21 & 200601 & 2 & INFO222 & $B$ \\
\hline & $\mathrm{F}$ & 21 & 200601 & 2 & TOUR230 & $\mathrm{C}+$ \\
\hline & $\mathrm{F}$ & 21 & 200601 & $A$ & TOUR110 & B \\
\hline & $F$ & 21 & 200601 & 1 & TOUR240 & B \\
\hline & $\mathrm{F}$ & 21 & 200601 & 2 & TOUR250 & $\mathrm{C}+$ \\
\hline & $\mathrm{F}$ & 21 & 200701 & 1 & TOUR390 & $\mathrm{B}$ \\
\hline \multirow{29}{*}{10} & $\mathrm{M}$ & 24 & 200401 & 1 & FNDN001 & B \\
\hline & $M$ & 24 & 200401 & 1 & FNDN002 & A- \\
\hline & $\mathrm{M}$ & 24 & 200401 & 2 & FNDN004 & A- \\
\hline & $\mathrm{M}$ & 24 & 200401 & 2 & FNDN020 & $\mathrm{B}+$ \\
\hline & $\mathrm{M}$ & 24 & 200401 & 2 & FNDN025 & $\mathrm{B}+$ \\
\hline & $\mathrm{M}$ & 24 & 200401 & 1 & FNDN003 & A- \\
\hline & $\mathrm{M}$ & 24 & 200401 & A & ACCY001 & $\mathrm{Q}$ \\
\hline & $\mathrm{M}$ & 24 & 200401 & B & FNDN898 & $\mathrm{P}$ \\
\hline & $\mathrm{M}$ & 24 & 200401 & $A$ & ECON130 & $\mathrm{B}+$ \\
\hline & $\mathrm{M}$ & 24 & 200401 & A & POLS113 & B \\
\hline & $\mathrm{M}$ & 24 & 200501 & 2 & ECON140 & B- \\
\hline & $\mathrm{M}$ & 24 & 200501 & 1 & QUAN102 & $\mathrm{B}+$ \\
\hline & $\mathrm{M}$ & 24 & 200501 & 1 & FCOM110 & B \\
\hline & $\mathrm{M}$ & 24 & 200501 & 2 & HIST114 & B- \\
\hline & $\mathrm{M}$ & 24 & 200501 & 2 & POLS112 & B- \\
\hline & $\mathrm{M}$ & 24 & 200501 & 1 & ACCY111 & $\mathrm{C}+$ \\
\hline & $\mathrm{M}$ & 24 & 200501 & A & QUAN103 & $A+$ \\
\hline & $\mathrm{M}$ & 24 & 200601 & 1 & ECON201 & $\mathrm{B}+$ \\
\hline & $\mathrm{M}$ & 24 & 200601 & 2 & ECON202 & B \\
\hline & $\mathrm{M}$ & 24 & 200601 & 2 & ECON309 & $\mathrm{C}+$ \\
\hline & $\mathrm{M}$ & 24 & 200601 & 2 & POLS207 & $\mathrm{B}+$ \\
\hline & $\mathrm{M}$ & 24 & 200601 & 2 & QUAN203 & A \\
\hline & $\mathrm{M}$ & 24 & 200601 & 1 & INTP247 & $\mathrm{B}+$ \\
\hline & $\mathrm{M}$ & 24 & 200601 & 1 & MOFI201 & A- \\
\hline & $\mathrm{M}$ & 24 & 200601 & A & CRIM211 & B- \\
\hline & $\mathrm{M}$ & 24 & 200601 & A & HIST228 & A- \\
\hline & $M$ & 24 & 200701 & 1 & ECON305 & B \\
\hline & $\mathrm{M}$ & 24 & 200701 & 1 & INTP371 & $\mathrm{B}+$ \\
\hline & $\mathrm{M}$ & 24 & 200701 & 1 & MOFI305 & $\mathrm{C}$ \\
\hline \multirow[t]{6}{*}{11} & $\mathrm{~F}$ & 23 & 200301 & 4 & ELIN932 & $\mathrm{P}$ \\
\hline & $\mathrm{F}$ & 23 & 200401 & 1 & FNDN001 & $\mathrm{C}+$ \\
\hline & $\mathrm{F}$ & 23 & 200401 & 1 & FNDN002 & B \\
\hline & $\mathrm{F}$ & 23 & 200401 & 2 & FNDN005 & B- \\
\hline & $\mathrm{F}$ & 23 & 200401 & 2 & FNDN023 & A \\
\hline & $\mathrm{F}$ & 23 & 200401 & 2 & FNDN025 & $\mathrm{C}+$ \\
\hline
\end{tabular}




\begin{tabular}{|c|c|c|c|c|c|c|}
\hline & $F$ & 23 & 200401 & 1 & FNDN003 & $\mathrm{C}$ \\
\hline & $F$ & 23 & 200401 & $B$ & FNDN898 & $\mathrm{P}$ \\
\hline & $F$ & 23 & 200401 & $A$ & QUAN102 & $\mathrm{D}$ \\
\hline & $F$ & 23 & 200401 & $A$ & ECON130 & $\mathrm{D}$ \\
\hline & $F$ & 23 & 200501 & 2 & WRIT151 & B- \\
\hline & $F$ & 23 & 200501 & 2 & QUAN111 & $\mathrm{C}$ \\
\hline & $F$ & 23 & 200501 & 1 & FCOM110 & $\mathrm{C}$ \\
\hline & $F$ & 23 & 200501 & 1 & ACCY111 & $E$ \\
\hline & $F$ & 23 & 200501 & 1 & MARK101 & $Q$ \\
\hline & $F$ & 23 & 200501 & 2 & MGMT101 & $\mathrm{C}$ \\
\hline & $F$ & 23 & 200601 & 1 & ECON130 & $\mathrm{C}$ \\
\hline & $F$ & 23 & 200601 & 2 & ECON140 & $\mathrm{C}+$ \\
\hline & $F$ & 23 & 200601 & 2 & STAT193 & $B$ \\
\hline & $F$ & 23 & 200601 & 2 & ACCY111 & $E$ \\
\hline & $F$ & 23 & 200601 & 1 & MGMT202 & B- \\
\hline & $F$ & 23 & 200601 & 1 & MGMT205 & $\mathrm{C}$ \\
\hline & $\mathrm{F}$ & 23 & 200601 & 2 & MGMT318 & $\mathrm{C}$ \\
\hline & $F$ & 23 & 200701 & 1 & MGMT308 & $\mathrm{C}$ \\
\hline & $F$ & 23 & 200701 & 1 & WRIT101 & $\mathrm{C}+$ \\
\hline & $\mathrm{F}$ & 23 & 200701 & 1 & MOFI201 & $\mathrm{D}$ \\
\hline & $\mathrm{F}$ & 23 & 200701 & 1 & MGMT206 & B- \\
\hline \multirow{22}{*}{12} & $M$ & 23 & 200401 & 1 & FNDN001 & $\mathrm{C}$ \\
\hline & $M$ & 23 & 200401 & 1 & FNDN004 & B- \\
\hline & M & 23 & 200401 & 2 & FNDN022 & A- \\
\hline & $M$ & 23 & 200401 & 2 & FNDN023 & $\mathrm{B}+$ \\
\hline & $M$ & 23 & 200401 & 2 & FNDN024 & B- \\
\hline & $M$ & 23 & 200401 & 1 & FNDN003 & $B$ \\
\hline & M & 23 & 200401 & $B$ & FNDN898 & $P$ \\
\hline & $M$ & 23 & 200501 & 1 & ECON130 & $\mathrm{C}+$ \\
\hline & $M$ & 23 & 200501 & 2 & ECON140 & $\mathrm{C}+$ \\
\hline & M & 23 & 200501 & 1 & FCOM110 & $\mathrm{C}+$ \\
\hline & M & 23 & 200501 & 1 & QUAN102 & $\mathrm{C}+$ \\
\hline & $M$ & 23 & 200501 & 2 & QUAN111 & A- \\
\hline & $M$ & 23 & 200501 & 2 & ACCY111 & $\mathrm{C}$ \\
\hline & $M$ & 23 & 200601 & 1 & MOFI201 & $\mathrm{B}+$ \\
\hline & $M$ & 23 & 200601 & 1 & ECON201 & $\mathrm{B}+$ \\
\hline & $M$ & 23 & 200601 & 2 & QUAN203 & A- \\
\hline & M & 23 & 200601 & 1 & QUAN201 & $B$ \\
\hline & $M$ & 23 & 200601 & 2 & QUAN301 & B- \\
\hline & M & 23 & 200601 & 2 & MOFI302 & $\mathrm{C}$ \\
\hline & M & 23 & 200701 & 1 & JAPA111 & B- \\
\hline & $M$ & 23 & 200701 & 1 & MATH104 & $A+$ \\
\hline & $\mathrm{M}$ & 23 & 200701 & 1 & QUAN304 & A \\
\hline \multirow[t]{14}{*}{13} & $F$ & 24 & 200401 & 1 & FNDN001 & $\mathrm{C}+$ \\
\hline & $F$ & 24 & 200401 & 1 & FNDN002 & $B-$ \\
\hline & $F$ & 24 & 200401 & 2 & FNDN022 & A- \\
\hline & $F$ & 24 & 200401 & 2 & FNDN023 & $A$ \\
\hline & $F$ & 24 & 200401 & 2 & FNDN025 & $\mathrm{C}+$ \\
\hline & $F$ & 24 & 200401 & 1 & FNDN003 & $B-$ \\
\hline & $F$ & 24 & 200401 & $B$ & FNDN898 & $P$ \\
\hline & $F$ & 24 & 200501 & 1 & ECON130 & $\mathrm{C}+$ \\
\hline & $F$ & 24 & 200501 & 2 & PHYS131 & B \\
\hline & $F$ & 24 & 200501 & 2 & STAT193 & $\mathrm{B}+$ \\
\hline & $F$ & 24 & 200501 & 2 & ENVI114 & $B$ \\
\hline & $F$ & 24 & 200501 & 1 & FREN112 & $\mathrm{C}+$ \\
\hline & $F$ & 24 & 200501 & 1 & GEOG111 & $\mathrm{C}+$ \\
\hline & $F$ & 24 & 200601 & 1 & GEOL242 & $\mathrm{B}+$ \\
\hline
\end{tabular}




\begin{tabular}{|c|c|c|c|c|c|c|}
\hline & $F$ & 24 & 200601 & 1 & BTEC101 & $\mathrm{C}+$ \\
\hline & $F$ & 24 & 200601 & 2 & PUBL207 & B \\
\hline & $\mathrm{F}$ & 24 & 200601 & 2 & BIOL132 & $\mathrm{C}+$ \\
\hline & $\mathrm{F}$ & 24 & 200601 & 2 & ENVI214 & B- \\
\hline & $F$ & 24 & 200601 & 1 & GEOL214 & B \\
\hline & $F$ & 24 & 200601 & 1 & BIOL116 & $\mathrm{C}$ \\
\hline & $\mathrm{F}$ & 24 & 200701 & 1 & GEOG212 & B \\
\hline & $\mathrm{F}$ & 24 & 200701 & 1 & BIOL371 & B- \\
\hline & $\mathrm{F}$ & 24 & 200701 & 1 & ESCl111 & $\mathrm{B}$ \\
\hline \multirow{22}{*}{14} & M & 24 & 200401 & 1 & FNDN001 & $\mathrm{C}$ \\
\hline & $M$ & 24 & 200401 & 1 & FNDN002 & B- \\
\hline & $M$ & 24 & 200401 & 1 & FNDN005 & $\mathrm{C}+$ \\
\hline & $M$ & 24 & 200401 & 2 & FNDN020 & $B$ \\
\hline & M & 24 & 200401 & 2 & FNDN021 & B- \\
\hline & M & 24 & 200401 & 2 & FNDN023 & $\mathrm{B}+$ \\
\hline & M & 24 & 200401 & B & FNDN898 & $\mathrm{P}$ \\
\hline & $M$ & 24 & 200501 & 1 & ECON130 & $\mathrm{C}$ \\
\hline & M & 24 & 200501 & 2 & ECON140 & $\mathrm{C}$ \\
\hline & $M$ & 24 & 200501 & 1 & WRIT151 & $\mathrm{C}$ \\
\hline & $M$ & 24 & 200501 & 2 & QUAN111 & B- \\
\hline & $M$ & 24 & 200501 & 2 & ACCY111 & $\mathrm{C}$ \\
\hline & M & 24 & 200501 & 1 & INF0101 & Q \\
\hline & $M$ & 24 & 200601 & 1 & QUAN102 & $\mathrm{D}$ \\
\hline & M & 24 & 200601 & 2 & STAT193 & $\mathrm{D}$ \\
\hline & M & 24 & 200601 & 1 & FCOM110 & $\mathrm{C}$ \\
\hline & M & 24 & 200601 & 2 & MOFI202 & $\mathrm{D}$ \\
\hline & $M$ & 24 & 200601 & 2 & IBUS202 & B \\
\hline & M & 24 & 200701 & 1 & IBUS309 & WD \\
\hline & M & 24 & 200701 & 1 & INFO101 & B- \\
\hline & $M$ & 24 & 200701 & 1 & IBUS201 & $\mathrm{D}$ \\
\hline & $\mathrm{M}$ & 24 & 200701 & 1 & IBUS305 & $\mathrm{K}$ \\
\hline \multirow{24}{*}{15} & $F$ & 22 & 200401 & 1 & FNDN001 & B \\
\hline & $\mathrm{F}$ & 22 & 200401 & 1 & FNDN002 & $A$ \\
\hline & $\mathrm{F}$ & 22 & 200401 & 1 & FNDN004 & $A$ \\
\hline & $\mathrm{F}$ & 22 & 200401 & 2 & FNDN020 & A- \\
\hline & $F$ & 22 & 200401 & 2 & FNDN022 & $\mathrm{B}+$ \\
\hline & $\mathrm{F}$ & 22 & 200401 & 2 & FNDN024 & A- \\
\hline & $\mathrm{F}$ & 22 & 200401 & B & FNDN898 & $\mathrm{P}$ \\
\hline & $\mathrm{F}$ & 22 & 200401 & A & MARK101 & $\mathrm{C}+$ \\
\hline & $\mathrm{F}$ & 22 & 200401 & A & INF0101 & B \\
\hline & $\mathrm{F}$ & 22 & 200501 & 1 & ECON130 & B- \\
\hline & $\mathrm{F}$ & 22 & 200501 & 2 & INFO102 & $A-$ \\
\hline & $\mathrm{F}$ & 22 & 200501 & 1 & QUAN102 & A \\
\hline & $F$ & 22 & 200501 & 2 & MARK202 & $\mathrm{B}+$ \\
\hline & $\mathrm{F}$ & 22 & 200501 & 2 & ACCY111 & B \\
\hline & $F$ & 22 & 200501 & 1 & GEOG111 & B \\
\hline & $\mathrm{F}$ & 22 & 200601 & 1 & INFO201 & A \\
\hline & $\mathrm{F}$ & 22 & 200601 & 1 & INFO221 & B \\
\hline & $\mathrm{F}$ & 22 & 200601 & 2 & INFO301 & A- \\
\hline & $\mathrm{F}$ & 22 & 200601 & 2 & INFO322 & A- \\
\hline & $\mathrm{F}$ & 22 & 200601 & 2 & MARK302 & $\mathrm{B}+$ \\
\hline & $F$ & 22 & 200601 & 1 & MARK211 & B- \\
\hline & $\mathrm{F}$ & 22 & 200701 & 1 & INFO241 & A \\
\hline & $F$ & 22 & 200701 & 1 & FCOM110 & $\mathrm{B}+$ \\
\hline & $\mathrm{F}$ & 22 & 200701 & 1 & MARK306 & $\mathrm{B}+$ \\
\hline \multirow[t]{2}{*}{16} & $\mathrm{~F}$ & 22 & 200301 & 4 & ELIN932 & $\mathrm{P}$ \\
\hline & $\mathrm{F}$ & 22 & 200401 & 1 & FNDN001 & $\mathrm{C}$ \\
\hline
\end{tabular}




\begin{tabular}{|c|c|c|c|c|c|c|}
\hline & $\mathrm{F}$ & 22 & 200401 & 1 & FNDN002 & B- \\
\hline & $\mathrm{F}$ & 22 & 200401 & 2 & FNDN005 & B- \\
\hline & $F$ & 22 & 200401 & 2 & FNDN023 & $A$ \\
\hline & $F$ & 22 & 200401 & 2 & FNDN025 & $\mathrm{C}$ \\
\hline & $F$ & 22 & 200401 & 1 & FNDN003 & $\mathrm{C}+$ \\
\hline & $F$ & 22 & 200401 & $B$ & FNDN898 & $\mathrm{P}$ \\
\hline & $\mathrm{F}$ & 22 & 200401 & $A$ & QUAN102 & B- \\
\hline & $\mathrm{F}$ & 22 & 200401 & $A$ & ECON130 & $\mathrm{C}+$ \\
\hline & $F$ & 22 & 200501 & 1 & MARK101 & $\mathrm{Q}$ \\
\hline & $F$ & 22 & 200501 & 2 & MGMT101 & B- \\
\hline & $F$ & 22 & 200501 & 2 & ACCY111 & $\mathrm{C}$ \\
\hline & $\mathrm{F}$ & 22 & 200501 & 1 & JAPA111 & B- \\
\hline & $F$ & 22 & 200501 & 1 & IBUS201 & $\mathrm{C}+$ \\
\hline & $F$ & 22 & 200501 & 2 & IBUS202 & B- \\
\hline & $\mathrm{F}$ & 22 & 200601 & $A$ & MGMT202 & $\mathrm{C}+$ \\
\hline & $\mathrm{F}$ & 22 & 200601 & $A$ & IBUS308 & $B$ \\
\hline & $F$ & 22 & 200601 & 1 & FCOM110 & $\mathrm{C}$ \\
\hline & $F$ & 22 & 200601 & 2 & IBUS301 & $\mathrm{C}+$ \\
\hline & $F$ & 22 & 200601 & $A$ & QUAN103 & $A+$ \\
\hline & $F$ & 22 & 200601 & 1 & HRIR201 & $\mathrm{C}+$ \\
\hline & $F$ & 22 & 200601 & 2 & HRIR301 & $\mathrm{C}$ \\
\hline & $F$ & 22 & 200601 & 2 & HRIR304 & B- \\
\hline & $\mathrm{F}$ & 22 & 200601 & 1 & IBUS305 & $\mathrm{C}+$ \\
\hline & $\mathrm{F}$ & 22 & 200701 & 1 & HRIR305 & $\mathrm{C}$ \\
\hline \multirow{28}{*}{17} & $F$ & 25 & 200301 & 3 & ELIN931 & $P$ \\
\hline & $F$ & 25 & 200301 & 4 & ELIN932 & $P$ \\
\hline & $F$ & 25 & 200401 & 1 & FNDN001 & $\mathrm{C}$ \\
\hline & $F$ & 25 & 200401 & 1 & FNDN002 & $B$ \\
\hline & $F$ & 25 & 200401 & 2 & FNDN004 & $\mathrm{C}+$ \\
\hline & $F$ & 25 & 200401 & 2 & FNDN021 & $\mathrm{B}+$ \\
\hline & $\mathrm{F}$ & 25 & 200401 & 2 & FNDN023 & $A+$ \\
\hline & $F$ & 25 & 200401 & 1 & FNDN003 & B- \\
\hline & $F$ & 25 & 200401 & $B$ & FNDN898 & $P$ \\
\hline & $F$ & 25 & 200401 & $A$ & QUAN102 & A- \\
\hline & $\mathrm{F}$ & 25 & 200401 & $A$ & ACCY111 & $\mathrm{C}+$ \\
\hline & $F$ & 25 & 200501 & 1 & ECON130 & $\mathrm{C}$ \\
\hline & $F$ & 25 & 200501 & $A$ & ACCY223 & $\mathrm{B}+$ \\
\hline & $F$ & 25 & 200501 & 2 & ACCY001 & $P$ \\
\hline & $F$ & 25 & 200501 & $A$ & ACCY231 & B- \\
\hline & $\mathrm{F}$ & 25 & 200501 & 2 & WRIT151 & B- \\
\hline & $F$ & 25 & 200501 & 2 & QUAN111 & $A+$ \\
\hline & $F$ & 25 & 200501 & 1 & FCOM110 & $\mathrm{C}+$ \\
\hline & $F$ & 25 & 200501 & 1 & MARK101 & $\mathrm{C}+$ \\
\hline & $F$ & 25 & 200501 & 2 & ECON140 & $B$ \\
\hline & $F$ & 25 & 200601 & 1 & MOFI201 & $B$ \\
\hline & $F$ & 25 & 200601 & 1 & ACCY232 & $\mathrm{C}+$ \\
\hline & $F$ & 25 & 200601 & 2 & ACCY306 & B- \\
\hline & $F$ & 25 & 200601 & 1 & ACCY308 & B- \\
\hline & $F$ & 25 & 200601 & 2 & MOFI202 & B- \\
\hline & $F$ & 25 & 200601 & $A$ & COML203 & $\mathrm{C}$ \\
\hline & $F$ & 25 & 200701 & 1 & ACCY305 & $\mathrm{C}+$ \\
\hline & $\mathrm{F}$ & 25 & 200701 & 1 & MOFI305 & B- \\
\hline \multirow[t]{5}{*}{18} & $\mathrm{~F}$ & 23 & 200301 & 4 & ELIN932 & $P$ \\
\hline & $F$ & 23 & 200401 & 1 & FNDN001 & B- \\
\hline & $F$ & 23 & 200401 & 1 & FNDN002 & B- \\
\hline & $F$ & 23 & 200401 & 2 & FNDN005 & $B$ \\
\hline & $F$ & 23 & 200401 & 2 & FNDN021 & $\mathrm{B}+$ \\
\hline
\end{tabular}




\begin{tabular}{|c|c|c|c|c|c|c|}
\hline & $\mathrm{F}$ & 23 & 200401 & 2 & FNDN025 & $\mathrm{B}+$ \\
\hline & $\mathrm{F}$ & 23 & 200401 & 1 & FNDN003 & B- \\
\hline & $\mathrm{F}$ & 23 & 200401 & B & FNDN898 & $P$ \\
\hline & $\mathrm{F}$ & 23 & 200501 & 1 & ECON130 & B \\
\hline & $\mathrm{F}$ & 23 & 200501 & 2 & ECON140 & B \\
\hline & $\mathrm{F}$ & 23 & 200501 & 2 & MGMT101 & B \\
\hline & $F$ & 23 & 200501 & 1 & FCOM110 & B \\
\hline & $\mathrm{F}$ & 23 & 200501 & 2 & ACCY001 & $\mathrm{P}$ \\
\hline & $\mathrm{F}$ & 23 & 200501 & 1 & QUAN102 & $\mathrm{B}+$ \\
\hline & $\mathrm{F}$ & 23 & 200501 & 2 & ACCY111 & $\mathrm{C}+$ \\
\hline & $\mathrm{F}$ & 23 & 200501 & $A$ & MARK101 & A- \\
\hline & $\mathrm{F}$ & 23 & 200601 & $A$ & FREN112 & $\mathrm{B}+$ \\
\hline & $\mathrm{F}$ & 23 & 200601 & 2 & MARK202 & B \\
\hline & $\mathrm{F}$ & 23 & 200601 & 2 & MARK203 & B \\
\hline & $\mathrm{F}$ & 23 & 200601 & 1 & IBUS201 & B \\
\hline & $\mathrm{F}$ & 23 & 200601 & 1 & MARK211 & B \\
\hline & $\mathrm{F}$ & 23 & 200701 & 1 & MARK304 & $\mathrm{B}+$ \\
\hline & $\mathrm{F}$ & 23 & 200701 & 1 & WRIT101 & B- \\
\hline & $\mathrm{F}$ & 23 & 200701 & 1 & MARK301 & $\mathrm{B}$ \\
\hline \multirow{24}{*}{19} & $\mathrm{~F}$ & 23 & 200401 & 1 & FNDN001 & B- \\
\hline & $\mathrm{F}$ & 23 & 200401 & 1 & FNDN002 & A \\
\hline & $\mathrm{F}$ & 23 & 200401 & 1 & FNDN004 & $\mathrm{B}+$ \\
\hline & $\mathrm{F}$ & 23 & 200401 & 2 & FNDN020 & A \\
\hline & $\mathrm{F}$ & 23 & 200401 & 2 & FNDN023 & A \\
\hline & $\mathrm{F}$ & 23 & 200401 & 2 & FNDN024 & A- \\
\hline & $\mathrm{F}$ & 23 & 200401 & B & FNDN898 & $\mathrm{P}$ \\
\hline & $\mathrm{F}$ & 23 & 200501 & 2 & $\mathrm{ARCH} 102$ & A- \\
\hline & $\mathrm{F}$ & 23 & 200501 & 2 & $\mathrm{ARCH} 112$ & A- \\
\hline & $\mathrm{F}$ & 23 & 200501 & 1 & PHYS130 & $\mathrm{B}+$ \\
\hline & $\mathrm{F}$ & 23 & 200501 & 2 & $\mathrm{ARCH} 172$ & $\mathrm{C}+$ \\
\hline & $\mathrm{F}$ & 23 & 200501 & 2 & $\mathrm{ARCH} 181$ & B- \\
\hline & $\mathrm{F}$ & 23 & 200501 & 1 & $\mathrm{ARCH} 111$ & $\mathrm{~B}+$ \\
\hline & $\mathrm{F}$ & 23 & 200501 & 1 & $\mathrm{ARCH} 101$ & B \\
\hline & $\mathrm{F}$ & 23 & 200601 & 1 & $\mathrm{ARCH} 280$ & $\mathrm{C}$ \\
\hline & $\mathrm{F}$ & 23 & 200601 & 2 & BBSC231 & $\mathrm{B}+$ \\
\hline & $\mathrm{F}$ & 23 & 200601 & 2 & BBSC251 & B- \\
\hline & $\mathrm{F}$ & 23 & 200601 & 1 & $\mathrm{ARCH} 211$ & B- \\
\hline & $\mathrm{F}$ & 23 & 200601 & 1 & $\mathrm{ARCH} 241$ & B- \\
\hline & $\mathrm{F}$ & 23 & 200601 & A & DESN104 & $A+$ \\
\hline & $\mathrm{F}$ & 23 & 200601 & 2 & $\mathrm{ARCH} 222$ & $\mathrm{C}+$ \\
\hline & $\mathrm{F}$ & 23 & 200701 & 1 & BBSC303 & $A+$ \\
\hline & $\mathrm{F}$ & 23 & 200701 & 1 & BBSC331 & B- \\
\hline & $\mathrm{F}$ & 23 & 200701 & 1 & BBSC351 & $\mathrm{K}$ \\
\hline \multirow[t]{14}{*}{20} & $\mathrm{M}$ & 26 & 200301 & 3 & ELIN931 & $P$ \\
\hline & $\mathrm{M}$ & 26 & 200301 & 4 & ELIN932 & $\mathrm{P}$ \\
\hline & $\mathrm{M}$ & 26 & 200401 & 1 & FNDN001 & $\mathrm{C}+$ \\
\hline & $\mathrm{M}$ & 26 & 200401 & 1 & FNDN002 & A \\
\hline & $\mathrm{M}$ & 26 & 200401 & 1 & FNDN004 & B \\
\hline & $\mathrm{M}$ & 26 & 200401 & 2 & FNDN020 & B \\
\hline & $\mathrm{M}$ & 26 & 200401 & 2 & FNDN021 & B- \\
\hline & $\mathrm{M}$ & 26 & 200401 & 2 & FNDN023 & B- \\
\hline & $\mathrm{M}$ & 26 & 200401 & B & FNDN898 & $P$ \\
\hline & $\mathrm{M}$ & 26 & 200401 & A & QUAN102 & $\mathrm{C}+$ \\
\hline & $\mathrm{M}$ & 26 & 200401 & A & ACCY111 & $\mathrm{D}$ \\
\hline & $\mathrm{M}$ & 26 & 200501 & 2 & ECON140 & B- \\
\hline & $\mathrm{M}$ & 26 & 200501 & 2 & QUAN111 & $\mathrm{B}+$ \\
\hline & $\mathrm{M}$ & 26 & 200501 & 1 & FCOM110 & $\mathrm{C}+$ \\
\hline
\end{tabular}




\begin{tabular}{|c|c|c|c|c|c|}
\hline M & 26 & 200501 & A & MARK101 & $\mathrm{C}+$ \\
\hline M & 26 & 200501 & 1 & MARK101 & $Q$ \\
\hline M & 26 & 200501 & 1 & ECON130 & C+ \\
\hline M & 26 & 200601 & 1 & ECON201 & B- \\
\hline M & 26 & 200601 & 2 & ECON202 & D \\
\hline M & 26 & 200601 & 1 & QUAN201 & C+ \\
\hline M & 26 & 200601 & 2 & QUAN301 & C \\
\hline M & 26 & 200601 & 2 & MARK202 & C \\
\hline M & 26 & 200601 & 1 & ACCY111 & B- \\
\hline M & 26 & 200701 & 1 & QUAN304 & C \\
\hline M & 26 & 200701 & 1 & MARK211 & B- \\
\hline M & 26 & 200701 & 1 & MARK306 & $\mathrm{C}+$ \\
\hline
\end{tabular}


Appendix Two: Interview Questions

\section{Personal Information}

1. First I'll record that you are male/female.

2. What is your age?

3. Where in China are you from?

4. How many years have you been in NZ?

\section{Pre-University Study}

5. Why did you choose to study at VUW?

6. Did you study in NZ before beginning your degree at VUW? If so, what, where and for how long?

7. Did you take any pre-degree courses at VUW (i.e. EPP, Foundation Studies)?

8. What was your highest level of schooling in China? (i.e. Senior High, University or other tertiary?) Have you worked in a full-time (not holiday) job?

\section{University Study}

9. How many years have you been doing your degree?

10. What is your degree and major? Have you changed degrees or majors since you started? If so, why?

11. How do you feel your study is going? Are you doing well? What about your grades? Have you failed many courses?

12. How would you rate yourself as a student, on a scale of $0-5(0=$ miss classes/lectures often, hand work in late; $5=$ attend most of the time, hand work in on time, do all the readings)? Is this for all courses?

13. Who or what has helped you most in your studies?

14. What are your teachers like?

15. What would you like more help or support with while studying at VUW?

16. Would you recommend your friends from China to come and study in VUW? Why or why not?

17. How do you feel about the way of learning at university in NZ? Are there any big differences from the education system in China? What about similarities?

18. What was it like in your first trimester of degree study? What new things did you have to learn? 


\section{English Language}

19. On a scale of $1-5$, how would you rate your English? $(1=$ very weak, $5=$ quite fluent).

20. Why did you give it that rating? What do you feel is good or lacking?

21. How much do you use English?

22. What has helped your English to improve? Any hindrances?

23. Do you think your English is adequate for your studies, or is it holding you back, or more than you need?

24. Is English important to you? Do you actively try to improve your English? If so, how?

\section{Life in NZ}

25. What are your living arrangements? Previous ones?

26. Tell me about your friends (where are they from? What do they do? Where did you meet?)

27. Do you have any family or close friends here?

28. Who do you go to when you need help?

29. How do you feel about New Zealand life? What was it like when you first arrived? What is it like now?

30. What do you wish someone had told you before you came to New Zealand?

31. What would you do differently if you had the chance?

32. What were your goals before you came to NZ. Have these changed since you have been here?

33. What are your future plans?

\section{For students who have done Foundation Studies}

34. How do you feel about Foundation Studies (Now)? And when you were doing it?

35. Do you think Foundation Studies helped to prepare you for your degree study? In what ways? What was not helpful? 


\begin{tabular}{l|l}
\hline TO & Melinda Hall \\
\hline COPY TO & Dr Limin Bai, Supervisor \\
\hline FROM & Dr Allison Kirkman, Convener, Human Ethics Committee \\
\hline
\end{tabular}

\begin{tabular}{l|l}
\hline DATE & 8 February 2008 \\
\hline PAGES & 1 \\
\hline
\end{tabular}

\begin{tabular}{l|l}
\hline SUBJECT & $\begin{array}{l}\text { Ethics Approval: No 15371, Preparing Chinese students for the } \\
\text { New Zealand academic environment: the Foundation Studies } \\
\text { Programme. }\end{array}$ \\
\hline
\end{tabular}

Thank you for your application for ethical approval, which has now been considered by the Standing Committee of the Human Ethics Committee.

Your application has been approved from the above date and this approval continues until 31 March 2009. If your data collection is not completed by this date you should apply to the Human Ethics Committee for an extension to this approval.

Best wishes with the research.

Allison Kirkman

Convener 


\title{
Appendix Four: Information Sheet for Participants
}

\author{
TE WHARE WÁNANGA O TE OPOKO O TE IKA A MÁUI

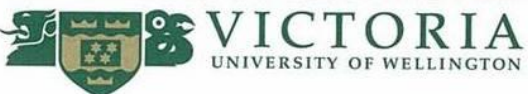 \\ Information Sheet for Participants \\ in a Study of \\ Preparing Chinese Students for the New Zealand Academic Environment
}

Researcher: Melinda Hall, School of Asian and European Languages and Culture, Victoria University of Wellington

I am a Masters student in Chinese at Victoria University of Wellington. For this degree I am undertaking a research project leading to a thesis. My thesis is designed to investigate how we can prepare Chinese students for the New Zealand academic environment, and I will be looking specifically at the Foundation Studies programme as one means of preparing students. This information could help universities in New Zealand better cater for our Chinese international students. This research project has Human Ethics approval.

When you volunteer to participate, you will be asked to take part in an interview. The interview will take approximately 1 hour, and will be located on one of the four VUW university campuses (whichever you prefer). The exact room will be arranged along with a suitable day and time. The types of questions you will be asked will include:

- Your age

- Where you are from

- Pre-university study (what other courses you have done in NZ or China)

- University study (what you are studying, how you feel about it)

- English language ability and use

- Life in New Zealand, including living arrangements, social activities, friends

- If you did the Foundation Studies Programme and your thoughts about it

You can choose not to answer questions you are not comfortable with.

Participation is voluntary and all research findings will be put together and reported on an anonymous basis. Your name will not be revealed and it will not be possible for you to be identified personally. There is no penalty for not participating or for withdrawing from participation at any stage. Your participation or non participation will not affect your university grades in any way. Should you feel that you wish to withdraw from the study, you may do so without question by telling me before 31 December 2008.

Responses will form the basis of my thesis which will be submitted for marking to the School of Asian and European Languages and Culture and deposited in the university library. Articles from this may be submitted for publication in academic journals. The data may also be used for a comparative study in the future. Your identity will be safeguarded and all material will be kept confidential. No other person besides me and my supervisor will see the information. All data collected will be destroyed within five years of the completion of the study.

SCHOOL OF ASIAN \& EUROPEAN LANGUAGES \& CULTURES Te Kura o ngă Reo me ngā Tikanga-ā-iwi o Āhia me Ũropi PO Box 600 , Wellington, New Zealand

Phone +64-4-463 6699 Fax +64-4-4635419 Email saelc@vuw.ac.nz Website www.victoria.ac.nz/saelc 
If you agree to participate you have the following rights

- decline to answer any particular question;

- withdraw from the study prior to 31 Dec 2008;

- ask any questions about the study at any time during participation;

- provide information on the understanding that your name will not be used unless you give permission to the researcher;

- be given access to a summary of the study findings when it is concluded if you wish.

If you have any questions about this project or you would like to receive further information please contact me by email at melinda.hall@vuw.ac.nz, telephone 463 9703, or my supervisor, Dr Limin Bai at limin.bai@vuw.ac.nz, telephone 4636462.

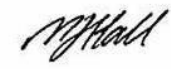

Melinda Hall 


\section{Appendix Five: Interview Consent Form}

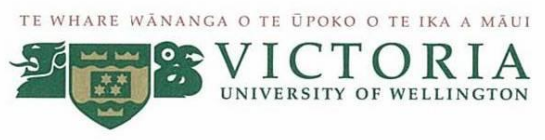

Consent Form for the interview

Preparing Chinese students for the New Zealand Academic Environment

$\square \quad$ I have read the Information Sheet relating to the nature and objects of this research project. I have understood this information.

$\square \quad$ I understand that records of any data from me will be kept confidential and that my identity will not be revealed.

$\square \quad$ I agree to participate in this study under the conditions set out in the Information Sheet.

$\square \quad$ I understand that my participation is voluntary and I have the right to withdraw from the research project up until $31 \mathrm{Dec}, 2008$.

\section{Full Name}

I wish to receive feedback from this project by being sent a summary of the research via email/post. This will not be available until 2009.

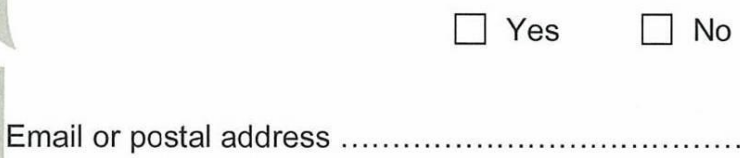

Date: 


\section{Appendix Six: t-Tests Conducted for Quantitative Study}

\section{t-Tests Comparing FS and DE Students}

\section{GPA at $1 \%$}

t-Test: Two-Sample Assuming Equal Variances

\begin{tabular}{lrr}
\hline & Variable 1 & Variable 2 \\
\hline Mean & 4.015480839 & 2.666528657 \\
Variance & 1.107595824 & 0.756246194 \\
Observations & 20 & 20 \\
Pooled Variance & 0.931921009 & \\
Hypothesized Mean Difference & 0 & \\
Df & 38 \\
t Stat & 4.41882705 \\
P(T<=t) one-tail & $4.00071 \mathrm{E}-05$ \\
t Critical one-tail & 2.428567627 \\
P(T<=t) two-tail & $8.00142 \mathrm{E}-05$ & \\
t Critical two-tail & 2.711557598 & \\
\hline
\end{tabular}

Pass Rate at $1 \%$

t-Test: Two-Sample Assuming Equal Variances

\begin{tabular}{lrr}
\hline & Variable 1 & Variable 2 \\
\hline Mean & 89.48749827 & 68.39540043 \\
Variance & 179.0713601 & 297.9939178 \\
Observations & 20 & 20 \\
Pooled Variance & 238.5326389 & \\
Hypothesized Mean Difference & 0 \\
Df & 38 \\
t Stat & \multicolumn{2}{c}{0} \\
P(T<=t) one-tail & 5.318628741 \\
t Critical one-tail & $5.42623 \mathrm{E}-05$ \\
P (T<=t) two-tail & 2.428567627 \\
t Critical two-tail & 0.000108525 & \\
\hline
\end{tabular}




\section{t-Tests Comparing Male and Female}

\section{GPA at $10 \%$}

t-Test: Two-Sample Assuming Equal Variances

\begin{tabular}{lrr}
\hline & Variable 1 & Variable 2 \\
\hline Mean & 3.572538438 & 3.027753285 \\
Variance & 1.269710251 & 1.423435126 \\
Observations & 23 & 17 \\
Pooled Variance & 1.334436514 & \\
Hypothesized Mean Difference & 0 & \\
Df & 38 & \\
t Stat & 1.474465746 & \\
$\mathrm{P}(\mathrm{T}<=\mathrm{t})$ one-tail & 0.074296768 & \\
t Critical one-tail & 1.304230204 & \\
$\mathrm{P}(\mathrm{T}<=\mathrm{t})$ two-tail & 0.148593537 & \\
$\mathrm{t}$ Critical two-tail & 1.685954461 & \\
\hline
\end{tabular}

\section{Pass Rate at $\mathbf{5 \%}$}

$\mathrm{t}$-Test: Two-Sample Assuming Equal Variances

\begin{tabular}{lrr}
\hline & Variable 1 & Variable 2 \\
\hline Mean & 8.39186885 & 7.220580746 \\
Variance & 3.07079202 & 3.385225304 \\
Observations & 23 & 17 \\
Pooled Variance & 3.203184982 & \\
Hypothesized Mean Difference & 0 & \\
Df & 38 & \\
t Stat & 2.046120025 & \\
P $(T<=t)$ one-tail & 0.023854923 & \\
t Critical one-tail & 1.685954461 & \\
$\mathrm{P}(\mathrm{T}<=\mathrm{t})$ two-tail & 0.047709846 & \\
t Critical two-tail & 2.024394147 & \\
\hline
\end{tabular}

